\title{
Beneath the "Thin Veneer of Civilization": Evolution, Masculinity, and Race in the Early Twentieth Century United States
}

by

Guy Joseph Edward Massie

A thesis submitted to the Faculty of Graduate and Postdoctoral Affairs in partial fulfilment of the requirements for the degree of

\author{
Master of Arts \\ in \\ History
}

Carleton University
Ottawa, Ontario

(C) 2014

Guy J. E. Massie 


\begin{abstract}
By the turn of the twentieth century, many Anglo-Saxon American men of a middle and upper class background began to define their identities by appealing to evolutionary thought. Homo erectus nordicus, they believed, was the greatest physical and mental specimen among the races of the world. Yet this narrative of evolutionary greatness through a history of Spencerian struggle in the natural world, defined by popular and scientific literature, seemed at odds with the condition of the modern American man. Their grand narrative of natural history stressed the need to engage with nature to embrace one's authentic identity as a man, in contrast to the effeminate and degenerative influences of civilization — which had been compromised, they believed, by the unnatural, growing cultural authority of women, immigrants, and organized labor. In this thesis, I argue that these evolutionary narratives of white masculinity portrayed the white male body as powerful yet vulnerable to degeneracy, setting an alarmist agenda for reclaiming a conservative cultural identity for the nation.
\end{abstract}




\section{Acknowledgments}

The writing of this thesis has been a journey of intellectual and personal maturity. It has been long and strenuous, but I am thankful to those who have helped me along the way. Their advice and encouragement has made it more enjoyable. I am grateful to Andrew Johnston, my supervisor, for his mentorship and patience during my graduate studies. I have also had the privilege of studying under a number of professors at the History Department who have taught me how to do history: John Walsh, Aleksandra Bennett, Shawn Graham, Susanne Klausen, and Joanna Dean. I have also benefitted from the assistance of my colleagues at the department, and on that note I would like to thank William Knight and Christina Williamson. Joan White, Regina Aulinskas, and Irene Sanna have helped me countless times in my years studying at the department and they have my heartfelt thanks.

This thesis could not have been completed without the indispensable support of my friends and family. I feel more grateful to them than can be properly expressed in words. I would like to thank my parents, Shirley and Bernie, my grandmother, Isabel, and my brothers, Fraser and Patrick. I am also thankful for the support and assistance of my uncle, Doug, in helping me understand the complex world of evolutionary biology and lending me a small library of books to that end.

Finally, much of the research that has gone into this project has been conducted using online archives or otherwise digitized sources. I would like to thank the people and organizations involved in digitization efforts in the field of history, and offer this thesis as proof of the importance of those efforts. 


\section{Table of Contents}

$\begin{array}{ll}\text { Abstract } & \text { ii }\end{array}$

$\begin{array}{ll}\text { Acknowledgements } & \text { iii }\end{array}$

Table of Contents $\quad$ iv

List of Appendices $\quad$ V

Chapter 1, Introduction: The White Male Body and the New Biology in America 1

Chapter 2, Antimodernism and the Ape Men: Tarzan, Evolution, and White Male Identities 14 in American Literature, 1890-1930

Chapter 3, Gun-Toting Paleontology: Science, Masculinity, and Race in the Natural History of Henry Fairfield Osborn and Roy Chapman Andrews

Chapter 4, Mendelian Doughboys: Eugenics, the U.S. Army, and the National (Male)

Body, 1900-1924

Chapter 5, Conclusion: Science at the Intersection of Gender, Race, and Nationalism

Bibliography

Appendices 


\section{List of Appendices}

Appendix A: Tarzan cover of the All-Story serial, October 1912

Appendix B: Photograph from the Central Asiatic Expeditions, 1923

Appendix C: Henry Fairfield Osborn's chart of the hominid and simian branches of evolution, 1927

Appendix D: Photograph of Major Robert M. Yerkes, c.1918

Appendix E: Photograph of U.S. Army soldiers taking the Army Alpha test, c.1917-1918

Appendix F: Illustrated chart of bodily measurements taken by Charles B. Davenport of 100,000

U.S. Army soldiers in 1919, and "The Average American Male" by Jane Davenport, 1921 


\section{Chapter 1}

\section{Introduction: The White Male Body and the New Biology in America}

"Know then thyself, presume not God to scan The proper study of Mankind is Man."

-Alexander Pope, An Essay on Man (1734)

The publication of Charles Darwin's On the Origin of Species in 1859 may have precipitated one of the most profound revolutions in Western scientific thought, but his ideas were initially slow to take root in the United States. Louis Agassiz, the preeminent American biologist of his day, discounted not only Darwin's theory of natural selection but the concept of evolution entirely. Botanist Asa Gray, the most vocal American supporter of Darwin's views, was nevertheless uneasy about the Origin's seemingly materialist overtones. Gray was strongly committed, more so than most of Darwin's allies, to divine agency in evolution. ${ }^{1}$ In short, Darwin had no bulldog in the United States - at least not yet.

After the death of Agassiz in 1873, evolution and the concept of natural selection would take root in American universities under a new generation of biologists. Yet, while few scientists were prepared to deny evolution outright, there was considerable disagreement as to the mechanisms that drove this change. ${ }^{2}$ Darwin's views came to be known as gradualism: the argument that members of a species (through methods that were admittedly not yet fully understood) would change slowly over time and environmental factors would drive some of those organisms to extinction while others would survive to reproduce. ${ }^{3}$ The evolutionary thought of Herbert Spencer placed special emphasis on competition between organisms, which

\footnotetext{
${ }^{1}$ Mark A. Largent, "Darwinism in the United States, 1859-1930," in The Cambridge Encyclopedia of Darwin and Evolutionary Thought (Cambridge: Cambridge University Press, 2013) ed. Michael Ruse, 227-228.

2 Ibid.

${ }^{3}$ Richard Milner, The Encyclopedia of Evolution (New York: Facts on File, 1990), 318-320.
} 
came to be associated with his phrase "survival of the fittest." Later editions of the Origin also contained this phrase. ${ }^{4}$

Other theories were influential beyond this "Darwinian" family of evolutionary thought. In 1900, Gregor Mendel's laws of inheritance were rediscovered, providing a mutational understanding of change: as opposed to the gradualism of Darwin, mutation in genes could cause changes to happen very quickly. Hugo De Vries' saltation theory argued that this was the method by which new species emerged. The Mendelian school of thought came to be the dominant theory in American biology until it was merged with Darwinism to produce "synthetic theory" in the late 1930 s and early 1940 s. $^{5}$ Mendelism and its early genetic theories also provided the biological and evolutionary basis for American eugenic thought.

These concepts of evolution, varied as they were, had a significant impact on American intellectual and cultural knowledge. One need not look far to find evidence of this, especially in the early twentieth century: in addition to the revolution in the biological sciences, the immense popularity of Tarzan, the development of eugenics, the media spectacle that was the "Scopes Monkey Trial," and the growth of palatial natural history museums were some of the defining symbols of the age. As these new ideas emerged, however, they challenged established ways of knowing. The authority of religion to answer ontological questions, especially relating to the origin and meaning of life, was forced to negotiate with upstart theories that replaced a divine, orderly world of nature — natural law — with a chaotic one - the laws of nature.

This had vast implications for the way that American men would define themselves and the world in which they lived. The opponents of evolutionary thought, such as William Jennings Bryan, were aware of its potential dangers. They witnessed Andrew Carnegie defend cutthroat

\footnotetext{
${ }^{4}$ Naomi Beck, "Social Darwinism," in The Cambridge Encyclopedia of Darwin and Evolutionary Thought; Milner, 424.

${ }^{5}$ Largent; Milner, 129-130, 298-300, 424-425.
} 
capitalism using Spencer's theories and they read biologist Vernon Kellogg's reports that officers in the Kaiser's army had "Germanized" evolution to support their warmongering. ${ }^{6}$ To Bryan and the anti-evolutionists, the proliferation of evolutionary ideas represented not only a challenge to the authority of the Bible but also a threat to traditional codes of morality. And no wonder that many took issue with evolution, or argued that others had gotten the facts of evolution wrong: implicitly, theories of evolution (and its corresponding anxiety) raised the question of man's relation to the natural world and his proper place therein. Evolutionary science was a system of knowledge through which authoritative ideas about an authentic male identity could be expressed and contested.

I use the term "man" in this context because these evolutionary narratives were strongly gendered. When people imagined their prehistoric ancestors, they had a strong tendency to depict them not only as men, but as embodying a timeless ethos of masculine power. They were hunters and warriors, and if evolution favored those who were strenuous and pugnacious, then they were the primary agents in that process. This comes as no surprise since, as R. W. Connell argues, science is not only practiced by men but portrays and privileges the cultural constructs of male identity in its understanding of the world. ${ }^{7}$ Specifically, during the early twentieth century, both "pop" and "expert" science dealt with the question of the evolution of man by reproducing within it conservative signs of white male supremacy, according to the tastes of this same class that directed the scientific agenda - either directly by practice or by funding its work. This is not to say that there were no voices of dissent, but by and large the mainstream scientific community cast its lot with biologically determinist theories that flattered its authors and audiences.

\footnotetext{
${ }^{6}$ Largent; Beck; Vernon Kellogg, "War and Human Evolution: Germanized," The North American Review 207, no. 748 (March 1918): 364-369.

${ }^{7}$ R. W. Connell, Masculinities, Second Edition (Berkeley: University of California Press, 2005), 6.
} 
My thesis will argue that a number of white middle class men and cultural movements in the early twentieth century United States used this vocabulary of human evolution to construct and reinforce a gendered, racialized, and often class-based hierarchy in which they situated their claims to power and privilege in society. These narratives may have differed slightly in their nuances, but together they formed a system of meaning that placed white male bodies and a mythologized, evolutionary past at the centre of antimodern anxiety. They offered solutions to the perceived problems of modern America: immigration, the transgression of gender roles, working class activism, and the effeminizing influences of overcivilization. ${ }^{8}$ By embracing a natural, authentic white male identity that transcended the artificiality of the modern condition, these men could rediscover the physical, mental, and moral power to maintain and assert their hegemony over a contested national identity.

To understand how these scientific ideas operated as a form of knowledge, I will spend the next few chapters discussing a few broad case studies. Chapter 2, "Antimodernsim and the Ape Men," argues that evolutionary thought inspired a generation of American literature that transcended different literary schools, providing a common vocabulary of natural, psychological, and primitive themes in describing its characters. The paramount example, and by far the most popular of this literary group, were the Tarzan stories, written by Edgar Rice Burroughs beginning in 1912. Tarzan's violent confrontations with men and beasts reinforced a hierarchy of race, class, gender, and species in the jungles of Africa and the cities of civilization alike. ${ }^{9} \mathrm{He}$ was the masculine epitome of empowerment through violence, Spencerian struggle, and escape from the modern world to embrace within the wilderness a primitive, authentic selfhood that lay

\footnotetext{
${ }^{8}$ Gail Bederman, Manliness \& Civilization: A Cultural History of Gender and Race in the United States, 1880-1917 (Chicago: University of Chicago Press), 13-14.

${ }^{9}$ David Leverenz, "The Last Real Man in America: From Natty Bumppo to Batman," American Literary History 3, no. 4 (Winter 1991): 766.
} 
beneath the "thin veneer of civilization." ${ }^{10}$ His Anglo-Saxon virility never fails him in battle, proving himself lord of the jungle and master of the natural world. Burroughs's fictional natural world contained moral lessons for civilized men, and there was something that they could learn in embracing their bestial nature. In his words:

It has pleased me throughout the long series of Tarzanian exploits to draw comparisons between the manners of men and the manners of beasts, and seldom to the advantage of men. Perhaps I hoped to shame men into being more like beasts in those respects in which the beasts excel men, and these are not few. ${ }^{11}$

In Chapter 3, "Gun-toting Paleontology,” I examine the evolutionary thought of Henry Fairfield Osborn, one of the most influential scientists in the United States during his lifetime, as well as his protégé, the hardy paleontologist Roy Chapman Andrews. These two men believed that paleontology — the science of finding and interpreting fossilized remains — was a masculine scientific endeavour that could solve the question of man's origins and his nature. To them, fossil evidence could show the evolutionary history of life on earth, including man's evolution from earlier species, as well as the mechanisms that drove evolution itself. Osborn constructed his prehistoric world of nature as a foil for the decadence and comfort that he saw in his own time, arguing that struggle and strain in difficult environments were the key to man's evolutionary progress. He also held deep anxieties about the future of the "Nordic race" in America, leading him to enthusiastically embrace the science of eugenics. Meanwhile, Andrews spent nearly a decade searching for the "missing link" fossils in the Gobi Desert with Dodge cars and Colt revolvers, fighting with bandits and commenting on the decline of the Mongol race from a nation of warriors who had lost their powerful fighting masculinity. Sent by Osborn and the American Museum of Natural History (AMNH), his Central Asiatic Expeditions in the 1920s were a

\footnotetext{
${ }^{10}$ John F. Kasson, Houdini, Tarzan, and the Perfect Man: The White Male Body and the Challenge of Modernity in America (New York: Hill and Wang, 2001), 200, 211-213.

${ }^{11}$ Edgar Rice Burroughs, “The Tarzan Theme," Reader's Digest (June 1932). available online at http://www.erbzine.com/mag0/0058.html (last accessed 4 February 2014).
} 
journey of masculine self-discovery in which he lived a Spencerian "frontier" lifestyle while trying to find the holy grail of human evolution — and prove Osborn's theories about the evolution and origins of man.

Lastly, in Chapter 4, "Mendelian Doughboys," I investigate the American eugenics movement with special attention to Charles Davenport and Robert Yerkes, who conducted a series of examinations on the bodies and minds of U.S. Army draft recruits during the First World War. These examinations constructed categories of "fitness" and "unfitness" in the bodies and minds of men, which closely followed their racial worldview. The eugenics establishment used the published results of the tests to successfully lobby for the anti-immigrant 1924 Johnson Act. In this way, the evolutionary construction of inferior and superior body types was used in an attempt to shape the male bodies of the nation. Like the writing of Osborn and Burroughs, it cast men of northern European stock as physically and mentally superior to Eastern and Southern Europeans, who had been migrating in increasing numbers to the United States since the 1890s. The bodies of Nordic men were therefore entitled to be members of a civilized republic whereas others were not highly evolved enough to be included in such a polity.

In one sense, this allows us to consider evolutionary determinism and its construction of white male identities in its many manifestations, giving us a more complete picture of the whole. I have also arranged the chapters in such a way that this thesis begins with popular depictions of men and evolution in literature (Chapter 2) and shifts to the scientists who helped to produce this knowledge (Chapter 3 on Andrews, Osborn, and the AMNH). Burroughs read Osborn's books and used them to depict early hominids in some of the Tarzan stories. ${ }^{12}$ With this chapter progression, I stress the similarity between pop science and expert science on the question of

\footnotetext{
${ }^{12}$ Marianne Sommer, "The Lost World as Laboratory: The Politics of Evolution between Science and Fiction in the Early Decades of Twentieth-Century America," Configurations 15, no. 3 (Fall 2007): 299-300.
} 
evolution and a transcendental male identity situated in the natural world. For Burroughs and Osborn, a man could reach his full potential only through struggle in nature. Whether it was Osborn arguing that an environment with "luxuriant" supplies of food did not stimulate evolutionary progress, or decrying the effeteness and lack of manual work in the laboratorybased biological sciences in contrast to the physical rigor of paleontology, he articulated very similar messages to the major themes of Burroughs's return-to-nature stories.

On the other hand, the story of Osborn's influence and scientific thought also speaks to the growing power of private institutions, such as the $\mathrm{AMNH}$, to construct and distribute scientific knowledge about the body through narratives of evolution. In the museum's case, the exhibit halls featured murals depicting the life of early hominids (at least as interpreted by Osborn), impressive reconstructions of prehistoric dinosaurs and mammals, and a number of evolutionary charts tracing the origin of the human races (he believed that each race was a biologically distinct species). The museum also distributed textbooks and other materials to schools. Another institution — the Eugenics Record Office—was the heart of the American eugenics movement, and its role in constructing knowledge about the body through Mendelian pedigree analysis is an important part of Chapter 4. Davenport and Harry Laughlin, who served as director of the ERO, built a network of eugenic experts, field workers, wealthy donors, and politicians to organize what was previously a nebulous group of people who shared vague ideas about human heredity. Osborn, Davenport, and Yerkes all drew their understanding of race from Madison Grant's The Passing of the Great Race (1916), which divided Europe amongst the Nordic, Alpine, and Mediterranean races. The translation of these racial ideas and corresponding biological determinism into federal legislation that privileged certain bodies over others in becoming American (via immigration restriction) is a telling example of the power of scientific 
institutions and their ability to shape cultural understandings of legitimate and illegitimate bodies that had real political consequences.

Underlining my arguments about these historical systems of thought is my interest in the production and distribution of scientific knowledge: that is, how an idea can be conceived and then made to be a part of the accepted cultural lexicon. This is no simple question. I also believe that the historical problems I have identified in this thesis are especially insightful in trying to understand power relations in the sciences. When Andrews explained that he and his expeditionary team thought it was more "fun" to dig up Stone Age tools than dinosaur eggs, he deferred to Alexander Pope: "The proper study of mankind is man."13 From a critical perspective, the construction of knowledge about oneself (white middle class men making themselves, directly or in directly, the object of their scientific investigations) presents an obvious conflict of interest. Yet Andrews, Osborn, and other evolutionary experts rendered this epistemological problem invisible by championing the objective nature of science. People might be involved in the scientific method, but that method was inherently impersonal and therefore a process to reveal pure, unadulterated truths.

For my understanding of science as a discourse of gender, I borrow from the sociological work of Martha McCaughey (The Caveman Mystique), Todd Reeser's poststructuralist interpretation of male identity and the body (Masculinities in Theory), and the well-established work of the previously mentioned R. W. Connell (Masculinities). McCaughey's study of "pop Darwinism" is concerned with evolutionary narratives of masculinity from the 1950s onward, with a special focus on more recent developments in the past few decades. I have nonetheless found her conceptual arguments useful as I focus my own research on the early twentieth

\footnotetext{
${ }^{13}$ Roy Chapman Andrews and Henry Fairfield Osborn, On the Trail of Ancient Man (New York: G. P. Putnam and Sons, 1926), 270.
} 
century. She points out that there is a symbiotic relationship between popular culture and scientific knowledge - the former frames the research objectives of the latter. At times, the distinction between the two can be quite porous. ${ }^{14}$ She and Connell both argue that the prestige of science has the power to construct narratives of male identity that shape lived experiences; it is hegemonic as a form of knowledge because it posits an objective truth in its statements that is privileged over other ways of knowing. ${ }^{15}$

Connell also draws attention to the ways in which the bodies of men have been constructed through a biologically determinist discourse: one that identifies a transcendental body that belongs to men exclusively (by possessing definitively male body parts and physical traits). This narrative attaches men's physical bodies to cultural ideas about masculinity, and gives meaning to those bodies by comparing them to others which are constructed as differentfor example, the bodies of women. ${ }^{16}$ If a body does not fall into one of these categories, its masculinity (or femininity) can be put into question. For a person's body to fall outside of this binary system does not disrupt that system, but subjects that person to cultural stigmas about adherence to gendered identities. The gendering of bodies can function as a birthright to power in society in a group context (such as denying women the right to vote or to enter certain career fields) or in an individual context: Theodore Roosevelt's political career was marked by the successful use of gendered language, constructing himself as masculine and his opponents as effeminate. ${ }^{17}$ Accordingly, a constant theme throughout this thesis is the deferred cultural

\footnotetext{
${ }^{14}$ Martha McCaughey, The Caveman Mystique: Pop-Darwinism and the Debates over Sex, Violence, and Science (New York: Routledge, 2008), 11.

${ }^{15}$ Ibid., 19; Connell, 6.

${ }^{16}$ Connell, 42-44.

${ }^{17}$ Bederman, 13, 170-171; Andrew M. Johnston, "Sex and Gender in Roosevelt's America," in Serge Ricard ed., $A$ Companion to Theodore Roosevelt, First Edition (Hoboken, NJ: Blackwell Publishing, 2011), 120.
} 
meaning of an idealized white male body to others - to awkward immigrant bodies, to physically defenseless women's bodies, and even to other (overcivilized and effeminate) white male bodies.

For Reeser, the male body is not only an important text for constructing masculinity in culture; it can also be the "locus" for anxieties about national identity. ${ }^{18}$ This is a recurring theme in the literature of Burroughs, Osborn, Andrews, Davenport, and Yerkes, and perhaps the most prevalent one - besides their common language of evolution and the body — that unites their narratives. Expressed particularly through eugenics, these men were all concerned by the alleged degeneracy of the Nordic race in the United States due to miscegenation, falling birthrates, and (less so for Davenport and Yerkes, who were Mendelists) the emasculating and decadent life of civilization. Even as Grant expressed his unshaken belief in the superiority of the Nordic race, he held deep fears about the vulnerability of the white male body due to the threat of "race suicide":

Neither the black, nor the brown, nor the yellow, nor the red will conquer the white in battle. But if the valuable elements in the Nordic race mix with inferior strains or die out through race suicide, then the citadel of civilization will fall for mere lack of defenders. ${ }^{19}$

Reeser also argues that there is a cultural taboo against the viewing of the male body by other men, which has homoerotic connotations. ${ }^{20}$ Indeed, if it were not for the use of scientific methods to study and view the bodies of men - an epistemological tradition defined chiefly by its objectivity and impersonality—it would be difficult to navigate the sexual tensions that might otherwise arise in such a project. It might also be argued that the biological arguments against "miscegenation" (a coded meaning for interracial sex) served to hide the sexual anxieties on the part of many white men related to the presence of non-white, or non-Nordic, people in the same urban spaces as white women. Anglo-Saxon men need not fear these foreigners, Grant argued,

\footnotetext{
${ }^{18}$ Todd Reeser, Masculinities in Theory (Chichester, UK: Wiley-Blackwell, 2010), 91-93.

${ }^{19}$ Madison Grant, The Passing of the Great Race, Fourth Edition (New York: Charles Scribner's Sons, 1922), xxxi.

${ }^{20}$ Reeser, 110.
} 
since they could be bested in battle — but it was women who were vulnerable and required protection.

In this light, it comes as no surprise that what had begun as a thesis about evolutionary narratives of masculinity in the early twentieth century United States quickly came to include the discourse of race. To ignore the racialized dimensions of these gendered identities in the time and place under investigation would leave quite an incomplete picture. Dorothy Ross (The Origins of American Social Science) points out that the new biology bolstered pre-existing racist views. ${ }^{21}$ However, as evidenced by the triple theory of European race popularized by Grant, itself closely based on the work of William Z. Ripley, this brand of scientific racism produced its own lexicon. The complicity of science in these narratives of Anglo-Saxon male supremacy is worth investigating since there was so little scientific literature, if any, that questioned these racist views until Franz Boas's studies on immigrants for the Dillingham Commission. ${ }^{22}$

The rise of the new biology was predicated on the "discovery" of a prehistoric age where many species of plants and animals had existed, and evolved, over many millions of years—far beyond the historical past that could be interpreted by records, chronicles, or traditions. For this point and the professionalization of scientific disciplines - especially paleontology — that could claim an intellectual monopoly over the study of this lost age and its geological artifacts, I draw from the work of Tony Bennett (Pasts Beyond Memory). ${ }^{23}$ These evolutionary narratives of white male identity reconfigured the natural world in two ways: first, by turning the earth's clock back to entirely new eras of geological time that extended far earlier than the conventional Christian understanding of a 6000-year old world, and second, by claiming nature as a masculine

\footnotetext{
${ }^{21}$ Dorothy Ross, The Origins of American Social Science (Cambridge: Cambridge University Press, 1991$), 146-147$.

${ }^{22}$ Marshall Hyatt, Franz Boas, Social Activist: The Dynamics of Ethnicity (New York: Greenwood Press, 1990), 110.

${ }^{23}$ Tony Bennett, Pasts Beyond Memory: Evolution, Museums, Colonialism (London: Routledge, 2004), 1-2.
} 
space. In the gendered language of Theodore Roosevelt, we see the codes of masculinity and femininity as he ridiculed those who viewed nature along the lines of Ralph Waldo Emerson and others "sentimentalists":

Death by violence, death by cold, death by starvation - these are the normal endings of the stately and beautiful creatures of the wilderness. The sentimentalists who prattle about the peaceful life of nature do not realize its utter mercilessness; although all they would have to do would be to look at the birds in the winter woods, or even at the insects on a cold morning or cold evening. Life is hard and cruel for all the lower creatures, and for man also in what the sentimentalists call a "state of nature."

In the world of Roosevelt, as for Burroughs and Osborn, the timeless truth of nature, even before men walked the earth, was that only those who struggled and fought and strained would survive.

Certainly, there are familiar figures who will appear across a number of chapters:

Roosevelt, Grant, Bryan, and Boas come to mind. For different reasons, the thought of these men with respect to evolution and white male identities could have merited their own chapters, but a research work of this size cannot give them each a fair treatment. Instead, I will bring them to bear on the works of Burroughs, Osborn, Andrews, Davenport, and Yerkes, since they can help us in understanding their ideas by contrast. Even in placing them alongside like-minded cultural hegemons, we can see that these thinkers and views contained their own nuances even as they shared conceptual themes. This way, my observations are not limited to the way that an individual happened to think, but are situated in a broader social context. I have chosen to closely examine the ideas of these five men because, collectively, they provide the best opportunity to study these narratives of man's prehistoric past that Bennett problematizes, and to show how its influence spread across American culture, scientific research, institutions, and legislation in the early twentieth century.

\footnotetext{
${ }^{24}$ Theodore Roosevelt, African Game Trails: An Account of the African Wanderings of an American HunterNaturalist (New York: Charles Scribner's Sons, 1910), 240-241.
} 
On a final note, I would like to comment on the accusation that these systems of thought represented a "pseudoscience." Indeed, the research methods of many of the historical figures who I refer to can (and should) be roundly criticized, as can their interpretation of the results that they produced. I cannot help but wonder, however, if the use of delegitimizing terms such as "pseudo" helps science to distance itself from ideas and thinkers that have fallen out of favour and therefore serves to perpetuate the unassailable position of science as a way of knowing. Each of the men that I consider in this thesis considered themselves scientists, and considered their work scientific, and had others, if not the majority of the scientific establishment, to support these claims. And, while I freely admit that I believe that science is a useful method for understanding the world in which we live, it is painfully obvious in any reading of the history of science that it has had a strong tendency to support pre-existing power relations in a given society (even as it created new ones, such as the "expert" or "professional"). To put it another way, I am comfortable with evolution as an explanation for the diversity of life and the natural history of the earth. To understand it more clearly, however, we must strip it of the cultural influences that have given it the discursive baggage of race, class, gender, and even species (among other, and no less important, categories of difference). This thesis is therefore a small contribution to that end, and with it I hope to bring some of the history of these contested ideas to light. 


\section{Chapter 2}

\section{Antimodernism and the Ape Men: Tarzan, Evolution, and White Male Identities in American Literature, 1890-1930}

"The savage personal combat, the blood, the contact with the mighty body of the carnivore had stripped from him the last vestige of the thin veneer of civilization... It was no man, but a wild beast, that raised its head and voiced the savage victory cry of the bull ape, a cry that stilled the multitude and froze its blood."

\section{—Tarzan and the Lost Empire (1929)}

In the past few decades, the Tarzan stories and their author, Edgar Rice Burroughs, have become a favorite topic among historians of gender and race in the United States. Tarzan of the Apes was first published in The All-Story serial in 1912, and with its dozens of sequels, Burroughs became the bestselling author of his time. ${ }^{1}$ When one adds to this consideration the immense, pioneering multimedia success of Tarzan in comics, radio, movies, and branded products, there can be little doubt that Burroughs had conceived a story and character that resonated strongly with the American psyche. Yet, how can one account for the popularity of such a virile, vine-swinging, "primitive" hero at a time when the United States was undergoing a period of rapid industrialization and urbanization?

The answer in large part can be found in the anxieties of some members of the white male middle class during the Gilded Age and Progressive Era. As David Leverenz argues, the story of Tarzan "fulfills almost every civilized white fantasy of class and race domination."2 Indeed, the story of an Anglo-Saxon man of noble blood, born and raised as an orphan in the West African jungle only to become its master through violent struggle, had a special significance for its audience. As early as the 1890s, there was a growing concern among progressive intellectuals about the large numbers of "new" immigrants arriving from Eastern and Southern Europe on the one hand, and the erosion of Victorian gender identities on the other.

\footnotetext{
${ }^{1}$ Bederman, 219.

${ }^{2}$ Leverenz, 758-759.
} 
While some celebrated a "cosmopolitan America," others spoke of a pending crisis for the future of the nation-a "race suicide."3

Burroughs and his readers constructed the African jungle as a primitive place: a natural space where the "survival of the fittest" was the only law, a foil to their own world of modern, industrial civilization. There, in an imaginary world where Tarzan's Anglo-Saxon white masculinity is put to the test, he succeeds in fighting savage animals, African natives, mutinous sailors, and brute-like primitive women. Tarzan was the literary (and, later, cinematic) performance of Progressive Era hierarchies of race, gender, and class, draped in the language of the new biology. ${ }^{4}$ His jungle battles are exciting, violent scenes in which the hero's innate biological greatness, coupled with a savage upbringing along the lines of Theodore Roosevelt's "strenuous life," allow him to come out on top of a Spencerian contest for supremacy.

Perhaps it is no surprise that Burroughs, like many members of the Anglo-American middle class, had an interest in evolution and eugenics that framed his view of human societies and consequently the characters and plots of his literature. ${ }^{5}$ In what sense, though, can we say that his readers understood and appreciated such ideas for their own part? John Pettegrew points out that "without diary entries or personal letters speaking of such an appeal, the novel's primitivist meanings remain a matter of speculation." ${ }^{, 6}$ It is with some regret that I agree, and must leave suspended the question of how the lived experiences of Burroughs's readers and viewers were influenced by the "culture" of Tarzan - what Americanist Alex Vernon has labelled "Tarzania."7

\footnotetext{
${ }^{3}$ Ross, 146-147.

${ }^{4}$ Sommer, "The Lost World as Laboratory," 309.

5 John Taliaferro, Tarzan Forever: The Life of Edgar Rice Burroughs, Creator of Tarzan (New York: Scribner, 1999), 92.

${ }^{6}$ John Pettegrew, Brutes in Suits: Male Sensibility in America, 1890-1920 (Baltimore: The Johns Hopkins University Press, 2007), 75.

${ }^{7}$ Alex Vernon, On Tarzan (Athens: University of Georgia Press, 2008), 4.
} 
On the other hand, an analysis of Tarzan presents an opportunity to place it as part of larger currents in American culture, at least within the confines of its predominantly white middle class readership. In this chapter, I will argue that the Tarzan books were part of a new cultural vocabulary with which this group articulated their identity as civilized men who, at heart, were members of the animal kingdom and therefore the natural world. They, like all animals, were subject to the laws of biology and evolution, including progress, regress, natural selection, and the "survival of the fittest." In providing a cosmic ordering of the universe and their place within it that rewarded the strenuous with virility and punished the slothful with weakness, this narrative of biological and evolutionary determinism set the terms for white middle class male privilege and empowerment at home and abroad. Men could not escape their heredity or the laws of nature, but it was a hierarchy of race, class, and gender in which they placed themselves at the top. To leave behind the effeminate tendencies and racial ambiguity of the metropolis and embrace struggle in nature was to become an authentic man. Such a conceptual reconfiguration in the understanding of male identity represented a challenge to the Victorian model of genteel manliness and self-restraint, and had become influential by the time that the first Tarzan books were published. ${ }^{8}$

These biologically determinist narratives of masculinity can be found not only in the "literature of hunting and killing" that boasts such mythologized figures as Tarzan and Roosevelt, but also in the American naturalist literature that bloomed in the final decades of the $19^{\text {th }}$ century. The works of Frank Norris and Jack London, like those of Burroughs, consider the inescapability of man's animal nature. Their characters are bound by instinct, the subconscious, and evolutionary atavism; only those who are able to adapt to their environment like their ancestors can become true heroes. Nature and the primitive, often in a violent context, were key

\footnotetext{
${ }^{8}$ Bederman, 217-218.
} 
to rekindling one's power as a man and discovering an "authentic selfhood" — an authenticity that suddenly seemed difficult to find or even define in the world of civilization. ${ }^{9}$ To American literary naturalists, the new biology of Charles Darwin and other evolutionary theorists provided a set of ideas with which to problematize the constraints of civilization on human instincts and desires. Their exploration of this theme was a conscious attack on the romantic idealism of other authors. $^{10}$

Given that Africa was seen by many anthropologists as a continent suspended in a primitive era of man — the Pleistocene-it was a fitting setting for the Tarzan stories to take place. ${ }^{11}$ Burroughs had never been to Africa, but his literature was part of a prolific canon of Western representations of the "Dark Continent" that included Roosevelt's sensational elevenmonth hunting safari in 1909-1910 and Joseph Conrad's Heart of Darkness (1898). Africa, whether constructed as a "dark," savage place inhabited by cannibals, a site of white masculine revival through violence, or victim of the excesses of European imperial greed, seemed to hold a kind of transcendental meaning for American men - a moral "lesson" that the beholder was invited to consider about the state of civilization.

I am indebted to the historians who have investigated Tarzan and its cultural context. In particular, I am writing in the shadow of the historical problems identified by Matthew Frye Jacobson, who remarked that, in its "essentials," the fiction of Burroughs seemed to be articulating the same message as many intellectuals and "serious writing" on the subject of race, gender, and foreign peoples at home and overseas. ${ }^{12}$ I am no less inspired by the work of

\footnotetext{
${ }^{9}$ Kasson, 200.

${ }^{10}$ Bert Bender, "Frank Norris on the Evolution and Repression of the Sexual Instinct," Nineteenth-Century Literature 54, no. 1 (June 1999): 75-76.

${ }^{11}$ Bederman, 207.

${ }^{12}$ Matthew Frye Jacobson, Barbarian Virtues: The United States Encounters Foreign Peoples at Home and Abroad, 1876-1917 (New York: Hill and Wang, 2000), 106.
} 
Marianne Sommer who has drawn direct connections between Tarzan and the paleontological work of Henry Fairfield Osborn, Roy Chapman Andrews, and the American Museum of Natural History. ${ }^{13}$ The important point to note here is that the line that divided fact from fiction was blurry, if not quite arbitrary. This is not to say that there were no dissenting voices: Franz Boas and his colleagues in cultural anthropology, among others, would mount a strong and consistent criticism of biological narratives of race and white supremacy in the early twentieth century. But their very dissent showed the location of the central organizing features of early twentieth century science and culture.

My purpose here, however, will be to show how this common language of evolutionary and biological essentialism appeared across a number of different authors and texts and spoke to the hopes and fears of white middle class men in the early twentieth century. Tarzania and the literature of naturalism reflected the mindset of a white middle class, their understanding of the world and the way that it operated. Such an argument will consider both the explicit and implicit messages conveyed by Burroughs and his contemporary authors, as well as the cultural and intellectual context that provided those messages with meaning.

Tarzan of the Apes begins with the journey of John Clayton (the Lord Greystoke) and his wife, Alice, on a ship taking them to a colonial mission in West Africa. There is a mutiny on the ship, but their lives are spared and they are marooned on the African shore by the jungle. John constructs a cabin, and the two live there for a year until Alice gives birth to a son and falls ill from childbirth. John is soon killed by Kerchak, the brutish leader of a troop of apes, but the child is adopted by one of the apes named Kala. She gives him the name "Tarzan," meaning "white skin."

\footnotetext{
${ }^{13}$ Sommer, "The Lost World as Laboratory," 299-300.
} 
The highborn Tarzan spends much of the book hunting and killing animals and Africans. The primitiveness and savagery of the young man is tempered by his discovery of, and frequent visits to, the cabin of his parents. Using their books and tools, he is able to teach himself to read and soon discovers his hereditary greatness: his realization that he is a man and not an ape marks a turning point in the book, followed by his first encounters with Africans and, later, Americans and Europeans.

Marooned by sailors in a similar fashion to Tarzan's parents, Jane Porter arrives, along with her father and their small party. This group includes Cecil Clayton, the cousin of Tarzan, who did not yet realize who his parents were. Tarzan and Jane meet briefly after he rescues her from the ape Terkoz, who had attempted to carry her off into the jungle as his unwilling mate. She and her companions leave shortly thereafter. Tarzan then saves Paul D'Arnot, a French officer, from African cannibals. In return the Frenchman teaches him the manners of civilization and brings him to Paris. The book ends with Tarzan arriving in the United States in search of Jane, only to learn that she is promised in marriage to another man; as it turns out, however, D'Arnot is able to confirm to Tarzan that Lord Greystoke was his father and that his titles rightfully belong to him — and not his uncle, Cecil's father. Tarzan decides against pressing the claim which would have won him the inheritance and Jane's hand in marriage.

In the first book, therefore, Tarzan sides with the world of the primeval and turns his back on civilization. In the sequel that Burroughs had not initially planned to write, The Return of Tarzan (1913), Tarzan marries Jane. Both the sequel and the marriage were prompted by insistent readers, suggesting that, at some level, what happened to Tarzan and his fictional world were important to them. ${ }^{14}$ Twenty years after writing the first book, though, Burroughs stressed

\footnotetext{
${ }^{14}$ Kasson, 213; Vernon, 3.
} 
that his stories were for entertainment only: "It is difficult or even impossible for me to take these Tarzan stories seriously, and I hope that no one else will ever take them seriously."

This statement should be taken with a grain of salt, however, as his literature was clearly influenced by his fascination with evolutionary themes, especially during the 1920s in which he expressed a greater interest in the booming topics of eugenics and paleontology. ${ }^{16}$ Even from the start, the world of Tarzan was rich with evolutionary and biological language. Burroughs, in other words, drew inspiration directly from the world of science in portraying his fictional characters. Tarzan of the Apes, in which Tarzan is born and grows to become a manprogressing from ignorance to civilization, growing up in the primeval forest and ending up in Wisconsin by the last chapter - can easily be read as a simulacrum for the evolutionary history of American men. In the words of James R. Nesteby, "Tarzan replays the evolutionary drama.",17 In what way were these ideas conveyed? These varied from references to Tarzan's “intelligence that was his by right of birth" or his father's reflection on "our ancestors of the dim and distant past" who struggled in the primitive jungles, to the narrator's quasi-Lamarckian digressions about how the physical and mental qualities of humans can "atrophy" over time. ${ }^{18}$ Tarzan was Burroughs's hero because, removed from the degenerative influences of a modern civilization, his mind and body are pure. Gail Bederman notes the paradox that is central to the Tarzan story and an important part of its moral lesson: "only civilized races possess the most potent manliness... yet civilization weakens the male body."19 Similarly, Burroughs's constant

\footnotetext{
${ }^{15}$ Burroughs, "The Tarzan Theme."

16 Taliaferro, 211; Sommer, "The Lost World as Laboratory," 308, 312-313.

17 James R. Nesteby, “The Tenuous Vine of Tarzan of the Apes," Journal of Popular Culture 13, no. 3 (1980): 484.

${ }^{18}$ Edgar Rice Burroughs, Tarzan of the Apes (1914), available online at http://www.gutenberg.org/files/78/78-h/78h.htm (last accessed 4 February 2014), chapters XIX, II.

${ }^{19}$ Bederman, 222.
} 
descriptions of bodies in the Tarzan stories, portraying Tarzan as lean and strong and his enemies as awkward brutes with menacing facial features, clearly reflect his interest in eugenics. ${ }^{20}$

Evolution and eugenics - the study of biological heredity and its implications for society — had a strong influence on the works of many authors in the late nineteenth and early twentieth centuries. Generally speaking, however, authors inspired by eugenics did not write stories that unambiguously favored eugenic legislation or social control: it merely set the terms for how their characters were composed and how they behaved in light of their heredity. This company included the likes of T. S. Eliot, F. Scott Fitzgerald, H. L. Mencken, Jack London, and Frank Norris. ${ }^{21}$ The latter two were among the defining authors of American naturalism, and had both attacked the sentimentalism of the Victorian novel as an "overcivilized literature" that did not capture the reality of ordinary life: strain, conflict, and pain. To Norris, the effeminate influences of civilization on modern man sapped him of his strength and morality; he was a beast at heart in the emasculating, gilded cage of modernity. ${ }^{22}$

Norris's literature, like other naturalist writers, was inspired by the evolutionary theories of Charles Darwin and Herbert Spencer. For Norris, the "struggle for existence" operated in civilization just as it did in the natural world. His characters are, in the end, bound by instinct and impulse. Civilization and the modern condition have not stripped away their animalistic tendencies which can resurface at a moment's notice, shedding any pretense of "civilized" behavior. $^{23}$

\footnotetext{
${ }^{20}$ Kasson, 186.

${ }^{21}$ Donald J. Childs, Modernism and Eugenics: Woolf, Eliot, Yeats, and the Culture of Degeneration (Cambridge: Cambridge University Press, 2001), 12-13.

${ }^{22}$ T. J. Jackson Lears, No Place of Grace: Antimodernism and the Transformation of American Culture, 1880-1920 (New York: Pantheon Books, 1981), 102-103, 130.

${ }^{23}$ Lois A. Cuddy and Claire M. Roche eds., Evolution and Eugenics in American Literature and Culture, 1880-1940 (Lewisburg: Bucknell University Press, 2003), 22, 27, 28-29.
} 
In Norris's McTeague (1898), the title character is a miner-turned-dentist who is described to the reader as large, strong, and brutish. In one early scene, he is about to perform some work on the anesthetized Trina, but he is nearly consumed by the primitive impulse to take advantage of the young woman in the dentist chair:

Below the fine fabric of all that was good in him ran the foul stream of hereditary evil, like a sewer. The vices and sins of his father and of his father's father, to the third and fourth and five hundredth generation, tainted him. The evil of an entire race flowed in his veins. Why should it be? He did not desire it. Was he to blame? But McTeague could not understand this thing. It had faced him, as sooner or later it faces every child of man; but its significance was not for him. To reason with it was beyond him. He could only oppose it to an instinctive stubborn resistance, blind, inert. ${ }^{24}$

McTeague's primeval urges lead to his ruin, as is the case for the other characters in the story. They are drawn to murder and greed, and thus the subconscious, psychological wants and desires from an evolutionary past have spelled disaster for a man in civilization. Norris's story was particularly dark for the naturalist school, inspired as it was by an 1893 San Francisco murder. ${ }^{25}$

For McTeague, "The evil of an entire race flowed in his veins"; but for Tarzan, whose instincts guide him in the natural setting of the African jungle where he is free to embrace his true identity as a hunter and killer, "In his veins... flowed the blood of the best of a race of mighty fighters. ${ }^{26}$ Burroughs's character doubtless came from a better bloodline than Norris's, but Tarzan is in the authentic world of nature whereas McTeague is constrained by the artificial conventions of civilization. His story is centred on the fatal tension between his innate biology and the thin veneer of civilization that constrains it. The dentist chair scene sets the tone for the

\footnotetext{
${ }^{24}$ Frank Norris, McTeague: A Story of San Francisco (New York: Doubleday and McClure, 1916), 32.

${ }^{25}$ Pettegrew, 117, 121.

${ }^{26}$ Norris, McTeague, 32; Burroughs, Tarzan of the Apes, chapter VI.
} 
rest of the book's plot as McTeague's instinctive sexual attraction to Trina increasingly brings out his bestial, violent personality, as it does for the rest of the characters. ${ }^{27}$

The literature of Jack London, by contrast, focused on heroes whose atavistic tendencies lead to their empowerment. His most celebrated works, The Call of the Wild (1903) and White Fang (1906), featured canines as their main characters. This is critical to London's writing style; Pettegrew argues that he "perfected the de-evolutionary story line" which "blurred the lines between human and animal consciousness." ${ }^{28}$ In this respect, a dog seems a fitting choice for an animal to parallel the condition of modern American men: they are both domestic creatures whose "true" place is in nature, and who share the dilemma of being estranged from the struggle for existence.

The Call of the Wild is the story of Buck, a dog owned by a wealthy California family. He is kidnapped and sold, soon finding himself on a dog sled team in the Yukon, where he is forced to adapt to a strenuous life of difficult work, a frequent lack of food, and primitive violence at the hands of men and beasts alike. He becomes leaner, stronger, and develops an appreciation for the wilderness that calls to his instincts. In one scene, Buck contrasts this with the comfortable life he had left:

Sometimes he thought of Judge Miller's big house in the sun-kissed Santa Clara Valley, and of the cement swimming-tank, and Ysabel, the Mexican hairless, and Toots, the Japanese pug; but oftener he remembered the man in the red sweater, the death of Curly, the great fight with Spitz, and the good things he had eaten or would like to eat. He was not homesick... Far more potent were the memories of his heredity that gave things he had never seen before a seeming familiarity; the instincts (which were but the memories of his ancestors become habits) which had lapsed in later days, and still later, in him, quickened and become alive again. ${ }^{29}$

\footnotetext{
${ }^{27}$ John Dudley, "Inside and Outside the Ring: Manhood, Race, and Art in American Literary Naturalism," College Literature 29, no. 1 (Winter 2002): 61-62.

${ }^{28}$ Pettegrew, 99.

${ }^{29}$ Jack London, The Call of the Wild (New York: The MacMillan Company, 1903), 112.
} 
Buck prefers his new world, closer to nature, where his true self becomes "alive" once more. His fight with Spitz, the previous leader of the pack, to earn his place as the alpha male is an essential part of the Spencerian struggle for existence that was so lacking in the "big house" of his onetime owner. The profession of that owner, Judge Miller, is no coincidence: the decadent life that Buck enjoyed under the laws of civilization, in hindsight, seem so dreary when compared to the excitement and empowerment of the laws of nature.

But not all characters are successful in their struggle against the harsh, natural landscape of the Yukon wild. Buck and the dog sled team are sold to new owners. As Buck observes, though, they are clearly "out of place, and why such as they should adventure the North is part of the mystery of things that passes understanding." ${ }^{30}$ The two men, Charles and Hal, along with Charles's wife and Hal's sister, Mercedes, are hopelessly inept at packing the sled and planning for the trip, and even have trouble getting the dogs to move the sled at the start of the journey. They are mocked by a number of seasoned men who nonetheless offer them advice which they are reluctant to accept and often ignore. The inability of Charles and Hal to adapt to the environment of the north is exacerbated by the feminine sentimentalism of Mercedes, who begs the men not to whip the dogs or treat them harshly and goes into a fit when they attempt to lighten the load on the sled by removing her civilized luxuries. This sets them up for a gendered downfall. Fortunately for Buck, he is saved by a man named Jack Thornton, and the two watch from afar as Charles, Hal, and Mercedes, along with the sled and its dogs, fall through the thin spring ice over a river and die. Only the fit can survive in such a place, and those foolish enough to ignore the lessons of nature must perish.

This anxiety over the excessive "feminization" of American culture was also expressed in Tarzania. Written during a decade of increasing feminist activism and transgressive female

\footnotetext{
${ }^{30}$ Ibid., 126.
} 
cultural icons, Tarzan and the Ant Men (1924) features some interesting commentary on "natural" gender roles and the need for real men, like Tarzan, to resist feminine influences. In the second chapter, he tells his son, "If you and mother had your way my nerves and muscles would have atrophied long since. They were given me to use and I intend using them-with discretion. ${ }^{31}$ Shortly thereafter, Tarzan crashes an airplane into the jungle and his unconscious body is carried off by a large, brutish woman of the Alalus tribe to be used as her Darwinian sex partner. Fortunately for the king of the apes, he is not so easily subdued. He escapes as the women battle over him, and through his eyes, we learn the predicament of this tribe, whose males have become overpowered by the females that have become stronger, dominant, and abusive. His observations are worth quoting at length:

The hideous life of the Alalus was the natural result of the unnatural reversal of sex dominance. It is the province of the male to initiate love and by his masterfulness to inspire first respect, then admiration in the breast of the female he seeks to attract...The gradually increasing ascendency of the female Alalus over the male eventually prevented the emotions of respect and admiration for the male from being aroused, with the result that love never followed. Having no love for her mate and having become a more powerful brute, the savage Alalus woman soon came to treat the members of the opposite sex with contempt and brutality with the result that the power, or at least the desire, to initiate love ceased to exist in the heart of the male - he could not love a creature he feared and hated, he could not respect or admire the unsexed creatures that the Alali women had become, and so he fled into the forests and the jungles and there the dominant females hunted him lest their race perish from the earth. ${ }^{32}$

Later, Tarzan escapes the cave with a number of the Alalus men. He teaches them to hunt and make weapons that are superior to those of the women's clubs. Eating meat from the hunt gives them strength, and by the end of the book the men have asserted their dominance over the women. A large number of the brutish women are killed in a battle, and the "comely" ones who survive are literally beaten into submission until they agree to cook for the men. At the end of the

\footnotetext{
${ }^{31}$ Edgar Rice Burroughs, Tarzan and the Ant Men (1924), available online at http://gutenberg.net.au/ebooks06/0600651h.html (last accessed 4 February 2014), chapter II.

${ }^{32}$ Ibid., chapter III.
} 
book, Tarzan looks on approvingly as the leader of the men indicates how gender-based violence has brought some measure of "civilization":

To entertain Tarzan and to show him what great strides civilization had taken in the land of the Zertalacolols, the son of The First Woman seized a female by the hair and dragging her to him struck her heavily about the head and face with his clenched fist, and the woman fell upon her knees and fondled his legs, looking wistfully into his face, her own glowing with love and admiration. ${ }^{33}$

Thus Tarzan corrects the unnatural state of things and imposes the "natural" supremacy of man.

The rupture in traditional gender roles in American society caused anxiety among conservative men in the early decades of the twentieth century, whether in the form of the growing number of female workers and college students or their agitation for suffrage. A number of sociologists expressed concern over the stability of the American family model. The fear of the progressive "feminization" was a recurring theme in the social science of the Gilded Age and Progressive Eras. $^{34}$

Likewise, in Tarzan, the simple truth of man and woman is exemplified by the first moment of interaction between Tarzan and Jane. He fights the ape Terkoz not only to save her, but to claim her as his mate in an evolutionary contest. ${ }^{35}$ Jane, observing Tarzan fight for possession of her, experiences a sexualized, instinctive appreciation of the man: "As the great muscles of the man's back and shoulders knotted beneath the tension of his efforts, and the huge biceps and forearm held at bay those mighty tusks, the veil of centuries of civilization and culture was swept from the blurred vision of the Baltimore girl." ${ }^{, 36}$ Jane's atavistic transformation, however momentary, guides her instincts as she offers herself to her new mate. Likewise, he acts by impulse, and the two experience a moment of natural, "real" love:

\footnotetext{
${ }^{33}$ Ibid., chapter XXII.

${ }^{34}$ Ross, 146-147, 394-395.

${ }^{35}$ Bederman, 228.

${ }^{36}$ Burroughs, Tarzan of the Apes, chapter XIX.
} 
When the long knife drank deep a dozen times of Terkoz' heart's blood, and the great carcass rolled lifeless upon the ground, it was a primeval woman who sprang forward with outstretched arms toward the primeval man who had fought for her and won her. And Tarzan? He did what no red-blooded man needs lessons in doing. He took his woman in his arms and smothered her upturned, panting lips with kisses. ${ }^{37}$

In the world of Tarzan, the subordinate status of women to men is not only natural; it is instinctual, if only men and women would embrace their true identities beneath the artificial conventions of civilization.

Violence is a strong theme in this literature. Aside from the action and excitement that it provides to a story at climactic moments, it is the literary device by which characters are developed and timeless truths in the natural world are revealed. Tarzan shows the supremacy of Anglo-Saxon masculinity in the evolutionary hierarchy during his jungle battles with other creatures and men. When the first African natives that Tarzan encounters move into his part of the jungle, he notes that "several had already fallen prey to old Sabor" and that as a result they "hesitated to trust themselves far from the safety of their palisades." ${ }^{38}$ The greatness of Tarzan, gifted with hereditary intelligence and martial prowess, is made clear implicitly when he kills Sabor, the lioness, not long after. It is also made explicitly when he kills Kulonga, a man from the African tribe - the first of many. Curiously, Tarzan has a tendency to kill them by ensnaring them around the neck with a rope and hanging them from trees. Bederman points to the uncanny similarity here to lynching in the American South at the same time that Burroughs was writing. His readers were evidently invited to make comparisons between African natives and AfricanAmericans. ${ }^{39}$

White male identity in Tarzania is therefore defined not only by who Tarzan "is," but who and what he comes to dominate: African natives, animals, and primitive landscapes.

\footnotetext{
${ }^{37}$ Ibid.

${ }^{38}$ Ibid., chapter IX.

${ }^{39}$ Bederman, 223-225.
} 
Burroughs constantly reminds his readers that Tarzan's greatness is owed to his biological superiority. He sits atop the evolutionary hierarchy, and Tarzan of the Apes is the story of his violent struggle to get there. In his own words, "None in all the jungle may face Tarzan of the Apes in battle, and live. I am Tarzan of the Apes - mighty fighter." ${ }^{40}$ When Tarzan fights and defeats someone or something in the jungle, it conveys to the reader a message about who is best in the struggle for existence. The cover of the October 1912 All-Story serial, in which Tarzan of the Apes was first published, shows the king of the apes engaged in mortal combat with a lion (Appendix A). His shocked civilized cousin, Cecil, looks on in awe.

Primitive, "Darwinian" characters like Tarzan marked a departure from the popular Victorian literary form of the medieval knight who, while still exercising violence against moral inferiors, was bound by chivalric codes of honor. Knights began to fall out of popularity by the First World War. ${ }^{41}$ In the literature of Burroughs and the American realists, raw, primal violence is a fact of life, uncaring for civilized ideals. In Norris’s short story, "Lauth," (1893) the main character is no knight but a medieval scholar with no martial experience. At heart, though, he has a primitive thirst for violence like the "savage Celtic ancestors" whose blood flows in his veins and comes to life during a street fight:

In an instant a mighty flame of blood-lust thrilled up through all Lauth's body and mind. At the sight of blood shed by his own hands all the animal savagery latent in every human being woke within him—no more merciful scruples now. He could kill. ${ }^{42}$

That protagonists like Tarzan or Lauth who undergo primitive transformations tended to be from the middle and upper classes was no coincidence. T. J. Jackson Lears identifies this "literature of action" as a cultural movement of "class revitalization." In violent worlds reconstructed

\footnotetext{
${ }^{40}$ Burroughs, Tarzan of the Apes, chapter XXIII.

${ }^{41}$ Lears, 101, 119; Linda Dryden, Joseph Conrad and the Imperial Romance (New York: St. Martin's Press, 2000), 23.

${ }^{42}$ Frank Norris, “Lauth,” Overland Monthly 21, no. 129 (September 1893): 224. Quoted in Lears, 130-131.
} 
according to the themes of biological and evolutionary essentialism, gender, race, and class identities can be imposed and mastered. ${ }^{43} \mathrm{~A}$ white man of the middle or upper class who embraced his primitive, violent instincts could best working class men or men of other "races" in combat.

American anthropologists and sociologists wrestled with the question of these categories as well, and considered the extent to which they had a basis in biology. William Z. Ripley developed the "cephalic index," a measure of skull dimensions which he used to catalogue biological differences in race and class. The upper classes of a given society, he argued, had their origins in an ancestral master race that had been able to conquer and wrest social and political hegemony away from the conquered race, who formed the lower class. ${ }^{44}$ Madison Grant, one of the most influential American writers on the subject of race biology, borrowed Ripley's theory of European races (Nordic, Alpine, and Mediterranean) in writing his famous The Passing of the Great Race (1916).

Such anthropological and sociological theories established these biological categories as something rooted in a long evolutionary narrative that extended back to the dawn of mankind. ${ }^{45}$ That their arguments seemed to be "timeless," in that sense, added to their discursive power, as did the "objective" and scientific language with which they were articulated. To writers like Burroughs who subscribed to this biologically essentialist ordering of humanity, a work of literature was an opportunity to recount an "allegory," as John F. Kasson argues, that "explained why its hero (and those like him) triumphed where others failed."46

\footnotetext{
${ }^{43}$ Lears, 102.

${ }^{44}$ Daniel E. Bender, American Abyss: Savagery and Civilization in the Age of Industry (Ithaca: Cornell University Press, 2009), 33-35.

${ }^{45}$ Ross, 154 .

${ }^{46}$ Kasson, 195-196.
} 
The sailors who appear in Tarzan of the Apes on the Fuwalda (carrying Tarzan's parents) and the Arrow (carrying Jane and her companions) are a chaotic and self-interested bunch, portrayed along the lines of a eugenic nightmare. They are "composed of the offscourings of the sea- unhanged murderers and cutthroats of every race and every nation. ${ }^{.47}$ Their inherent criminality, coupled with their racial ambiguity, instantly cast them in Burroughs's eyes as dangerous and evil. The captain is a "brute" who rules by violence, the only authority his crew submits to, and his officers are "coarse, illiterate fellows, but little above the villainous crew they bullied. ${ }^{48}$ We observe them first through the eyes of Tarzan's parents, who are appalled by these modern day savages. Later, Tarzan — hiding in the trees of the jungle—considers the sailors who land on the shore with Jane and friends, and he reads the codes of class as well as any civilized elitist.

Just as one "cowardly," "vengeful," and "rat-faced" sailor aims his pistol to shoot Cecil while his back is turned, Tarzan throws a heavy spear that pierces his shoulder, saving his cousin. Tarzan the strike breaker knows how to deal with the mutinous sailor who has dared take up arms against his social and moral better. Consequently, the cabin of his dead parents which he calls his home must be protected from the seamen and Africans (by lynching no less), but he is more than happy to allow Jane, Cecil, and their party to use it. Interestingly, Catherine Jurca compares Tarzan's defense of his household with the "white flight" suburbanization that began during the Progressive Era; after all, the African tribe and the barbarous sailors are infringing on his territory. ${ }^{49}$ The mutinous sailors represent a chaotic, self-destructive threat to society posed by radical labour; when the "rat-faced" one has assumed command of the mutineers by killing the previous leader, he orders them to dig a hole on the beach to bury some treasure. One sailor

\footnotetext{
${ }^{47}$ Burroughs, Tarzan of the Apes, chapter I.

${ }^{48}$ Ibid.

${ }^{49}$ Catherine Jurca, “Tarzan, Lord of the Suburbs,” Modern Language Quarterly 57, no. 3 (1996): 480-481, 499-500.
} 
insists that he, despite being the leader, take up a shovel as well. The rat-faced sailor's end is symbolically appropriate for an unruly union agitator: “'Then, by God,' replied Tarrant, 'if you won't take a shovel you'll take a pickax.' With the words he raised his pick above his head, and, with a mighty blow, he buried the point in Snipes' brain."

Race and class are two recurring markers by which the reader can identify the enemies of Tarzan. Such villains can be found not only in the primitive jungle but also in the most "civilized" spaces of the world. In The Return of Tarzan, the lord of the apes hears the scream of a woman in a seedy street in Paris. He responds to the cry for help to find a terrified woman in a room, but they are not alone. "As Tarzan turned toward the men about him he saw the crafty, evil faces of habitual criminals." ${ }^{51}$ Yet, as brutish as they might be, the aristocratic Tarzan is a product of the struggle for existence, a Spencerian champion underneath his expensive tailored suit: "But the brain, and the agility, and the muscles that had coped with the mighty strength and cruel craftiness of Terkoz and Numa in the fastness of their savage jungle were not to be so easily subdued as these apaches of Paris had believed." ${ }^{, 52}$ The metaphorical use of the term "apache" suggests that they are savages of the city, but Tarzan is able to match their bestial aggression, beating them with teeth and fists even as they come at him with crude weapons like knives and bludgeons. The woman watches in awe as the hero reminds her of "a panther she had seen at the zoo." "'MON DIEU' she cried; 'he is a beast!",53

Criminals and other nefarious social types in Tarzania frequently represent a threat to white women, who need to be protected by the lord of the jungle. This is especially true for Jane, the classic white American Southern belle. The scene in which the ape Terkoz attempts to abduct

\footnotetext{
${ }^{50}$ Burroughs, Tarzan of the Apes, chapter XVII.

${ }^{51}$ Edgar Rice Burroughs, The Return of Tarzan (1915), available online at http://www.gutenberg.org/files/81/81h/81-h.htm (last accessed 4 February 2014), chapter III.

52 Ibid.

53 Ibid.
} 
her and carry her off into the jungle's depths represents a coded fear of miscegeneation. In the movie version of the book, Tarzan the Ape Man (1932), there is no Terkoz; the scene is shot with an African native kidnapping Jane instead. ${ }^{54}$ In both cases, Tarzan saves her from a racialized rapist. The Return of Tarzan and The Beasts of Tarzan (1914), the second and third books, respectively, feature a Russian man named Nikolas Rokoff as Tarzan's main antagonist. As Jane observes, "The Russian had exhibited every trait of his true character-selfishness, boorishness, arrogance, cowardice, and lust. ${ }^{, 55}$ Consequently, she laments that Tarzan was not there to protect her from the primitive, degenerate Eastern European: “Ah, if the invincible forest god of that dead past were but with them now. No longer would there be aught to fear from prowling beasts, or from the bestial Russian., ${ }^{, 56}$ Rokoff is arrested by the end of the book, only to trouble Tarzan and Jane in the following one, which ends with Tarzan killing him.

But beyond violence at the hands of Tarzan, what is the answer to the social problem of criminality? Burroughs, a eugenicist, certainly had his ideas — and they were not limited to his fictional worlds. During the trial of William Edward Hickman, accused of the horrific murder and mutilation of a twelve-year-old girl in Los Angeles in 1928, Burroughs acted as a celebrity guest writer covering the case for a local paper. The defendant pleaded insanity, and the Tarzan author could not resist the opportunity to advocate for an ambitious scheme to rid the nation of "moral imbeciles" like Hickman: they were "a different species that numbers countless members and is daily growing larger... Destruction and sterilization are our only defense and we should invoke them while we are yet numerically in the ascendancy." ${ }^{, 57}$

\footnotetext{
${ }^{54}$ Kasson, 208.

${ }_{56}^{55}$ Burroughs, The Return of Tarzan, chapter XXI.

${ }^{56}$ Ibid.

${ }^{57}$ Quoted in Taliaferro, 229-331.
} 
The late 1920s marked a decline in the influence and cultural authority of the eugenics movement, attacked as it was by geneticists and other experts who began to rejects its science as outdated. It is not surprising that Burroughs was attacked and even ridiculed for his views in his columns. This did not stop him from implementing a eugenics program in his literary worlds, however. ${ }^{58}$ In Tarzan and the Lost Empire (1928), published the same year, we learn that a city of the Roman Empire has survived and remained undiscovered by modern civilization. There, a rudimentary kind of eugenics has eliminated criminality from the city's population:

...Honus Hasta, who became the first Emperor of the East, swore that there should be no criminals in Castrum Mare and he made laws so drastic that no thief or murderer lived to propagate his kind. Indeed, the laws of Honus Hasta destroyed not only the criminal, but all the members of his family, so that there was none to transmit to posterity the criminal inclinations of a depraved sire. ${ }^{59}$

If the modern world of civilization required such interventionist social policies as eugenic sterilization or "destruction," it was because the "survival of the fittest" no longer operated there. Criminals and other degenerates were free to breed in large part due to the charity of others. Eugenics therefore represented a form of "artificial selection" that its proponents compared to the "natural selection" of Darwin's world of nature.

That Africa was chosen as a natural space for the Tarzan stories to take place reflects the influence of antimodern sentiment across the western world, but particularly the "frontier" character that was seen as an essential part of the American national identity. The U.S. Census Bureau had announced in 1890 that the frontier had effectively been "closed" as—at least according to their calculations - homesteads had now occupied virtually all of what was once a virgin, primitive land. A powerful cultural vocabulary began to take shape that championed the

\footnotetext{
${ }^{58}$ Ibid.

${ }^{59}$ Edgar Rice Burroughs, Tarzan and the Lost Empire (1929), available online at http://gutenberg.net.au/ebooks06/0600911h.html (last accessed 4 February 2014), chapter VIII.
} 
wilderness and the primitive, centred on the crisis of identity that signalled the rise of a new urban, industrial order in America. ${ }^{60}$

The anxiety over the loss of a mythologized "frontier" lifestyle in the wake of urbanization and industrialization in the American city was felt very keenly by the white middle class. Whether it was William James and G. Stanley Hall lamenting the excessive comfort of modern life in contrast to the bodily virility of the working class or Roosevelt warning about civilization weakening the "virile fighting virtues," the language with which these men described the condition of modern man was strongly gendered. ${ }^{61}$ The natural world, along with struggle, strain, and physical power, had become a site for masculine regeneration against the effeminate influences of civilization.

Conceived as it was in the naturalist and biologically determinist nature of man's animal identity, to rediscover one's natural, primitive side was an act of liberation. Reverting to one's authentic self often took place in the untamed wilderness - whether the western frontier or a faroff, uncivilized place like the African jungle. The spatial narratives at work here cannot be understated: the very space itself had a primitive character that lent itself to the man and transformed him, much in the way that Frederick Jackson Turner's "frontier thesis" argued that the European colonists had become "Americans" the further they moved westward.

In one sense, a return-to-nature story of masculine empowerment could have happened in any "uncivilized" space—and it did, whether on Mars in Burroughs's John Carter series or London's Arctic North. But Africa and its inhabitants had a special place in the American imagination, conceived by Burroughs in the literary context of other fiction and non-fiction

\footnotetext{
${ }^{60}$ David M. Wrobel, The End of American Exceptionalism: Frontier Anxiety from the Old West to the New Deal (Lawrence, KA: University Press of Kansas, 1993), 88, 95-97.

${ }^{61}$ Jeffrey Sklansky, The Soul's Economy: Market Society and Selfhood in American Thought, 1820-1920 (Chapel Hill: University of North Carolina Press, 2002), 150, 165-166.
} 
writers. Joseph Conrad's Heart of Darkness (1898) is one of the works that inspired his vision of the continent. Written in the literary style of an imperial romance, it is nonetheless a story of imperial excess and abuse - the "darkness" that lies in the hearts of civilized men—in an equally dark, primitive land. The main character, Marlow, is hired as the captain of a riverboat on the Congo. He experiences the savagery of the African continent firsthand. From the safety of the boat, he hears the drums of cannibals on the shore, but resists the call to go native and jump down "for a howl and a dance." He is able to battle the impulse, unlike the morally bankrupt imperialist Kurtz, who has participated in the "unspeakable rites" of the cannibals and led them to pillage ivory from other villages. ${ }^{62}$

Conrad's book is a warning against the involvement of civilized white men in the heart of Africa, as no good seems to come of it. It is a place to be feared; by contrast, Tarzan celebrates what Jacobson calls "the triumphal return of Anglo-Saxondom to the realm of the primeval." For Burroughs, American men were "prisoners of civilization" who yearned to be free. ${ }^{64}$ While Marlow hears the beats of cannibal drums and imagines that it is the rhythm of his own heart, ultimately resisting it, Tarzan proudly proclaims to Jane, "I am still a wild beast at heart."

Heart of Darkness may have questioned the morality of European imperialism-it did not unambiguously condemn it—-but it certainly did little to disabuse its readers of the notion that African natives were savages who could be easily duped, ruled, or killed by white men. Contemplating the "conquest of the Earth" by Europeans, Marlow contends that "what redeems it is the idea only. ${ }^{, 66}$ To Conrad, the mission civilisatrice, the goal to uplift the savage and bring

\footnotetext{
${ }^{62}$ Joseph Conrad, Heart of Darkness (Garden City, New York: Doubleday, Page \& Company, 1916), 34, 46.

${ }^{63}$ Jacobson, 106.

${ }^{64}$ Burroughs, "The Tarzan Theme."

${ }^{65}$ Conrad, 61; Burroughs, Tarzan of the Apes, chapter XVII.

${ }^{66}$ Conrad, 5. Quoted in Dryden, 34.
} 
him to a state of civilization, was at least a good "idea" in spirit, predicated on the notion that the west was superior to the racial other and was in a position to accomplish such a feat.

Yet not all white American men were fond of European-style imperialism, Burroughs included. Tarzan's father is initially sent to Africa as part of an investigation into colonial abuses at the hands of King Leopold II of Belgium, who the narrator identifies as an "arch hypocrite." Along with Conrad, Burroughs's literature shows disillusionment with imperialism, but retains its racist intellectual underpinnings and coded fears of miscegenation. ${ }^{68}$

It was only with the Casement Report of 1904, published years after Heart of Darkness, that criticism of Leopold's treatment of natives in the Congo became mainstream in AngloAmerican culture.${ }^{69}$ While there was ambivalence towards "formal" imperialism in Africa, given that it was divided between the European powers at the Berlin Conference, the U.S. was still very much involved with commerce, missionary work, and scientific expeditions in and around the Congo basin. ${ }^{70}$ Given the popularity of Tarzan and, to an extent, Heart of Darkness, the interest of the American white middle class in Africa had at least as much to do with literature as it did with the direction of foreign policy.

The hunting travelogues along the likes of Roosevelt's African Game Trails (1910) contributed to the popular image of Africa as a continent filled with wild beasts and savage tribes. In Roosevelt's account, the lines that divide man from beast, however, are not always clear. His descriptions of Africans use animalistic language:

The dark-skinned races that live in the land vary widely. Some are warlike, cattle-owning nomads; some till the soil and live in thatched huts shaped like beehives; some are

\footnotetext{
${ }^{67}$ Burroughs, Tarzan of the Apes, chapter XXI.

${ }^{68}$ Allen Carey-Webb, "Heart of Darkness, Tarzan, and the 'Third World': Canons and Encounters in World Literature, English 109," College Literature 19/20, no. 3/1, Teaching Postcolonial and Commonwealth Literatures (Oct. 1992 - Feb. 1993): 123, 127, 129; Jeannette Eileen Jones, In Search of Brightest Africa: Reimagining the Dark Continent in American Culture, 1884-1936 (Athens, GA: University of Georgia Press, 2010), 80.

${ }^{69}$ Jones, $50-51$.

${ }^{70}$ Ibid., 52.
} 
fisherfolk; some are ape-like naked savages, who dwell in the woods and prey on creatures not much wilder or lower than themselves. ${ }^{71}$

Bederman argues that the Africa described by Burroughs in Tarzan, published a couple years after Roosevelt's hunting trip, is "strongly reminiscent" of the one described by the former president. ${ }^{72}$ Both narratives describe the adventures of an upper-class white man in the African jungle, and depict their main character primarily as a hunter. Both characters observe the "primitive" conditions of the people of Africa and contrast it with the advanced technology of the West. Burroughs described the African jungle as a "primeval forest" while Roosevelt described the continent as being in the "Pleistocene."73

Africa was conceived as a prehistoric place where Americans of a certain gender, race, and class could recreate the evolutionary struggles of their ancestors. To do so, to fight in the survival of the fittest, was to test the strength of one's masculine power. ${ }^{74}$ In a modern society where middle class men felt, in the words of Kasson, constrained by a new "impersonal, bureaucratic, and corporate society" and its "pressures on manhood," return-to-nature narratives provided an escapist fantasy to feel like a real man once more. ${ }^{75}$ It is this important role that Africa fulfilled in narrating the masculine regeneration of American men. Burroughs described the jungle where Tarzan was born as one "diametrically opposite" to the world of civilization, a place that offered freedom and restoration from the modern condition. ${ }^{76}$

In describing the people who inhabited these mythologized natural spaces, Burroughs, Roosevelt, and other writers placed them as being suspended in a previous state of time; Africans, to them, were not only living in the Stone Age, but were Stone Age people who had

\footnotetext{
${ }^{71}$ Roosevelt, $\mathrm{x}$.

${ }^{72}$ Bederman, 218

${ }^{73}$ Ibid., 209.

${ }^{74}$ Ibid., 209-210.

${ }^{75}$ Kasson, 211-212, 160.

${ }^{76}$ Burroughs, "The Tarzan Theme."
} 
not evolved, biologically or socially, to the state of civilization or even barbarism. While Franz Boas, Robert Lowie, and other cultural anthropologists had begun in the 1910s to argue that cultures did not advance according to a linear path from savagery to civilization, Lewis Henry Morgan had established early in the post-Civil War era that primitive people of the day were "living fossils" who could be studied as evidence of how people lived in previous eras of man. ${ }^{77}$

The new biology argued that men were the result of an ongoing evolutionary process. If civilization was degenerative to one's masculinity, and the "survival of the fittest" only really occurred in primitive spaces like Tarzan's jungle or the American frontier, then it followed that American men needed to return to nature, even if temporarily, to maintain their superiority. This was the projected dream of Burroughs's writing and of literary and cultural figures like London and Roosevelt. Through their literature, perhaps white middle class boys and men could experience some kind of "call of the wild" and leave the troubles of civilization behind.

Such an interaction with nature was not necessarily one of conquest, but of mastery. In many cases, as with apes, elephants, and other animals, Tarzan is able to form a symbiotic relationship with the creatures of the jungle. At the end of Tarzan of the Apes, he refuses to press his rightful claim to the title of his deceased father, Lord Greystroke, and declares that the African jungle is his true home after all. Even if he did embrace some measure of civilization in the later books, one thing was clear: beneath "the thin veneer of civilization," he was "still a beast at heart." Through all the changing representations of Tarzan in the century since his introduction to readers in The All Story, that much has always been true.

Yet for all of its celebration of the primitive and the "survival of the fittest," the naturalist and return-to-nature literature of the early twentieth century was paradoxically cloaked in the mantle of science, arguably the epitome of modern civilization. The transcendental truths about

\footnotetext{
${ }^{77}$ Daniel E. Bender, 26-27.
} 
Anglo-Saxon men and their place within nature and its hierarchy of race, class, and gender were narrated in this literature by the objective, disinterested narrator of scientific knowledge- $\mathrm{a}$ series of biological and evolutionary laws that guided the destinies of its characters, a set of cosmic truths that simple "were."

At the same time that these Progressive Era authors described their fictional or mythologized worlds with the signs and symbols of evolution and biology, the narrative of evolutionary essentialism was presented to a middle class public in other ways. At the American Museum of Natural History (AMNH), president Henry Fairfield Osborn directed considerable resources to the construction of grandiose, awe-inspiring exhibits on prehistoric men and the creatures that lived alongside them. Many of these exhibits, such as the Hall of African Mammals, used animal specimens collected from Roosevelt's safari. In understanding the secrets of evolution and imparting them to museumgoers, Osborn and his colleagues hoped that they would undergo a transformative experience with nature along the lines of Roosevelt, Tarzan, and Buck.

The common vocabulary with which these ideas about the evolutionary past and present were communicated is evident. Burroughs's descriptions of Neanderthals in Tarzan at the Earth's Core (1929) are very similar to those of Osborn, one of the leading experts on paleontology in the Progressive Era. ${ }^{78}$ And, while Tarzan travelled through primitive landscapes to discover peoples and creatures from different eras, uncovering essential truths about his Anglo-Saxon identity in the process, the AMNH was planning a similar adventure for a virile, white middle class man. Roy Chapman Andrews, a gun-slinging, bandit-killing zoologist and protégé of Osborn, had one foot in the world of civilization and the other on the wild frontier. The Central Asian Expeditions that he led for nearly a decade in the 1920s brought him and his

\footnotetext{
${ }^{78}$ Sommer, "The Lost World as Laboratory," 317.
} 
scientific team into a primitive space where they could test their masculinity against the forces of nature and dangerous barbarians. Their transformative, time-traveling journey also had an ambitious scientific goal: the discovery of the earliest human fossils, of the "missing link" itself - the sacred text that would tell the secrets of man's genesis.

Such a question also had a profound meaning for Burroughs and Tarzan on a personal level. The final words of Tarzan of the Apes are a reflection on his own origin and upbringing in the primeval forest: “'I was born there,' said Tarzan, quietly. 'My mother was an Ape, and of course she couldn't tell me much about it. I never knew who my father was.",79

\footnotetext{
${ }^{79}$ Burroughs, Tarzan of the Apes, chapter XXVIII.
} 


\section{Chapter 3}

\section{Gun-Toting Paleontology: Science, Masculinity, and Race in the Natural History of Henry Fairfield Osborn and Roy Chapman Andrews}

"The earth has buried its secrets as if it were reluctant to reveal the history of our past."

—Henry Fairfield Osborn, “The Earth Speaks to Bryan” (1925)

Evolution was a hot topic in the early twentieth century American city. It was the era of great natural history museums funded by the wealth of the Robber Barons: Andrew Carnegie built his in Pittsburgh, Marshall Field in Chicago, and New York's elite businessmen founded the American Museum of Natural History. ${ }^{1}$ These cities were the same spaces in which these men had made their fortunes. As a consequence, they were also home to large numbers of immigrants who had come to fill the demand for labour. It is no coincidence, then, that these museums weighed into questions of race, progress, and civilization, portraying human evolution and natural history through the lens of white urban upper and middle class men.

No man was more central to the world of American natural history and its museums than Henry Fairfield Osborn, the powerful and patrician President of the AMNH. He was born into the New York aristocracy and possessed close friends and acquaintances there. J. P. Morgan, his uncle, sat as Treasurer of the museum. With the support of such men on the board of directors, Osborn dictated the museum's agenda during his long reign (1908-1933). Like his predecessor, Morris K. Jesup, he believed that the AMNH was an institution with a social mission. Through its work, the museum would teach the lessons of nature and evolution to its visitors. ${ }^{2}$ There, they could experience a natural regeneration that would help counter the degenerative influences of

\footnotetext{
${ }^{1}$ Paul D. Brinkman, The Second Jurassic Dinosaur Rush: Museums and Paleontology in America at the Turn of the Twentieth Century (Chicago: The University of Chicago Press, 2010), 1.

${ }^{2}$ Brinkman, 20; Donna Haraway, Primate Visions: Gender, Race, and Nature in the World of Modern Science (New York: Routledge, 1989), 42; Sommer, "The Lost World as Laboratory," 326.
} 
modern civilization. The museum was their tool to save the white race in America, if only they could learn the truths of nature and embrace their identity therein. ${ }^{3}$

Osborn's understanding of natural history, and particularly of human evolution, reflected his political and social views about the modern America in which he lived. He was a cultural conservative who was critical of the "new woman" and the transgression of traditional gender roles, as well as the arrival of the new immigrant from Eastern and Southern Europe since the 1880s. ${ }^{4}$ In these respects he possessed a similar mindset to his personal friend, Theodore Roosevelt, as well as Edgar Rice Burroughs_-all influential cultural commentators. In their minds, evolution was a gendered and racialized narrative of human progress that told timeless truths about man's identity and his relation to the natural world. William Jennings Bryan, with whom Osborn would engage in cultural battles over evolution in the 1920s, realized the discursive power of such a grand narrative of life on earth and its implications for the meaning of a cosmic male identity: “A man's whole thought and view of life is revolutionized when he looks to the jungle for his ancestry."

Burroughs, of course, envisioned the jungles of West Africa as the "primeval forest" in which white Anglo-Saxon men could retrace their origins, but not so for Osborn. He was convinced that the arid plateau of Central Asia was the place where mammals had first evolved from reptiles; and, by the 1920 s, he extended this theory to include the evolution of the first humans. ${ }^{6}$ Osborn's books and his AMNH exhibits described the evolution of early man in epic

\footnotetext{
${ }^{3}$ Ronald Rainger, An Agenda for Antiquity: Henry Fairfield Osborn and Vertebrate Paleontology at the American Museum of Natural History, 1890-1935 (Tuscaloosa: The University of Alabama Press, 1991), 4.

${ }^{4}$ Constance Areson Clark, God-or Gorilla: Images of Evolution in the Jazz Age (Baltimore: The Johns Hopkins University Press, 2008), 18; Henry Fairfield Osborn, "Lo, the Poor Nordic!” The New York Times, 8 April $1924,18$.

${ }^{5}$ William Jennings Bryan, Seven Questions in Dispute (New York: Fleming H. Revell Company, 1924$), 144$.

${ }^{6}$ Henry Fairfield Osborn, "Present Status of the Problem of Human Ancestry," Proceedings of the American Philosophical Society 67, no. 2 (1928): 152.
} 
narratives of struggle, conquest, and racial fulfillment. ${ }^{7}$ To him, the challenging climate of Central Asia in the Cenozoic period was a perfect setting for such a story to take place. Here, millions of years ago and halfway across the world, Osborn's "Dawn Man" was a noble savage with a moral lesson for a civilized age.

Yet Osborn's early hominids were nameless, and white American men needed living heroes to serve as masculine role models. If Tarzan as a character embodied all that Burroughs had imagined in the perfect American man — a man who, though possessing civilization by birthright, had embraced his primitive identity and its power — then Osborn had created his own champion: Roy Chapman Andrews, the gun-toting museum curator he sent to lead the Central Asiatic Expeditions (1922-1931) on behalf of the AMNH, and search for the fossil remains of the earliest man in Mongolia. ${ }^{8}$

Andrews was an ambitious, charismatic scientific organizer who knew how to appeal to Jazz Age audiences. He described the CAE to the press and the public as a romantic adventure to a "new frontier" in a faraway land, a quest for the discovery of what he and Osborn called "Dawn Man" and what the public usually called the "missing link." This narrative glossed over the eclectic and multidisciplinary work of the expedition, however. In reality, the work of the CAE was divided between collecting fossils, live specimens, plants, geological samples, surveying, and ethnography. Andrews's emphasis on the romance of such an undertaking, along with its search for the holy grail of human evolution, helped him raise $\$ 700,000$ in funding to finance the expeditions. ${ }^{9}$

\footnotetext{
${ }^{7}$ Roger Lewin, Bones of Contention: Controversies in the Search for Human Origins (Chicago: The University of Chicago Press, 1997), 34-35.

${ }^{8}$ Rainger, 104.

${ }^{9}$ Clark, 36-37.
} 
Andrews, with the help of his patron and mentor, Osborn, constructed an identity for himself as a masculine frontiersman who battled the harsh conditions of the Gobi Desert and fought bandits, all in the service of scientific knowledge. He drew this gendered ethos from a tradition of American paleontology in the fossil regions of Colorado and Wyoming whose physically demanding fieldwork and occasional danger-from Native American tribes and rival fossil-hunters - shone in favourable contrast to the decadent consumption and comfortable life of the Jazz Age. ${ }^{10}$ However, as evidenced by the many press reports, private donations, and lecture tours, his tales of masculine romance and adventure were only another good to be purchased and consumed on a cultural level. ${ }^{11}$

What I set out to do in this chapter is to demonstrate how Andrews's narrative of masculine experience on the Mongolian "frontier" stood alongside, and negotiated with, scientific questions of authentic male identity as articulated by Osborn's-and "his" museum's - narratives of human evolution. Here, we can uncover some of the contradictions of American masculinity in the early twentieth century. Andrews and Osborn wrestled with the riddle of male identity posed by the new biology of Charles Darwin, Herbert Spencer, and other evolutionary theorists since the second half of the nineteenth century: was man's authentic place in civilization or the natural world? Their answer would ultimately be both, at least for white American men, and to retain their greatness they had to maintain a precarious balance between the two worlds.

The science of Andrews and Osborn was conservative in its scientific practice, clinging to older theories of evolution even as groundbreaking work in genetics and cytology challenged

\footnotetext{
${ }^{10}$ Keith Thomson, The Legacy of the Mastodon: The Golden Age of Fossils in America (New Haven: Yale University Press, 2008), 5-6.

${ }^{11}$ Lears, 300. I borrow here from Lears's argument that antimodernism posited a binary choice between "authentic experience and the false comforts of modernity," with the former became a marketed commodity during the 1920 s.
} 
them. But it was also conservative in its cultural meaning. Their search for "new" knowledge about male identity through the discovery and examination of prehistoric fossils, in fact, represented old hierarchies of race, gender, and class as revealed through the masculine worlds of paleontology and natural history.

In 1932, after the Central Asiatic Expeditions were completed, Andrews delivered a lecture at a private women's liberal arts college where he told his female audience that exploration was a male-only enterprise. It was off limits to women, he argued, because only men possessed the physical and mental traits necessary for "life in the desert." ${ }^{12}$ American paleontology had quite a reputation for being rough in all senses of the word: the Jurassic era fossil sites like Powder River Basin and Como Bluff were located in difficult, barren terrain. ${ }^{13}$ Furthermore, the intense competition for fossils between Gilded Age paleontologists Edward Drinker Cope and Othniel C. Marsh was rife with scheming and allegations of serious misconduct, including dynamiting excavation sites to prevent rivals from using them. ${ }^{14}$ As a result, their reputations were seriously damaged by the 1890s; American paleontology thereafter became the domain of natural history museums with much greater funding and resources at their command. ${ }^{15}$

The adventure and strenuous nature of this scientific fieldwork appealed to Osborn, and he praised it as a moral and epistemological example for men in the life sciences. In writing an obituary for paleontologist Samuel Wendell Williston in 1919, he described his life as one which "affords a splendid example to many of our youth, whose careers are rendered easy by the wonderful facilities of laboratories and museums in all parts of our land, who may thus fail to

\footnotetext{
12 “Andrews Rules Out Women Explorers,” The New York Times, 6 January 1932, 23.

${ }^{13}$ Brinkman, 8; Tom Rea, Bone Wars: The Excavation and Celebrity of Andrew Carnegie's Dinosaur (Pittsburgh, University of Pittsburgh Press: 2001), 71-72.

${ }^{14}$ Milner, 94-95.

${ }^{15}$ Brinkman, 9-10, 16.
} 
acquire the rugged determination which Williston transferred from his manual to his intellectual life." ${ }^{16}$ Even if Osborn did not make a name for himself in the fossil fields-his early career was marked by rapid advancement in academia and institutions like the AMNH, largely thanks to his powerful connections - he made a habit of visiting expeditions in the field, including the Central Asiatic Expeditions. As with all forms of progress in the history of man, science and the accumulation of knowledge required some degree of struggle and masculine experience.

Keith Thomson points out the interesting place that paleontology occupied in late nineteenth and early twentieth century notions of science and civilization. The paleontologist was both civilized and a rugged frontiersman, a laboratory scientist and romantic adventurer. ${ }^{17}$ Since Andrews and the CAE were generations removed from the years of Cope and Marsh, however, new scientific and technological innovations presented a problem to a narrative of masculine struggle. Just how strenuous was scientific fieldwork, nearly half a century later? Steam and rail had opened up the American West and enabled the first generation of fossil hunters, and in Andrews's time, the automobile was the new revolutionary tool for expeditionary work. $^{18}$

The confusion between an older, historically-grounded way of "roughing it" in the wilderness and the promise of American material progress — a defining sentiment of the age - is an important theme in Andrews's accounts of the expeditions. The Mongolian landscape was, like the American frontier, an ideological space where the contradictions of an industrialized, urban American civilization were brought to the surface and grappled with. Andrews, at least in his narrative, does not so much resolve these contradictions as explore them through a differing

\footnotetext{
${ }^{16}$ Henry Fairfield Osborn, "SAMUEL WENDELL WILLISTON: The Man and the Paleontologist," Sigma Xi Quarterly 7, no. 1, In Memoriam: Samuel Wendell Williston (March, 1919): 2.

${ }_{17}$ Thomson, 331-332.

18 Ibid.
} 
set of perspectives. For instance, one of his books criticized those who sought "adventure," which he defined as the foolish courting of danger. ${ }^{19}$ Expeditions like the CAE needed to be carefully planned to avoid any mishaps. On the other hand, pamphlets promoting his lectures on the expeditions described them as "plenty of adventure." 20 Andrews never seemed to be able to decide which narrative to stay true to.

The primitive masculinity of his constructed persona was held in check by another distinctly American form of male identity that championed science and its practical use to overcome challenging landscapes. This is identified by Lisa Bloom in her work on gendered narratives of American polar expeditions. The masculine ethos represented by explorers like Robert Peary was that of a "scientific manager" and was strongly tied to a progress-oriented American national identity. ${ }^{21}$ To Andrews, the role of an expedition leader was to "study his problem, plan it out on paper, get the best equipment, and above all the men who are fitted physically and mentally for the job.",22

Charles Gallenkamp, one of Andrews's biographers, describes the first expedition in the spring of 1922 as "three automobiles and two trucks transporting a group of heavily armed scientists," a humorous image if indeed it had not been a serious undertaking. ${ }^{23}$ The robust masculinity that had tamed the American frontier was needed to overcome the harshness of the Mongolian landscape, but so too was the American scientific mind. The photographs and films of Dodge cars in the desert were particularly effective in communicating a sense of technological

\footnotetext{
${ }^{19}$ Andrews and Osborn, On the Trail of Ancient Man, 20.

20 "The Roy Chapman Andrews Lectures: unearthing Asia's secrets in quest of "the missing link" (Streator, IL: A.H. Anderson Printing Co., c.1926), available online at http://sdrcdata.lib.uiowa.edu/libsdrc/details.jsp?id=/andrews/1 (last accessed 5 February 2014).

${ }^{21}$ Lisa Bloom, Gender on Ice: American Ideologies of Polar Expeditions (Minneapolis: University of Minnesota Press, 1993), 117; Peter C. Kjærgaard, "The Missing Links Expeditions — or how the Peking Man was not found," Endeavour 36, no. 3 (September 2012): 99-100.

${ }^{22}$ Andrews and Osborn, On the Trail of Ancient Man, 20.

${ }^{23}$ Charles Gallenkamp, Dragon Hunter: Roy Chapman Andrews and the Central Asiatic Expeditions (New York: Penguin, 2001), xiii.
} 
progress; these cars and trucks were the first to be used on a scientific expedition (Appendix B). ${ }^{24}$ According to Andrews, the Dodge cars - his accounts of the CAE mentioned them by name as a nod to his sponsors—allowed for the expedition's work to be completed ten times as quickly. ${ }^{25}$

The image of cars in the desert was an interesting twist to the frontier mythos, but Andrews made it clear, implicitly and explicitly, that Mongolia was analogous to the Old West. In his first major book on the early expedition seasons (1922-1925), On the Trail of Ancient Man, he considered the question of why Westerners found Mongolia so attractive: "They have never phrased to themselves the fact that they have the frontiersman's spirit- the same spirit that won our American West, that won Alaska and will continue to win the wasted places of the earth until all have been reclaimed. ${ }^{, 26}$ Both this book and his second major work on the expeditions, The New Conquest of Central Asia (1932), featured a map of Mongolia superimposed over one of the United States as an indicator of size. ${ }^{27}$ The subtle implication was that the former, just like the West, was an expansive land that was ripe for the taking in the name of civilization.

If the Mongolian terrain looked similar to that of the American frontier-and it did, particularly in photographs taken in the Gobi-it was also home to some familiar characters. Andrews claimed that Mongolia was "foggy with bandits. ${ }^{28}$ Much like the Indians of western lore, the bandits were portrayed as barbarians who could not match the fighting prowess of civilized men and their guns. The expedition carried a large number of rifles, shotguns, and revolvers. Andrews's preference was for a pair of Colt .38 police special revolvers as well as a Savage Arms bolt action rifle. These were not only for protecting the scientific work of the

\footnotetext{
${ }^{24}$ Michael Novacek, Time Traveler: In Search of Dinosaurs and Ancient Mammals from Montana to Mongolia (New York: Farrar, Straus and Giroux, 2002), 281.

${ }^{25}$ Roy Chapman Andrews, "Explorations in Mongolia: A Review of the Central Asiatic Expeditions of the American Museum of Natural History," The Geographical Journal 69, no. 1 (Jan. 1927): 2-4.

${ }^{26}$ Ibid., 108.

${ }^{27}$ Roy Chapman Andrews, The New Conquest of Central Asia (New York: The American Museum of Natural History, 1932), 6.

28 "Andrews Rules Out Women Explorers."
} 
expedition, but to recreate the violent frontier lifestyle. "Our men were simply spoiling for a fight," Andrews recounted. ${ }^{29}$ In his narrative, the triumph of American arms was foreordained. If the bandits were not immediately killed, they rode off at the sight and sound of bullets. While speaking to the press about one such incident in 1931, in which one of his men killed two bandits from his speeding car with a rifle, he showed little anxiety: "After all, we were two white men and there were only thirty bandits." 30

Andrews himself was a skilled and accomplished hunter. While accompanying whaling crews in the prewar years, he had killed a beluga in the St. Lawrence. ${ }^{31}$ As part of the CAE, he shot many animals to bring back to the museum as specimens, including antelopes and mountain goats, but also hunted game as a way of supplementing the expedition's food supplies. The most prized game he ended up killing, however, were men. Andrews returned home with three notches on his pistol, one for every bandit that he had killed. ${ }^{32}$ The violence (or threat thereof) of these masculine scientists was not reserved only for bandits, however. China had been going through years of civil war by the time that the CAE had arrived. To the American men, the differences between bandits, Chinese soldiers under the command of warlords, and corrupt local authorities were not always clear. As a consequence, Andrews often used guile and intimidation to get his caravan through checkpoints on the road. The conspicuous carrying of guns was one method, and if that did not work, the expedition members were prepared to draw them. On some occasions, Andrews bluffed about having a machine gun. ${ }^{33}$

\footnotetext{
${ }^{29}$ Andrews and Osborn, On the Trail of Ancient Man, 122.

30 "Dr. Andrews Tells of Gobi Bandit Fight," The New York Times, 7 January 1931, 29.

${ }^{31}$ Roy Chapman Andrews, Whale Hunting with Gun and Camera: A Naturalist's Account of the Modern ShoreWhaling Industry, of Whales and their Habits, and of Hunting Experiences in Various Parts of the World (New York: D. Appleton and Company, 1916), 274-275.

${ }^{32}$ Discovery Communications, "Searching for Lost Worlds: Dragon Hunters" (1999), available online at http://gutenberg.net.au/ebooks06/0600911h.html (last accessed 20 February 2014).

${ }^{33}$ Andrews and Osborn, On the Trail of Ancient Man, 345; Gallenkamp, 231.
} 
Andrews, Osborn, and their colleagues believed that the men of expedition, as members of a civilized race acting in the service of science, had an inalienable right to travel through Mongolia and take fossils and other objects of scientific value back with them to the United States. This assumption rested on the premise that they understood the scientific value of these artifacts while the people who lived there did not. ${ }^{34}$ The refusal of the land's inhabitants to submit to the advance of civilization meant that the American men could do no wrong in the imperial quest for the "Dawn Man" fossils. This was expressed quite frankly in Geology of Mongolia, one of the publications of the CAE's geological staff: "Fossil bones had previously been found in central Asia, but they meant little or nothing to the people who found themperhaps they were 'dragon bones,' good for medicine or magic! An occasional fragment was carried away from the desert and reached hands of greater competence. ${ }^{35}$ The discovery of scientific knowledge was therefore not only limited to people of a certain gendered identity, but also to those of a certain racially-determined civilization.

The expedition's search for fossils of dinosaurs and early mammals was more successful than anyone could have hoped. Many of the regions that the CAE had explored were eroded by wind over long periods of time, exposing geological rock formations that were millions of years old. Thousands of new species were identified, and the scientific publications based on the CAE's fieldwork numbered in the hundreds. ${ }^{36}$ Their most celebrated achievement was the discovery of the first dinosaur eggs known to science. ${ }^{37}$ The site of the finding, called the "Flaming Cliffs" by Andrews and known as Shabarakh Usu to the native Mongolians, was a particularly valuable area for excavating fossils, many of which were visibly exposed at the

\footnotetext{
${ }^{34}$ Rainger, 104.

${ }^{35}$ Charles P. Berkey and Frederick K. Morris, Geology of Mongolia: A Reconnaissance Report Based on the Investigations of the Years 1922-1923 (New York: The American Museum of Natural History, 1927), 39.

${ }^{36}$ Kjærgaard, 102.

${ }^{37}$ Novacek, 283.
} 
surface. The CAE also found a number of stone tools from the Late Paleolithic (Old Stone Age) period at this location; Andrews referred to the people to whom they belonged as the "Dune Dwellers. ${ }^{38}$

This was far too recent to be anything near the early age of the "Dawn Man" of Osborn's and Andrews's imagination, but it was the closest that the expedition had come to finding evidence of ancient humans in Central Asia. Osborn theorized that the Dawn Man, whom he defined as the first distinct hominid species, first appeared in the Tertiary period of the Cenozoic. This placed the origin of humans much earlier than any of his colleagues in the Western scientific establishment. ${ }^{39} \mathrm{He}$ and Andrews were ecstatic in 1926 when a separate excavation project headed by Canadian David Black and Swede J. G. Anderson, funded by Rockefeller money, announced their discovery of "Peking Man" near the Chinese capital of Peking (Beijing). Osborn believed that the discovery, evidently an early hominid, supported his theory of Central Asiatic origin, and that other, earlier species would be discovered in Mongolia. ${ }^{40}$

Darwin had originally predicted that Africa was the continent where humans had first evolved from earlier anthropoids. The discovery of "Java Man" in 1891 in Indonesia by the Dutch Eugène Dubois had convinced many, including Osborn, that Asia might be another possibility. ${ }^{41}$ Java Man and Peking Man would eventually be reconciled by paleoanthropologists as the same species, Homo erectus. Just as the CAE and Peking Man excavations were taking place, however, a new early hominid fossil was found that would prove to be groundbreaking.

\footnotetext{
38 Andrews and Osborn, On the Trail of Ancient Man, 257.

${ }^{39}$ Henry Fairfield Osborn, "Recent Discoveries Relating to the Origin and Antiquity of Man," Proceedings of the American Philosophical Society 66, The Record of the Celebration of the Two Hundredth Anniversary of the Founding of the American Philosophical Society, (1927): 375.

${ }^{40}$ Gallenkamp, 227-228.

${ }^{41}$ Lewin, 133.
} 
Raymond Dart, an Australian anatomist, announced the discovery of "Taung Child," or Australopithecus africanus in the same year as the Peking Man find. This presented a confusing challenge to the existing narrative of man's evolution, as the fossils were found in South Africa - and they were much older. Most of the scientific establishment played down the discovery as being too ape-like (and therefore not a true hominid); as Gallenkamp and Ronald Rainger point out, however, few experts were prepared to accept Africa as the place of human genesis simply because of the racial implications of such a reconfiguration of man's natural history. $^{42}$

Osborn's theory of Central Asiatic evolution, for mammals as well as hominids, was based on an understanding that organisms could "progress" better in certain environments than in others. This departed from the original theories of Darwin, who attempted to avoid using language that suggested progress or advancement—including the word "evolution"—in explaining how species changed over time. Marianne Sommer describes Osborn's geographic centres of progressive evolution as "evolutionary hotspots" where new organisms arose through environmental stimulus and competition with other species. ${ }^{43}$ In particular, Osborn believed that the first humans had evolved as the result of a great "leap" from lower species, and that such a change would have come from the challenging struggle of a changing climate. ${ }^{44}$

Osborn's most concise explanation of the necessary type of environment for human evolution comes from 1925, while reaching out to the American public during the years of the "Scopes Monkey Trial":

It is upon plateaus and relatively level uplands that life is most exacting and response to stimulus most beneficial. An alert race cannot develop in a forest—a forested country can

\footnotetext{
${ }^{42}$ Gallenkamp, 228-229; Rainger, 102-103.

${ }^{43}$ Sommer, "The Lost World as Laboratory," 312-313.

${ }^{44}$ Kjærgaard, 98-99.
} 
never be a centre of ascent for man; nor can the higher type of man develop in a lowland river bottom country with plentiful food and luxuriant vegetation. ${ }^{45}$

His fascination with high altitudes and upland spaces suggests an allegorical association with progress and “ascent." Osborn's Man Rises to Parnassus (1927), a history of early human evolution, takes its title from the Greek mountain of mythological significance. The high plateau of Central Asia provided just the right such space for an equally mythologized narrative of ancient man's origins.

His use of the term "luxuriant" was a conscious criticism of the environment in which modern Americans lived, particularly during the Jazz Age. ${ }^{46}$ As with his exhortations for scientific men to engage in fieldwork, Osborn was a lifelong believer in the moral and evolutionary benefits of living a strenuous lifestyle. He was not alone in these beliefs: something about "cave men" in the public imagination captured the spirit of a difficult life that was free of the artificial constraints of modernity. ${ }^{47}$ Andrews held similar views. Overindulgence in luxury goods had, according to him, led to the degeneracy of the Mongol race despite their existence in a strenuous and stimulating environment:

Existence in Mongolia is not easy. A man cannot obtain food enough in a day to maintain himself for a week as in the forested tropics. If he is to survive, he must be able to ride and shoot and to endure fatigue and hunger, cold and thirst. It was such hardihood that made the Mongol hordes the terror of Europe in the days of Genghis Khan... It was not until the poison of luxury gained from conquered western peoples had begun to sap their strength that they in turn were conquered. ${ }^{48}$

This provided an explanation for why the bandits of Mongolia could not compete in gunfights with him and his men. But if the American race was to retain its place as, to use the gendered language of Roosevelt, a "manly fighting race," it was necessary to embrace a lifestyle that could

\footnotetext{
${ }^{45}$ Henry Fairfield Osborn, "The Earth Speaks to Bryan," The Forum (June 1925): 801-802.

${ }^{46}$ Rainger, 233.

${ }^{47}$ Clark, 7-8, 17-18.

${ }^{48}$ Andrews and Osborn, On the Trail of Ancient Man, 122.
} 
counter the decadent influences of high civilization. When the "strenuous life" argument was applied to women, however, it was a call to embrace motherhood and moral purity. ${ }^{49}$ As it happened, the desire for the revival of these "natural" gender identities signified a broader disillusionment on the part of middle class white men with giving way to economic and career equality with their female counterparts in the $1920 \mathrm{~s}^{50}$

Osborn's theories of evolution also had implications for social class. His AMNH exhibit on the titantothere family of horse-like mammals stated that they had become extinct because of too much "specialization," or evolutionary change that had become too specific and could not adapt to change in a species' environment. In this case, it argued, their teeth had evolved too specifically towards their food sources and they could not eat anything else once those sources were depleted. ${ }^{51}$ In Osborn's view, there was too much "specialization" in the machine-like world of modernity and its Taylorist obsession with work organization. ${ }^{52}$ Yet, to experience the kind of evolutionary stimulus that was necessary for progress - an interaction with nature, preferably along the lines of Spencerian struggle — required leisure time: hunting, outdoorsmanship, and even visiting natural history museums. The over-specialized working men needed this kind of natural regeneration the most, yet the socioeconomic structure of American society effectively denied it to them.

On the other hand, Osborn's theory of aristogenesis argued that evolutionary change along positive lines happened through the "best" members of the species anyway. ${ }^{53}$ It was the elite men of the race, in particular, who ought to embrace the same Spencerian lifestyle of early

\footnotetext{
${ }^{49}$ Johnston, 122.

${ }^{50}$ Peter Filene, Him/Her/Self: Gender Identities in Modern America, Third Edition (Baltimore: The Johns Hopkins University Press, 1998), 154, 157.

${ }^{51}$ Rainger, 169.

52 Ibid.

${ }^{53}$ Milner, 23-24.
} 
hominids. This, after all, was the key to the evolutionary progress of humans in the past. Visitors to the AMNH were treated to impressive visual displays like artist Charles R. Knight's murals of spear-wielding Neanderthals, artistic cave-painting Cro-Magnons, and hunting Neolithic (New Stone Age) men. Aside from providing inspirational examples of primitive masculinity, Knight's artwork, carefully designed with Osborn's scientific guidance, was meant to have a direct regenerative effect on the viewer. These visual displays and others — of savage beasts and natural life - were intended to provide a Spencerian stimulus akin to the literal viewing of prey or predator species. Here, the "creative mind" and "powers of observation" that were required in nature, yet atrophied in civilization, could be revived. ${ }^{54}$

This was an important mission for Osborn. The history of the races of the world, especially in Europe, was one of conquest, progress, and degeneracy. A race of mighty warriors like the Mongols, the Greeks, or the Romans could rise to become masters of vast empires in one era and submit to racially superior conquerors in another. Such cycles went as far back in European prehistory, in which Osborn specialized, as its first inhabitants. In his view, the Neanderthals were defeated in struggle by the Cro-Magnons, who had migrated to the continent and possessed "superior intelligence and physique" along with more advanced weapons. ${ }^{55}$ Eventually, the Cro-Magnons would fall from their pedestal as they lost touch with the natural world and its evolutionary stimuli. Just as importantly, however, miscegenation with other species had spelled disaster. The former was a direct cause of the latter, as a people who truly understood the lessons of nature would know not to breed with an inferior species. ${ }^{56}$

\footnotetext{
${ }^{54}$ Victoria E. M. Cain, “'The Direct Medium of the Vision': Visual Education, Virtual Witnessing and the Prehistoric Past at the American Museum of Natural History, 1890-1923," Journal of Visual Culture 9, no. 3 (2010): 288-289.

${ }^{55}$ Henry Fairfield Osborn, Men of the Old Stone Age: Their Environment, Life, and Art (New York: Charles Scribner's Sons, 1916), 258.

${ }_{56}$ Marianne Sommer, "Seriality in the Making: The Osborn-Knight Restorations of Evolutionary History," History of Science 48 (September/December 2012): 472-474.
} 
Osborn's theory of decline in the Cro-Magnons, as with other hominid species, informed his views on race in the modern American metropolis (or vice versa). He was a firm eugenicist and advocate for heavily restrictive immigration reform, and served as honorary president of both the Second and Third International Congresses of Eugenics, hosted at his AMNH in 1921 and 1932. When his friend and fellow eugenics advocate Madison Grant wrote his influential The Passing of the Great Race (1916), Osborn wrote a preface that outlined both his biological determinism and fear of miscegenation with the arrival of immigrants:

If I were asked: What is the greatest danger which threatens the American republic today? I would certainly reply: The gradual dying out among our people of those hereditary traits through which the principles of our religious, political, and social foundations were laid down, and their insidious replacement by traits of less noble character. ${ }^{57}$

Eventually, restrictionist federal immigration laws of the type demanded by Osborn and Madison would be passed in the early 1920s, particularly the 1924 Johnson Act.

Grant was a trustee of the AMNH and the chair of the New York Zoological Society. Although there were fundamental differences in their understanding of evolution-Grant was, like the vast majority of American biologists and eugenicists after 1900, a Mendelian whereas Osborn held a "progressive" understanding of evolution that flirted with neo-Lamarckism—-their understanding of race and the immigration question was quite similar. They subscribed to William Z. Ripley's theory of the three "white" European races: the Nordics, Alpines, and Mediterraneans. The line between race and species (or "subspecies") in the literature of Madison and Osborn was often ambiguous, and at times the terms were used interchangeably.

In a similar way, men in the civilized world were the direct products of a racialized and class-oriented evolutionary past. Grant contrasted "the Piccadilly gentleman of Nordic race" with

\footnotetext{
${ }^{57}$ Grant, viii.
} 
the "cockney costermonger of the old Neolithic type." metropolis represented lower orders of men on an evolutionary scale in which being an upper or middle-class Anglo-Saxon meant being at the top. Breeding between these superior and inferior populations almost always led to degeneracy. It was therefore necessary to do away with "sentimentalism" and restrict the flow of Southern and Eastern Europeans into the country, Grant argued, "or else the native American must turn the page of history and write: FINIS AMERICAE."

For Osborn, the salvation of the Nordic race in America required not only a restrictive racial immigration policy but a lifestyle that corresponded with his own particular views of evolutionary progress. He defined his theory of evolution in opposition to Darwinian gradualism and the new field of Mendelian genetics, the two leading theories of the day. ${ }^{60}$ Darwin argued that a species would change slowly over time due to mechanisms which were not yet known. As a consequence, some would survive and others would perish depending on how "fit" they would turn out to be for their environment. The family of Mendelian evolutionary thought posited that change over generations occurred due to genetic mutations, often very quickly. The two theories would eventually be reconciled in the late 1930s and early 1940s as "synthetic theory," years after Osborn had died. $^{61}$

His reasons for arguing against these theories were numerous. First, he was reluctant to surrender a grand narrative of human genesis and progress through racial fulfillment to what he saw as a chaotic theory of chance and luck: in his words, he was "directly opposed to all accidental, discontinuous or mutational hypotheses of the causes of the bio-mechanical evolution

\footnotetext{
58 Ibid., 29.

${ }^{59}$ Ibid., xxxi.

${ }^{60}$ Henry Fairfield Osborn, “Aristogenesis, the Observed Order of Biomechanical Evolution," Proceedings of the National Academy of Sciences of the United States of America 19, no. 7 (July 15, 1933): 702.

${ }^{61}$ Milner, 424-425.
} 
of the germ plasm." ${ }^{2}$ These theories undermined the "creative," or divine element of his understanding of evolution. While most American biologists reconciled their evolutionary views with their Protestant Christianity, Osborn was especially insistent that evolution was an ordered - and not "random"- - process of change, with God's design steering the whole thing somewhere behind the scenes. ${ }^{63}$

Lastly, Osborn's theories stemmed principally from paleontology, the science on which he had based his career and museum. ${ }^{64}$ The stakes were high for him and the AMNH, considering the financial and personnel investments that the museum had made in pursuit of dinosaur, mammal and hominid fossils across the world. The newer fields of genetics and cytology not only represented competing methods of biological research that challenged conventional theories, they were laboratory-based disciplines that embodied none of the masculine struggle of his paleontological fieldwork. Genetics and similar fields also seemed to undermine Osborn's mission to regenerate the race: while Mendelism was the intellectual basis of the eugenics movement, there was little that white men could do to "will" themselves to mutate into a superior species. If evolution could be reduced to a process as structural and impersonal as the interaction of genes or environmental selection, there would be little motivation to live a Spencerian lifestyle and embrace the power of nature. Such a position had vast philosophical implications that Osborn would have found fatalist, especially given his concern over the precarious position of "superior" races in history, like the Nordics in his own time.

\footnotetext{
${ }^{62}$ Henry Fairfield Osborn, "Paleontology versus Devriesianism and Genetics in the Factors of the Evolution Problem," Science, New Series, Vol. 73, no. 1899 (May 22, 1931): 548.

${ }^{63}$ Rainger, 138-139.

${ }^{64}$ Simon Baatz, Knowledge, Culture, and Science in the Metropolis: The New York Academy of Sciences, 1817-1970 (New York: The New York Academy of Sciences, 1990), 183.
} 
His own views on the actual mechanisms of evolutionary progress were complex. It was clear to him that a certain type of environment—such as a high plateau—was necessary to provide a challenging lifestyle ${ }^{65}$ If a species could rise to such a challenge, a mix of physical and non-physical forces would create what was effectively a blueprint for that species' evolution, directly adapted from the experience. "Resistance" and "hard work" were some of the direct stimuli for evolution in limbs and organs. ${ }^{66}$ Such a theory was effectively Roosevelt's strenuous life written into a more "scientific" grand narrative of evolutionary determinism. As evidence of this adaptive and progressive theory of evolution, Osborn cited fossil records like Marsh's laterto-be-debunked work on the evolution of horses, which incorrectly demonstrated that that their extremities changed piecemeal from toes to hooves over the course of several geological erasas if part of some progressive plan. ${ }^{67}$

Perhaps most importantly, paleontology connected man to his evolutionary past, to which he was inescapably bound. The discovery of fossils, such as that of early hominids, were both evidence of and clues into a prehistoric world whose secrets could be unmasked by science and then distributed to public audiences. ${ }^{68}$ As Tony Bennett argues, the science of paleontology described a "past beyond memory," a prehistory that had only become known in the nineteenth century. This challenged previous understandings of the history of human life on earth, turning back the clock by millions of years. By their very nature, the prehistoric sciences sought to have an intellectual monopoly on the study of this "new" past. ${ }^{69}$

\footnotetext{
${ }^{65}$ Osborn, "The Earth Speaks to Bryan," 801-802.

${ }^{66}$ Henry Fairfield Osborn, "Application of the Laws of Action, Reaction, and Interaction in Life Evolution," Proceedings of the National Academy of Sciences of the United States of America 3, no. 1 (Jan. 15, 1917): 8; Osborn, "Paleontology versus Devriesianism and Genetics in the Factors of the Evolution Problem," 548.

${ }^{67}$ Ibid., 548-549; Milner, 222-223.

${ }^{68}$ Baatz, 490; Bennett, 123.

${ }^{69}$ Ibid., 1.
} 
This presented a conceptual challenge to the biblical literalist interpretation of geological history, in which God created Adam as the first man and the Earth was approximately six thousand years old. The diverse evolutionary theories were the product of a scientific discourse which was not only constructed by men, but urban men. On a cultural level, fundamentalist Christianity was most powerful in rural America. The 1925 trial of John T. Scopes in Tennessee therefore embodied not only the question of man's origins, but a power struggle between rural and urban institutions to prescribe grand narratives for a transcendental male identity. ${ }^{70}$

In this light, it should have come as no surprise that Bryan, the populist advocate for farmers and working men, volunteered to serve as prosecutor in the case. The business elite of the Gilded Age, particularly Andrew Carnegie, had enthusiastically embraced—and reinterpreted - the evolutionary theories of Herbert Spencer as justification for the intense competition of the free market. ${ }^{71}$ Indeed, Bryan believed that evolution (he did not differentiate between different schools of thought) was a false system of beliefs that eroded morality, from doctrines such as Spencer's "survival of the fittest" to German war theorist Friedrich von Bernhardi’s "might makes right."72 In his own words, "It leads those who accept it to look downward to the brute for interpretations of themselves.",73

Bryan's most pressing concern, however, was theological. Fundamentalists were determined to stem the growing influence of Christian liberals and modernists and remove them from teaching positions at religious colleges.$^{74}$ Likewise, Bryan believed that the growing influence of evolution, especially by way of publicly funded schools and of colleges, was

\footnotetext{
${ }^{70} \mathrm{It}$ is interesting to see how, beyond the churches and natural history institutions, this cultural battle was waged in the schools and courts. For an extended analysis of the role of institutions in forming gendered identities, particularly in the context of science, see Connell, 42.

${ }^{71}$ Beck.

${ }^{72}$ Bryan, 146.

${ }^{73}$ Ibid., 144.

${ }^{74}$ Clifford Putney, Muscular Christianity: Manhood and Sports in Protestant America, 1880-1920 (Cambridge, MA: Harvard University Press, 2001), 199.
} 
responsible for this movement away from conservative Christianity: "Scratch a critic of the Bible and you are sure to find an evolutionist." ${ }^{, 75}$ These attacks irritated Osborn, who was himself a religiously committed man. ${ }^{76}$ As the President of the AMNH, the largest and most prestigious natural history museum in the country, he also felt a responsibility to engage the public as a defender of evolutionary theory and invested considerable energy in doing so. ${ }^{77}$ As it happened, there was also a personal connection to the trial: Scopes had studied under Arthur M. Miller, one of Osborn's doctoral students. ${ }^{78}$

Osborn's arguments regarding the controversy were twofold. First, he argued that the opponents of evolution did not understand biology. If they did, they would know that the fossil evidence clearly showed that change occurred in species over long periods of time. ${ }^{79}$ To this effect, he chastised Bryan using the fossilized tooth of Hesperopithecus haroldcookii as an example:

In my reply to Bryan I quoted a verse from the Book of Job that has always impressed me: Speak to the earth and it shall teach thee (Job 12:8)... It is noteworthy that shortly after his pledge to accept the Truth appeared in 1922, the Earth spoke to Bryan and spoke from his own native State of Nebraska, in the message of a diminutive tooth, the herald of our knowledge of anthropoid apes in America. ${ }^{80}$

That fossil would later be turn out to be a pig tooth, but was exposed as such only after the deaths of both Bryan and Osborn. ${ }^{81}$ Naturally, Osborn's most direct evidence for evolution was drawn from paleontology.

\footnotetext{
${ }^{75}$ Bryan, 8, 125.

${ }^{76}$ William King Gregory, his colleague at the AMNH and a close friend, wrote in his obituary for Osborn that his mother's religious nature had an influence on his thought. William King Gregory, "Henry Fairfield Osborn," Proceedings of the American Philosophical Society 7, no. 3 (1936): 405, 408.

${ }^{77}$ Lewin, 54.

${ }^{78}$ Henry Fairfield Osborn, "Evolution and Education at the Tennessee Trial," Science, New Series, vol. 62, no. 1594 (July 17, 1925): 43.

${ }^{79}$ Ibid., 44.

${ }^{80}$ Osborn, "The Earth Speaks to Bryan,” 799. Quoted in Lewin, 54.

${ }^{81}$ Lewin, 55.
} 
Second, Osborn defined evolution as being a long, drawn-out process of creation. God had established the laws of nature, including those of evolution. Man was one result of such a progress-oriented phenomenon in the natural world, which they had in common with all animals - "bone by bone, muscle by muscle"-but was unique in that he had "a superior spirit which we call the soul.. ${ }^{\prime 2}$ As much as he was a staunch defender of evolution, however, the controversy of the 1920s had an effect on Osborn's own understanding of man's natural history. Rainger points out that it in was 1925 that Osborn began to define his "Dawn Man" theory, which essentially argued that humans had not evolved from lower orders of apes. ${ }^{83}$ Rather, apes and hominids had evolved independently from "an Oligocene neutral stock." 84

Osborn, one of the most influential scientists in the United States, was virtually the only evolutionary theorist in the country to hold such a view, although English anthropologist Sir Arthur Keith had expressed similar ideas. ${ }^{85}$ Even before 1925, however, Osborn expressed symptoms of what his friend and colleague at the AMNH, William King Gregory, would call "pithecophobia," or the fear of ape ancestry ${ }^{86}$ As early as 1916 , he criticized the ape-like depictions of early humans in art:

No doubt, our ancestors of the early Stone Age were brutal in many respects, but the representations which have been made chiefly by French and German artists of men with strong gorilla or chimpanzee characteristics are, I believe, unwarranted by the anatomical remains and are contrary to the conception which we must form of beings in the scale of rapidly ascending intelligence. ${ }^{87}$

\footnotetext{
${ }^{82}$ Ibid.

${ }^{83}$ Rainger, 231.

${ }^{84}$ Osborn, "Recent Discoveries Relating to the Origin and Antiquity of Man," 376.

${ }^{85}$ Rainger, 231; Milner, 23-24; Lewin, 57.

${ }^{86}$ Milner, 24.

${ }^{87}$ Osborn, Men of the Old Stone Age, xii.
} 
The question of intelligence was central to his arguments. He cited the 1912 discovery of Piltdown Man, later to be exposed as a hoax in the 1950s, as evidence of a large cranial capacity as early as the Pliocene (Appendix C). ${ }^{88}$

At the AMNH, Gregory was the principle challenger to Osborn's "Dawn Man" theory. Gregory's own work in primate anatomy made him an expert on the subject of anthropoid evolution, and he was not blind to the fact that Osborn's views on natural history were heavily influenced by the social questions of race and immigration, as well as his religious beliefs. ${ }^{89}$ The Hall of the Natural History of Man at the museum, curated by Gregory, portrayed the mainstream scientific narrative of man being "a curious side-shoot from the anthropoid stock" and closely related to gorillas and chimpanzees, even as Osborn's Hall of the Age of Man told a different story. ${ }^{90}$

The insistence on an evolutionary history of man that was separate from that of apes, much like his "progressive" theory of evolution, placed man upon a pedestal above and beyond the rest of the animal kingdom. Osborn's ambiguous belief in a divine plan behind the evolution of life would seem out of place if men were little more than monkeys or gorillas with larger brains. The story of man's evolution was an epic infused with moral lessons, as evidenced in the three large murals by Knight commissioned for the Hall of the Age of Man: early hominids were warriors, hunters, and cave artists who had been close to nature and its inherent struggle. The staff of the AMNH, however, voiced concern about these artistic depictions, creative as they were in their interpretation of the scientific evidence (or lack thereof). ${ }^{91}$

\footnotetext{
${ }^{88}$ Lewin, 73; Osborn, "Recent Discoveries Relating to the Origin and Antiquity of Man," 378.

${ }^{89}$ Rainger, 225, 231.

${ }^{90}$ William King Gregory, "The Origin, Rise and Decline of Homo Sapiens," The Scientific Monthly 39, no. 6 (Dec. 1934): 488; Rainger, 231.

${ }^{91}$ Cain, 293.
} 
Gregory's early men, by contrast to Osborn, were only "hunters" fairly recently in their history. For the most part, they hardly embraced such a martial ethos:

Man is a sort of living solar engine running by means of the potential energy that he has stolen from the plants and animals. This of course is nothing new, but for our present purpose it is fundamental. On the physical side man is primarily a machine for the transformation of potential into kinetic energy and on the biological side man is in a sense a parasite and a robber, sponging on the plants, killing the animals and eating them both. Moreover, as we shall presently see, man's ancestors have practically always been robbers, not until recently killers of big game but persistent harriers of creatures smaller than themselves. ${ }^{92}$

In this interpretation, early man was more sneaky than pugnacious, and there was little to be found in the way of a courageous, transcendental, Spencerian narrative of a natural or authentic male identity. Rather, as Gregory quoted from popular film actor Bobby Burns, "My ancient but ignoble blood/Hath rolled through scoundrels ever since the Flood." 93

A third major challenge to Osborn's theories came from cultural anthropology. Franz Boas and his colleagues were particularly concerned by the explicit racism not only in his scientific work but also in his social commentary. ${ }^{94}$ On both the subject of race and human evolution more generally, Osborn argued that the question "centres chiefly in the skull and in the brain. ${ }^{95}$ Ripley's cephalic index proved to be an important part of the canon of scientific racism. The dimensions of the skull, argued Grant, were among the most consistent traits within a race, and thus could show evidence of its biological basis. ${ }^{96}$ Boas challenged this interpretation in his work for the Dillingham Commission, and found that the cephalic index of second and third

\footnotetext{
${ }^{92}$ Gregory, "The Origin, Rise and Decline of Homo Sapiens," 482-483.

${ }^{93}$ Ibid., 483.

${ }^{94}$ Bennett, 121.

${ }_{95}$ Osborn, Men of the Old Stone Age, xi.

${ }^{96}$ Grant, 20-21.
} 
generations of immigrant families in America tended to change due to environmental factors. What this meant, he argued, was that the biological basis for race was overstated. ${ }^{97}$

Such a conclusion would be damning to Osborn's racial theories. Biological determinism was the lynchpin by which his views on evolution and progress had any relevance for the social questions on which he weighed in so prolifically. Seizing on this, cultural anthropologists would attack it on explicitly scientific and anti-racist grounds. Furthermore, they stressed the need for linguistics and ethnology to study the question of race and early human history—not just physical biology. ${ }^{98}$ The biological determinists saw the danger in yielding this scientific authority, and in turn trivialized the work of cultural anthropology. The true nature of man could not be discovered in something as artificial and fleeting as culture. Only a study of his connection to the natural world could shine light on the subject. In Grant's words:

Man is an animal differing from his fellow inhabitants of the globe not in kind but only in degree of development and an intelligent study of the human species must be preceded by an extended knowledge of other animals, especially the primates. Instead of such essential training, anthropologists often seek to qualify by research in linguistics, religion or marriage customs or in designs of pottery or blanket weaving, all of which relate to ethnology alone. ${ }^{99}$

If Grant's The Passing of the Great Race was the call to arms for white supremacy and restricting immigration, then Boas's The Mind of Primitive Man was its antithesis. ${ }^{100}$ Boas would pay close attention to the immigration question as Osborn and his allies successfully fought for the Johnson Act. The science of eugenics was critical in this project, which will be explored in detail in chapter four.

The riddle of Henry Fairfield Osborn tells us much about the power structures of race and gender during the early twentieth century. His views on human evolution were unconventional,

\footnotetext{
${ }^{97}$ Hyatt, 108.

${ }^{98}$ Ibid., 105.

${ }^{99}$ Grant, 3.

${ }^{100}$ Hyatt, 113 .
} 
and his command of scientific knowledge in the public sphere was powerful even when many of his colleagues disagreed with him. His voice was not the only one in American science, but it was among the most powerful. A detailed examination of his ideas, as well as the conceptual challenges he faced from other voices, is essential in understanding the scientific scaffolding that supported early twentieth century hierarchies of race, class, and gender, even as they were being challenged on all sides.

Alexander Pope's "The proper study of Mankind is Man" was the creed of Osborn and Andrews, in all of its possible meanings. The science of these two men constructed a grand narrative of man's evolution, positing a natural and timeless identity for him that was at odds with modernity. To learn and apply the lessons of evolution was key to rekindling a primitive masculinity that lay buried beneath the layers of civilization, and such was the goal of paleontology and the AMNH—at least with respect to Anglo-Saxon men. ${ }^{101}$ Yet masculine struggle was also necessary for that knowledge to be unearthed, as nature did not part with its secrets easily. In the world of Osborn and Andrews, male identity was therefore self-referential. This attempt to resolve the crisis of gendered authority that had existed since the Gilded Age bridged the yearning for a lost pastoral past with the realities of modern civilization.

Andrews' quest to prove Osborn's theory of Dawn Man's Central Asiatic origin had failed to find the elusive fossils. They informed his worldview through and through, as well as that of a certain white male middle class in America. When he went "a-digging in Mongolia," as one press reporter described it, he dreamt that "primitive men were fighting a battle to the death with gigantic fish just outside the tent." ${ }^{102} \mathrm{He}$ was engaged in the same Spencerian struggle as they were, retracing the steps of his evolutionary ancestors, and in his persona lay the

\footnotetext{
${ }^{101}$ Bennett, 5 .

${ }^{102}$ Andrews and Osborn, On the Trail of Ancient Man, 307.
} 
consummate American man in Osborn's universe. Perhaps this is why, in his old age, Osborn gave to the gun-toting paleontologist the most important duty conceivable in his mind: he picked Andrews to be his successor to the presidency of the AMNH, and to continue his mission of teaching the lessons of evolution to a civilized race in need of regeneration.

This knowledge about the biological nature of man was not merely ideational. It shaped the lived experiences of people of all genders and "races," and set the terms for their inclusion or exclusion from American society. This Osborn and his colleagues would accomplish most directly through the science of eugenics, the application of his study of the past to the problems of the present. He proclaimed that the Second International Congress of Eugenics in 1921 was "the most important scientific meeting ever held in the Museum." ${ }^{103}$ His museum and his life would be devoted to the cause.

Years after his death in 1935, almost all of Osborn's major biological theories would lose credibility in the public and scientific spheres. The paleontological evidence would redeem Dart's discovery and show that Africa was indeed the evolutionary "Garden of Eden," and the biological basis for race would give way to theories that aligned more with the relativism of Boas and the cultural anthropologists. Andrews would resign in 1941, unable to live up to the high expectations placed upon him by his predecessor. Osborn reigned as king over the world of natural history and paleontology in America; yet, his intellectual legacy would not stand the test of time. Posterity would make a monkey out of Osborn and his science.

One of the definitive moments in Tarzan of the Apes was Tarzan's discovery that he was not really an ape, but a man. Osborn's reluctance to accept a simian ancestor for the hominid family perhaps echoes a similar sentiment: as much as man was bound to the animal kingdom, he

\footnotetext{
${ }^{103}$ Henry Fairfield Osborn, "The American Museum and Citizenship," 53 ${ }^{\text {rd }}$ Annual Report, 1922, 2. Quoted in Haraway, 57.
} 
was unique. Was civilization not proof that American men were better than the rest of creation, from monkeys to the "lesser" races? He and other eugenicists appealed to such an idea in arguing that civilization should have a biological basis for including or excluding those who sought to become a part. The American republic, they argued, was in peril from evolutionary degeneracy in the form of immigrants whose minds and bodies were not fit to become a part of the national community. 


\section{Chapter 4}

\section{Mendelian Doughboys: Eugenics, the U.S. Army, and the National (Male) Body, 1900-1924}

"A soldier must have a good nervous system, heart and vessels without serious defect, good feet, strong inguinal muscles and fascia, strong bones and ligaments, and well-functioning joints, keen sense organs, and freedom from organic diseases."

—Charles B. Davenport and Albert M. Love, Army Anthropology (1921)

"The mental tests are not intended to replace other methods of judging a man's value to the service. It would be a mistake to assume that they tell us infallibly what kind of soldier a man will make. They merely help to do this by measuring one important element in a soldier's equipment, namely, intelligence... intelligence is perhaps the most important single factor in military efficiency, apart from physical fitness."

—Robert M. Yerkes and Clarence S. Yoakum, Army Mental Tests (1920)

The eugenics movement in the United States has been studied by many historians from a wide variety of perspectives. It has proven to be a useful case study for understanding gender, race, and disability in the early twentieth century. ${ }^{1}$ Its development from a largely theoretical set of ideas about biological heredity into an influential movement with broad institutional and professional power provides an opportunity to trace precisely how ideas can be translated into power over peoples' bodies. Through its biological construction of "fit" and "unfit" bodies, it was responsible for the sterilization of hundreds of thousands of American men and women, restrictive immigration legislation that ended a longstanding "open door" policy and, through its interaction with its German counterpart, contributed to the intellectual foundation of German racial hygiene policies and the Holocaust. Far from a fringe movement, eugenics enjoyed

\footnotetext{
${ }^{1}$ While I would direct the reader to the bibliography, a couple works on the eugenics movement in the United States are particularly noteworthy, and I am indebted to them for my own conceptualization of eugenics as a discourse of power: Wendy Kline's Building a Better Race: Gender, Sexuality, and Eugenics from the Turn of the Century to the Baby Boom (Berkeley: University of California Press, 2001) offers a detailed, gendered analysis of eugenics. Gerald V. O'Brien's Framing The Moron: The Social Construction of Feeble-mindedness in the American Eugenic Era (Manchester: Manchester University Press, 2013) is an excellent analysis of the vocabulary of eugenics and its cultural meaning.
} 
mainstream support and counted respectable figures like Theodore Roosevelt and Alexander Graham Bell among its members.

In an era when questions of biological fitness-particularly with respect to the white male body — were tied to national identity, eugenics was a discursive tool with which to pronounce some bodies legitimate and others illegitimate. If some members of society were, because of their physical or mental shortcomings, a burden to the public, then why should they be entitled to reproduce more generations of the same? This was the basic premise of eugenics. In the same way that animal breeders were using pedigree analyses to produce certain kinds of dogs and horses, eugenics enthusiasts believed that better humans could be bred through the application of biological knowledge. Some began to speak of the "superman" that a successful eugenics program could bring about: tall, white, virile, but perhaps most importantly, gifted with a well-developed nervous system and mind. ${ }^{2}$

To early twentieth century biology, especially in an evolutionary context, the human mind was a part of the physical body and did not exist on a transcendental plane. Charles Darwin's argument that the mind played an important role in evolution provided the basis for the new discipline of psychology, especially the American functionalist school. ${ }^{3}$ The brain was therefore part of a biological "machine" (i.e., the body) that could be rationally known and studied by science in relation to its environment. Davenport described this biologically determinist viewpoint in his 1919 study of sailors and their hereditary biology: "The performance of any man depends to a large degree upon his inherent, inheritable traits; for behavior is reaction to stimulus, and the nature of the reaction is determined in part by the nature

\footnotetext{
${ }^{2}$ For examples of the concept of the "Superman" and his mental and nervous development being a greater achievement than his physical body, see "Superman a Being of Nervous Force," The New York Times, 11 January 1914, 12, and Victor C. Vaughn, "Eugenics from the Point of View of the Physician," in Morton A. Aldrich et al., Eugenics: Twelve University Lectures (New York: Dodd, Mead and Company, 1914), 70-71.

${ }^{3}$ Ross, 155 .
} 
of the reacting nervous machinery." ${ }^{4}$ This was a rejection of the longstanding Cartesian dualism that separated the mind from the body in Western thought and privileged it. Eugenicists conceived of a man's identity through his observable mental and physical traits, and both were located in the body.

Necessarily, this biological concern with the physical and mental state of men's bodies both reflected and challenged pre-existing notions of male identity in the United States. As Wendy Kline argues, the language of eugenics was strongly shaped by questions of race and gender. ${ }^{5}$ She points out that one of the central themes of the movement was a concern over declining birth rates for white middle class families and a sense that women needed to embrace motherhood as a special duty for the good of the American race. The sexual freedom of the "new woman" was seen as a moral threat rooted in defective mental traits. ${ }^{6}$

I believe that there is also room to investigate how the American eugenics movement helped construct and renegotiate male identities and made male bodies the focus of debates about race and national identity in the early twentieth century United States. Eugenics in the Progressive Era, along with Edgar Rice Burroughs' Tarzania and the American Museum of Natural History's paleontological exhibits and publicized expeditions, constructed a male identity that was rooted in the new evolutionary biology. The three shared a number of narrative themes such as the dangers of miscegenation and the contradictory strength, yet vulnerability of, the white male body. Eugenics, for its own part, would develop its institutional power and expand it to state policy. Its supporters took these biologically determinist ideas about American men and the "other" to Congressional debates about immigration policy and successfully argued

\footnotetext{
${ }^{4}$ Charles B. Davenport and Mary Theresa Scudder, Naval Officers: Their Heredity and Development (Washington: Carnegie Institution of Washington, 1919), 9.

${ }^{5}$ Kline, 2.

${ }^{6}$ Ibid., 18-19.
} 
for sweepingly restrictionist immigration reforms. But how did their cultural authority grow to such a level? I will argue that the project of two American eugenicists, Charles B. Davenport and Robert M. Yerkes, to examine the bodies of draft recruits during the First World War was one of the major turning points in the growth of eugenics as an influential force in American society and public policy.

Eugenicists had a wide range of motives particular to their understanding of biology, race, and heredity, as well as their role as mediators of this knowledge: they sought to expand their professional and social authority; they believed that the white American "race" of AngloSaxon stock was regressing into physical, mental, and moral inferiority (for a variety of reasons); and, as the movement matured during and after the First World War, they became unapologetically xenophobic and worked tirelessly to lobby for the passage of the Immigration Acts of 1921 and $1924 .^{7}$

Before the war, however, eugenicists as a group were cautious about supporting such "eugenic" laws, including those that would allow for the sterilization of the unfit. As late as 1914, Davenport attacked these laws and claimed that eugenics, as a science, was too experimental and undeveloped to inform social policy. ${ }^{8}$ This is a stark difference from the immediacy with which he and other mainstream eugenicists demanded restrictionist immigration laws in the early 1920s. This fundamental change in the mood of eugenic thought has been

\footnotetext{
${ }^{7}$ Their understanding of the reasons for white "Nordic" degeneracy in America, of course, provided a blueprint for solutions. Among these reasons were miscegenation with non-Nordic whites and other races, itself caused by their arrival in larges waves of immigration, declining birthrates among white middle class families - a problem that was placed solely on the shoulders of women - and an excess of sentimentalism in civilization which led to charity and state-run care for the mentally and physically inferior. Respectively, their proposed solutions were to limit interracial breeding (there was some debate as to whether or not this should be legislated or simply discouraged; generally, only white-black or white-Asian marriage bans were enshrined in law in some states), restrict immigration from non-Nordic populations, and encourage higher birth rates among the white middle class. There was, however, no strong movement among eugenicists to eliminate charity or these types of state institutions.

8 "Doctor Ridicules Laws for Eugenics," The New York Times, 21 June 1914, 14. For similar statements by Davenport around this time, see also Charles B. Davenport, "American Work Strongly Defended," The New York Times, 9 November 1913, SM2.
} 
largely unexamined by historians of the early twentieth century. It has been established that a number of factors contributed to a rise in xenophobia and nationalism during and after the First World War in the United States, which may in part explain the shift, but the particular arguments articulated by eugenicists are worth analyzing in their own right. ${ }^{9}$

With America's entry into the war, millions of draft recruits had to be clearedquickly — as physically and mentally fit for service. Such an opportunity was promising to eugenicists, who were interested in developing or improving scientific methods of measuring peoples' bodily traits. ${ }^{10}$ In the prewar era, these methods had been developed through work with students, "defective" families, and patients held at mental asylums. Yerkes, a Harvard psychology professor, administered a program of intelligence tests for draft recruits that was later extended to most of the army. Davenport, the leading figure of the American eugenics movement and head of its most important institutions, collaborated with the army to examine the physical bodies of drafted men and catalogue that information for rigorous statistical analysis.

The volumes written about the physical and mental qualities of these millions of American men, interpreted through the lens of gender and race, was used by eugenicists, nativists, and their allies to advocate for restrictionist federal immigration laws. With such a vast amount of statistical information on a cross-section of American men (over three million), eugenicists could now use their professional authority to make "objective" statements about those bodies and the threat that "defective" types posed. In this way, the bodies of American men

\footnotetext{
${ }^{9}$ Chief among these reasons are anti-German sentiment during the war, endorsed by the federal government and leading to a more general atmosphere of Eastern and Southern European xenophobia, as well as the corresponding growth in nationalism and retreat from Wilsonian internationalism. Pacifist and labour activism during the war was also seen in a racialized and seditious light. Gary Gerstle, American Crucible: Race and Nation in the Twentieth Century (Princeton: Princeton University Press, 2001), 91.

${ }^{10}$ Stephen Jay Gould, The Mismeasure of Man (New York: W. W. Norton \& Company, 1996), 223-224.
} 
became the focus of debates about national identity—who was to be included or excluded from membership in the American nation, and on what grounds.

Gary Gerstle identifies a longstanding contest in American history between "civic nationalism" and "racial nationalism." While civic nationalism pointed to a set of Enlightenment political ideals and institutions to which any man could embrace and become American, racial nationalism argued that American democracy and civilization were inherently limited to white Anglo-Saxon men. ${ }^{11} \mathrm{He}$ argues that the federal immigration legislation of the early twentieth century, as well as the strongly xenophobic vocabulary of eugenics that contributed to its ideational basis, marked an important turning point in embracing the latter as the basis for citizenship in the United States. ${ }^{12}$

Among the arguments made by eugenicists were that immigrants from Southern and Eastern Europe, who had been arriving at Ellis Island in increasing numbers since the 1880s, were largely "feebleminded," shorter, and in general showed a higher frequency of physical and mental defects. Because they often trivialized or dismissed entirely the influence of environment, Davenport, Yerkes, and others warned that these traits were hereditary. These immigrants would pass on their defective traits to future generations and, through miscegenation, dilute the strong hereditary traits of the Nordic race in America. For all their work, the eugenicists were satisfied with the Johnson-Reed Act of 1924, which strongly limited immigration by setting restrictive quotas. ${ }^{13}$ This policy remained in place until 1965, and as a result, helped shape the ethnic character of the American nation for generations.

\footnotetext{
${ }^{11}$ Gerstle, 3-5.

${ }^{12}$ Ibid., 105-108, 126.

${ }^{13}$ Ian Robert Dowbiggin, Keeping America Sane: Psychiatry and Eugenics in the United States and Canada, 18801940 (Ithaca: Cornell University Press, 1997), 227.
} 
But these were not their only lasting contributions. Yerkes's work in army intelligence testing during the war became the basis of the Intelligence Quotient (IQ) test, as well as the Scholastic Aptitude Test (SAT). ${ }^{14}$ Similarly, Davenport's data and experimental analysis helped redefine the field of biometrics and established a longstanding statistical concern with the bodily dimensions of the average American — a concern which, as it exists today, has familiar undertones of emasculation, the decadence of modern life, and a need to embrace strenuous physical activity. All of this was rooted in the efforts of eugenicists to define desirable and undesirable traits in men's bodies, and to separate superior men from the inferior. Their biologically determinist worldview, far from being objective, only magnified and reinforced the biases of a white, male, professional middle class and the philanthropic elite who held the purse strings for their projects. The popular perception that American bodies and minds were deteriorating now had a "scientific" basis to it.

Unlike Edgar Rice Burroughs's exciting return-to-nature stories and the American Museum of Natural History's anti-modern portrayals of prehistoric man, eugenics and its representations of the male body was explicitly concerned with social control. In terms of evolutionary thought, it stressed the need for "artificial selection" to save the vulnerable white male body, whereas the narratives of "natural selection" promised that white masculinity would prevail in the struggle for existence. Yet Burroughs and Henry Fairfield Osborn, both strong supporters of eugenics, believed that the struggle itself had been compromised in civilization. Through state and private institutions meant to better to conditions of the less fit, the biologically defective were allowed to prosper and reproduce at the cost of the superior American race. To eugenicists, nature alone could not save the virility of the white male body. Their salvation lay in science.

${ }^{14}$ Gould, 229. 
Francis Galton, an English intellectual and the cousin of Charles Darwin, laid down the basic foundation for "eugenics," including the term itself, in 1869. His Hereditary Genius, published that year, argued that traits such as exceptional intelligence were inherited. This could be easily demonstrated, he believed, by examining the family lines of accomplished people such as great musicians. In an attempt to understand exactly how these traits were carried over from parents to children, he and his students developed what became known as the biometric school. Their methodology relied on heavy statistical analysis of a person's observable traits (both mental and physical) across generations. ${ }^{15}$

Davenport, an American professor of zoology at Harvard, quickly affiliated with the new field of biometry in the final years of the nineteenth century. This, in combination with his earlier training in engineering, would provide a strong mathematical and statistical influence to his work for the rest of his career. ${ }^{16}$ Around the turn of the century, however, a major challenge arose to Galton's biometrical school of thought. The plant-breeding experiments of Gregor Mendel, initially conducted in the 1860 s, were "rediscovered" by 1900 and became influential among American biologists-Davenport included. Its emphasis on the study of traits as either dominant or recessive could better explain, model, and predict the appearance (or disappearance) of mental and physical features over a long span of generations. ${ }^{17}$

Mendelism provided an accurate explanation for the inheritance of basic traits in organisms - both plants and animals - which could be demonstrated in breeding experiments. In the first decade of the twentieth century, it redefined American biology. Building on its influence in academic circles, animal breeders began to use pedigree analyses based on these early genetic

\footnotetext{
${ }_{15}^{15}$ Milner, 46, 184.

${ }^{16}$ Garland E. Allen, "The Eugenics Record Office at Cold Spring Harbor, 1910-1940: An Essay in Institutional History," Osiris 2, vol. 2 (1986): 228.

${ }^{17}$ Elof Axel Carlson, Times of Triumph, Times of Doubt: Science and the Battle for Public Trust (Cold Spring Harbor, New York: Cold Spring Harbor Laboratory Press, 2006), 40.
} 
theories. Many of these breeders became affiliated with the eugenics movement at an early stage: the American Breeders' Association formed a Eugenics Section in 1906. Indeed, the assembling of "pedigree charts" became one of the staples of eugenic field work, especially with the series of family studies that proved to be very popular and well-read. Gerald O'Brien argues that the shared intellectual bases of eugenics and animal breeding meant that they both "carried with it an undercurrent of animalization" and, therefore, dehumanization. ${ }^{18}$

While this was the premise behind the evolutionary narrative as it applied to men-that they were members of the animal kingdom — people with undesirable bodies, it was argued, were lower on the evolutionary scale. Davenport's very influential Heredity in Relation to Eugenics made the point clear in 1911: "In a word the traits of the feeble-minded and the criminalistic are normal traits for infants and for an earlier stage in man's evolution." ${ }^{19}$ Similarly, this is the way that "defective" rural families were portrayed in the family studies, which included the analysis of the Juke family in 1877 and the Kallikaks in 1912. In contrast to the authors and their audiences, these families were "feeble-minded" and amoral, closer to the natural world than that of civilization. ${ }^{20}$

The changing narrative of the family studies reflected a harder turn towards biological determinism. While Richard Dugdale's The Jukes: A Study of Crime, Pauperism, Disease and Heredity (1877) held open the possibility for both innate deficiency and environmental influences in degenerate people, the later studies favored, to the virtual exclusion of other explanations, a hereditarian determinist approach. These kinds of studies were conducted by

\footnotetext{
${ }^{18}$ O’Brien, 61.

${ }^{19}$ Charles B. Davenport, Heredity in Relation to Eugenics (New York: Henry Holt and Company, 1911 ), 262.

${ }^{20}$ Nicole Hahn Rafter, White Trash: The Eugenic Family Studies, 1877-1919 (Boston: Northeastern University Press, 1988), 28.
} 
trained experts (most of the authors were affiliated with Davenport's Eugenics Record Office) and, at least ostensibly, drew their conclusions from objective scientific analysis. ${ }^{21}$

The growing fear of biological degeneracy, especially in the form of the feeble-minded, began to appear in the form of eugenic legislation. In 1912, the Protestant Episcopal Bishops of Chicago declared that candidates for marriage must obtain a physician's "clean bill of health." It was hailed at the time by the New York Times as the "climax" of the eugenics movement. ${ }^{22}$ The fact that the authority of eugenic experts was now being welcomed in the traditional power sphere of religious institutions was especially telling. To Davenport and others, however, these laws were simply premature. To them, eugenics was an experimental science and it had yet to answer the questions of human heredity in a definite way. Perhaps the fact that any physician or biologist could pass as an expert on eugenics added insult to injury. For these reasons, biologists who identified with the eugenics movement sought to consolidate their professional and institutional power in the prewar years.

A major milestone in this effort was the founding of the Eugenics Record Office (ERO) in 1910. It was an extension of the Station for the Experimental Study of Evolution, which was administered by Davenport. ${ }^{23} \mathrm{He}$ had received funds from the Carnegie Institution of Washington to build the complex in 1903 and, along with the wealthy Gilded Age widow E. H. Harriman, it would be the primary source of funding for the work of Davenport and the ERO. In 1902, Osborn, by then an accomplished paleontologist and soon to be the President of the American Museum of Natural History, expressed his personal support to Davenport for his plans

\footnotetext{
${ }^{21}$ Ibid., 8, 15.

22 "Bishops Approve Plan to Apply Eugenics to Marriage," The New York Times, 31 March 1912, SM8.

${ }^{23}$ Allen, "The Eugenics Record Office at Cold Spring Harbor," 226.
} 
to found a eugenics institution in the United States. ${ }^{24}$ The ERO was the first of its kind in the country and would act as the anchor of the American eugenics movement. It offered training in eugenic field work, published eugenic literature, and would come to store a prodigal amount of data on families and individuals over the twenty-nine years of its existence. Its influence spread internationally as well. ${ }^{25}$

To assist the ERO's researchers in their field work, Davenport assembled and published The Trait Book in 1912. It became the standard reference guide for their efforts to catalogue the physical and mental traits of individuals. ${ }^{26}$ The book's list of traits was organized according to a numerical code: a specific physical trait would be recorded as a number that ranged from two to seven digits. For example, muscular atrophy was given the code 252, while brown eyes were assigned $56323 .^{27}$ These codes would be listed on a record card for each individual studied. As Davenport explained, the intention was to create a vast list of traits that could be recorded, even if they were not obviously hereditary. A full page was dedicated to the shape of the outer ear alone, while the list of occupations was six pages long. This ambitious plan to record information about American bodies using Davenport's system — what Garland Allen compares to the Dewey decimal one - was meant to foster a collection of data that could be analyzed by eugenic experts. ${ }^{28}$ The cards for individuals could then be cross-referenced with their family members and relatives. In this way, they sought to better understand the hereditary nature of these traits across generations of breeding using the signs and symbols of mathematical, scientific methodology.

\footnotetext{
${ }^{24}$ Edwin Black, War against the Weak: Eugenics and America's Campaign to Create a Master Race (New York: Four Walls Eight Windows, 2003), 37.

${ }^{25}$ Allen, "The Eugenics Record Office at Cold Spring Harbor," 226, 251.

${ }^{26}$ Ibid., 239.

${ }^{27}$ Charles B. Davenport, The Trait Book (Cold Spring Harbor, NY: Eugenics Record Office, 1912), $17,31$.

${ }^{28}$ Allen, "The Eugenics Record Office at Cold Spring Harbor," 239.
} 
The Trait Book's fourth section on mental traits, ranging from "special abilities" in sports to "logicalness" and sexual morality, was contributed by Edward L. Thorndike and Yerkes. ${ }^{29}$ While the extensive and curious variety of traits in this part was not out of place with the rest of the book, which tried to cast its net widely (was "matter-of-factness" hereditary?), it did reflect the experimental and speculative nature of psychology, especially around the turn of the century. Early psychology would play a central role in defining American eugenics, especially its concern over defective minds.

Yerkes was a leading figure in the young field of intelligence testing and held a professorship at Harvard. To him, the development of accurate and useful mental tests would also mean the development of psychology as a discipline and profession. ${ }^{30}$ It is also telling that the height of interest in this kind of experimental testing coincided with the apex of the fear of "feeble-mindedness," or mental disability, in the United States — around the time of the First World War. ${ }^{31}$ Long after the scare had subsided, the fruits of the labors of Yerkes, Thorndike, and their colleagues would prove to have a lasting influence on standardized tests in the forms of general IQ and college entrance examinations.

These early tests were conducted chiefly on schoolchildren and persons held in mental asylums. Such places, later including the U.S. Army, were all disciplinary institutions which sought to understand and discipline the minds of those subject to its control. Psychologists easily found their expertise to be of utilitarian benefit to these state institutions and, in return, these institutions made their records available for eugenic analysis at the ERO. ${ }^{32}$ While the case for mental testing could be made to each of these institutions for particular contextual situations

\footnotetext{
${ }^{29}$ Davenport, The Trait Book, 2, 21-30.

${ }^{30}$ Gould, 222-223.

${ }^{31}$ O'Brien, 9. Interestingly, concern over feeble-mindedness and other mental defects in the army arose only after the results of the mental tests were published - and not before or during the war itself.

32 Black, 52.
} 
(assessing the progress of students, for example), Yerkes believed his work had more important eugenic applications. He believed that the results from these tests could be used to learn more about the heredity of mental traits, an important step in the quest to limit the frequency of feeblemindedness and other "defects" of the mind in future generations.

The relationship between Yerkes and Davenport is interesting, and speaks to their different backgrounds as well as the unorganized nature of the eugenics movement in the prewar era. Yerkes studied under Davenport at Harvard while doing his graduate work there (18971902). From that point, their paths split: Davenport became head of the new Station for Experimental Evolution and its associated ERO at Cold Harbor, developing his authority in the field of eugenics by founding and administering the work of its largest institution. His power within the movement and his visibility in the public eye were enviable. By contrast, Yerkes would become an accomplished and well-respected academic, but his influence did not extend far beyond those circles.

He did contribute to The Trait Book for the ERO, but wrote fairly critical reviews of the work of Davenport and the institution—including work that was based on The Trait Book itself. His review of Davenport's The Hill Folk, written in 1913 in collaboration with an ERO researcher named Florence Danielson, pointed out the fallacy of using indirect sources of information to construct Mendelian records for individuals:

The method of the investigation was not such as to furnish highly accurate as well as extensive information concerning the individuals in the pedigree... Miss Danielson gathered this information by personal visits, interviews with the individuals, their relatives, physicians, town officials, neighbors, and from court and town records. She undoubtedly made excellent use of these various sources of information, but it is, of course, to be recognized that the direct measurement by reliable methods of the physical and mental traits of the persons described is much to be desired. ${ }^{33}$

\footnotetext{
${ }^{33}$ Robert M. Yerkes, review of The Hill Folk by Florence H. Danielson and Charles B. Davenport, American Journal of Sociology 19, no. 2 (Sept. 1913): 261.
} 
More damningly, he did not hide his dislike for Davenport's much-celebrated Heredity in Relation to Eugenics in 1912, calling it "ineffective" and "not very interesting." 34 Any conclusions that could be drawn from the eugenic records at the ERO—barely two years old at the time- -were, to him, "meager and inconclusive.",35

Some of this hostility may have simply risen out of frustration with the often crude research methods of the ERO. Eugenics was a science that Yerkes took seriously, and he was not keen to see field workers collect data on people using rudimentary methods—such as interviewing a dead person's relatives to record their traits from memory—while his own work to measure mental traits received much less attention. Davenport, though, did not take the bait to counter-attack. This is somewhat surprising, as Elof Axel Carlson argues that he did not take criticism well and had an "insecure" personality. ${ }^{36}$

Davenport also received harsh criticism from another group of eugenicists: his English counterparts, among whom Karl Pearson was the most prominent and the de facto leader. They attacked him and the research of the ERO on similar points to Yerkes, adding that the conclusions drawn from the data collected was thus flawed. ${ }^{37}$ It was against these overseas rivals that Davenport would energetically defend himself and his colleagues, attacking them spitefully in return. "The main source of irritation that has led to this reaction of the Galton Laboratory," he wrote, "is, of course, that they are committed to a law of heredity which, so far as I am aware, has been discarded by every biologist who is working experimentally in the field of heredity." 38

\footnotetext{
${ }^{34}$ The reviews of this book by others, however, were generally quite positive. Robert M. Yerkes, review of Heredity in Relation to Eugenics by Charles B. Davenport, American Journal of Sociology 18, no. 1 (July 1912): 117.

${ }^{35}$ Ibid., 116-117.

${ }^{36}$ I suspect that Carlson may be overstating this in his psychological profile of Davenport, as some of his sources date from the postwar period when eugenics in general was seen in an especially negative light after the fall of Nazi Germany. Nevertheless, when Davenport was willing to fight he did not mince words. Carlson, 41.

${ }^{37}$ Davenport, "American Work Strongly Defended."

38 Ibid.
} 
The English eugenicists, at least under Pearson, were still largely devoted to Galton's biometric methods and were slow to embrace Mendelism. ${ }^{39}$ As part of this feud in the prewar years, Davenport would strongly criticize biometrical methods and (according to him) their overreliance on mathematical "figuring" rather than the more practical approach that his ERO field workers used. ${ }^{40}$ On the other hand, Davenport would later borrow heavily from statistical methods as part of his projects with the U.S. Army, and praised later developments in biometrics after the war. ${ }^{41}$

By then, he still believed that the Mendelian analysis of physical and mental traits could show that they were hereditary and predict their outcome in human breeding. Statistics, on the other hand, might be used to measure those traits (such as bodily dimensions or an intelligence score). With enough information, the hereditary traits of large populations could be analyzed and cross-referenced: according to race, for example. This is precisely what Davenport and Yerkes had in mind when, in April of 1917, the United States entered the First World War and drafted millions of men whose physical and mental fitness for combat had to be evaluated and recorded. To experiment with ways of measuring mental and physical traits in American men, the U.S. Army would become their laboratory.

Eugenicsts like Yerkes, Davenport, Thorndike, Lewis M. Terman, Clarence S. Yoakum, and Henry H. Goddard were interested in mental testing - increasingly to be called "intelligence testing" as it developed - as a method of determining which people possessed good mental traits, such as high intelligence, and negative ones, like feeble-mindedness. ${ }^{42}$ As a discipline, eugenics

\footnotetext{
${ }^{39}$ Milner, 45-47.

${ }^{40}$ Davenport summarized his criticisms of Pearson and the English eugenicists in Charles Davenport, review of Social Problems: Their Treatment, Past, Present and Future. Questions of the Day and of the Fray by Karl Pearson, American Journal of Sociology 18, no. 6 (May 1913): 833-835.

${ }^{41}$ David Heron, "English Expert Again Attacks Davenport," The New York Times, 4 January 1914, SM14.

${ }^{42}$ Garland E. Allen, "The Misuse of Biological Hierarchies: The American Eugenics Movement, 1900-1940," History and Philosophy of the Life Sciences 5, no. 2 (1983): 114.
} 
was the study of not only the heredity of mental and physical traits, but also the tools with which society could reverse the status quo of the least "fit" breeding more than the "fittest." 43 The tests were therefore conceived as an important part of the project to separate the good from the bad.

Goddard developed an English-only test that he administered to a sample of immigrants passing through Ellis Island. In 1917, he used the results to argue that an overwhelming number of newcomers from Southern and Eastern Europe - upwards of eighty per cent, depending on nationality—suffered from feeble-mindedness. ${ }^{44}$ Yerkes, aware of the obvious flaws in administering a test in a language that a subject could not understand, would attempt to solve the problem with the army tests by developing a secondary one (Army Beta) for illiterate or nonEnglish speakers alongside his primary one (Army Alpha).

Before his work with the army, Yerkes sought to create a system of mental tests that was intended to be universally applicable — and not just for schoolchildren like French psychologist Alfred Binet's tests. To this end, in 1915 he proposed a "point scale for measuring mental ability" that would measure seven different mental "functions" including memory, perception, and judgment. The scores for each function would then be assembled to form a single numerical score, hence a "point scale." ${ }^{45}$ Earlier models such as the Binet test scored people based on a "mental age" (the effective age to which one had developed mentally, compared to the averageso an intelligent twelve-year old student might be scored as having a mental age of thirteen).

This ambitious goal was not without criticism from other psychologists. As one reviewer of Yerkes' A Point Scale for Measuring Mental Ability expressed, "Mental ability is so complex

\footnotetext{
${ }^{43}$ The use of the term "society" here is admittedly vague, as some eugenicists - especially Osborn-conceived of the eugenics project in explicitly nationalist terms while others did not. The former represented the main trend in American eugenic thought.

${ }^{44}$ Michael Kimmel, Manhood in America: A Cultural History, Third Edition (Oxford: Oxford University Press, 2012), 141.

${ }^{45}$ Robert M. Yerkes, “A Point Scale for Measuring Mental Ability,” Proceedings of the National Academy of Sciences of the United States of America 1, no. 2 (Feb. 15, 1915): 114-115.
} 
that none of us can be sure he has made a proper qualitative analysis of it, and certainly any attempt to weight definitely the various elements of mental ability can as yet be little more than a random guess."46 Yerkes was open to some criticism and often responded by stressing the experimental nature of his work - it needed improvements, he conceded, and would become more precise over time. On the other hand, he and his colleagues were adamant that only "adequately trained professional psychologists" could be involved in the development and interpretation of mental testing. ${ }^{47}$ The experts had not yet come up with something useful, but they were very careful to protect it from outside tampering - and to keep their monopoly over the scientific and objective evaluation of human minds.

The initial proposal for intelligence testing in the U.S. Army came from as distinguished and "expert" a group on the subject as could be put together. It was delivered by Yerkes, in his official capacity as chair of the Subcommittee on Recruit Testing, under the National Research Council's Psychology Committee in late April of 1917 - the same month that the United States had entered the war. For its own part, the army found itself with the considerable administrative task of sorting through about three and a half million men selected by the draft. ${ }^{48}$ Among the psychologists that would take part in the committee's work and have a hand in the development of the tests were Yerkes, Walter Bingham, Goddard, and Terman. Yerkes' plan was dissected and significantly modified by the other members of the committee while they considered the matter at Goddard's research base at a school for children with mental disabilities. ${ }^{49}$

\footnotetext{
${ }^{46}$ M. R. Trabue, review of A Point Scale for Measuring Mental Ability by Robert M. Yerkes, James W. Bridges, and Rose S. Hardwick, The Journal of Philosophy, Psychology and Scientific Methods 14, no. 12 (June 7, 1917): 332.

${ }^{47}$ Trabue, 332-333; Robert M. Yerkes, James W. Bridges, and Rose S. Hardwick, A Point Scale for Measuring Mental Ability (Baltimore: Warwick \& York, 1915), 87; the quotation is from Robert M. Yerkes, "Mental Examination of Police and Court Cases," Journal of the American Institute of Criminal Law and Criminology 7, no. 3 (Sept. 1916): 369.

${ }^{48}$ Black, 80.

${ }^{49}$ Ibid.; John Carson, “Army Alpha, Army Brass, and the Search for Army Intelligence,” Isis 84, no. 2 (June 1993): 284-285.
} 
William Gorgas, the Surgeon General of the Army, accepted the initial proposals to subject a number of draft recruits to an experimental series of tests, designated Army A-the precursor to Alpha and Beta. Yerkes was also given a commission as a Major in the Sanitary Corps and tasked with organizing its new Psychology Division (Appendix D). Sixteen psychological experts were added to his staff with the rank of First Lieutenant, and two dozen were hired in a civilian capacity. A special training school for army psychologists was also formed to produce hundreds more by the end of the war. ${ }^{50}$ Psychologists, often with no military background or training, were donning the uniforms of officers and entering the army's chain of command with all the authority that it entailed — by virtue of providing expert assistance to further the war effort.

Gorgas laid out the primary goal of the mental testing in a January 1918 communiqué: to discover which men possessed inferior or superior intelligence from the norm. Respectively, they could be discharged or sent to officers' training; and, on a larger scale, the army's units could be balanced more evenly in terms of "mental strength." ${ }^{, 1}$ Army $A$ was first deployed from October to December of 1917, and about 100,000 men were tested during that time. The total number had increased to 140,000 by April of the following year. ${ }^{52}$ The army brass was generally happy with the results, despite opposition from a number of officers. Gorgas authorized full-scale testing in January of 1918 for all newly drafted men and most enlisted soldiers and officers. From then to July $1^{\text {st }}$, the total had risen to 600,000 men tested, and Yerkes reported that up to that point, “ $0.25 \%$ had been recommended by psychological examiners to psychiatrists for discharge

\footnotetext{
${ }^{50}$ Robert M. Yerkes, "Measuring the Mental Strength of an Army," Proceedings of the National Academy of Sciences of the United States of America 4, no. 10 (Oct. 15, 1918): 295-296.

${ }^{51}$ Quoted in Carson, 293.

52 Ibid., 297.
} 
because of mental deficiency, and about $0.5 \%$ had been recommended for assignment to service organizations for development battalions because of mental inferiority.",53

By the time that the draft and the corresponding testing had both ended in January of 1919, over 1.7 million men had been examined by Yerkes' psychological staff using Army A, Army Alpha, Army Beta and special tests given to those whose cases were judged to require more careful evaluation (Appendix E). ${ }^{54}$ The intelligence testing school of psychology was happy with the extent to which the mental tests had been developed and tested on such a large number of subjects. On the other hand, lower and mid-level officers attempted to push back against the growing power of the tests and Yerkes' Psychological Division. Their concern was that the tests, which were by the admission of their authors largely experimental, were encroaching on the longstanding military traditions of character judgment as the basis of advancement and placement. In defining the qualities of an officer, the military had privileged the virtues of manliness in the Victorian sense of a man's courage, sensibility, and judgment. This concern with the moral man, rather than "intelligence" as defined by psychology and the scientific analysis of the mind, marked a moment of contested male identities that reflected turn-of-thecentury gender anxiety more generally. ${ }^{55}$

A number of investigations were ordered to examine the complaints of the officers, and while they found that most officers found the tests to produce similar findings as their own judgments of soldierly competence in men, they resulted in the issuing of General Orders no. 74. Its effect was to give commanding officers the choice of whether or not to apply the results of mental tests to soldier placement, promotion or discharge. It remained the primary tool in sorting

\footnotetext{
${ }^{53}$ Ibid.

${ }^{54}$ Yerkes ed., Psychological Examining in the United States Army, 99.

${ }^{55}$ Carson, 305; Bederman, 19.
} 
draft recruits in camps where it was used, however. ${ }^{56}$ Concerns about the suitability of psychological tests for the military had existed since the plan was first put forward in 1917. The U.S. Navy rejected Yerkes outright on the grounds that drafted men might fake feeblemindedness and purposefully score low on the tests in the hopes of being discharged from service — a problem common enough to have its own term, "malingering."

The developers of the tests were aware of these criticisms, and decided to frame their project in a way that would appear useful to army brass. To this end, they took their knowledge of intelligence testing — previously a tool used with students and the feeble-minded — and gave it a uniquely military flavor. ${ }^{58}$ When men were tested, the instructions would be read out by one of the psychological officers in full uniform. The orally-issued directions for one version of Army Alpha were as follows: “Attention! 'Attention' always means 'pencils up.' Look at the circles at No. 1 . When I say 'Go!' but not before, make a cross in the second circle and also a figure 1 in the third circle. Go!" 59

With officers shouting instructions at the subordinate examinees, the performance of the test was clearly designed according to a military fashion. Yerkes, Thorndike, and others associated with the project stressed that it was designed specifically to measure mental ability in soldiers, or "military intelligence," and not necessarily intelligence in a more general context. Yerkes and Yoakum reported that

Modifications made in the tests, such as scoring and weighting, were all intended to make it a better measure of ability in the Army. This specialization of the group examinations for the Army makes them less valuable in other fields. ${ }^{60}$

\footnotetext{
${ }^{56}$ Carson, 297-299.

${ }^{57}$ Ibid., 286.

${ }^{58}$ Ibid., 279.

59 "Secret Mind Tests of the Army," The New York Times, 16 February 1919, 69.

${ }^{60}$ Clarence S. Yoakum and Robert M. Yerkes eds., Army Mental Tests (New York: Henry Holt and Company, 1920), 8. For a similar statement from Thorndike, see Gould, 289.
} 
This would not stop them and other eugenicists from later interpreting the results as a cross-section of the general intelligence of all American men, however. For the moment, it was important to convince the army's commanders that the tests were conceived and used strictly according to military necessity. Their efforts to do so were mixed, as evidenced by General Orders no. 74. On the other hand, they were able to convince the military that "intelligence" was an important factor in assessing a man's fitness for military service. Before the First World War, this term and its meaning were not part of the vocabulary with which officers would describe their men. The experience of the mental tests changed that, and it would continue to be a part of the standard assessment for the army. ${ }^{61}$

For all of the decorum of "military intelligence" and its implicit assessment of fitness for soldierly duty, however, Yerkes and his colleagues reported that conscientious objectors had earned higher scores than the average man. ${ }^{62}$ Such an irony points to a conceptual flaw in the tests that was pointed out by cultural anthropologists like Franz Boas. ${ }^{63}$ Among the groups that scored higher than the norm were those with better education and, for people who had immigrated to the United States, those who had spent more time in the country as opposed to new arrivals. These results were interpreted in a biologically determinist lens which negated the influence of environment upon a man. Yerkes argued that the mental tests measured "native ability," or innate intelligence, and were not "a measure of schooling or opportunity to attend school." ${ }^{, 64}$ In a similar way, the higher scores of northern black men in contrast to southern black

\footnotetext{
${ }^{61}$ Carson, 280-281.

${ }^{62}$ Nancy Ordover, American Eugenics: Race, Queer Anatomy, and the Science of Nationalism (Minneapolis: University of Minnesota Press, 2003), 26.

${ }^{63}$ Gould, 230.

${ }^{64}$ Yerkes and Yoakum, Army Mental Tests, 7-8.
} 
men was said to be because the more innately intelligent group had moved north — and not because of better educational opportunities that existed beyond the reach of Jim Crow laws. ${ }^{65}$

White men who had immigrated from Eastern and Southern Europe also tended to score low on the tests, although still higher than black examinees. Carl C. Brigham, a student of Yerkes and the most prolific interpreter of the army mental test results for a public audience, used the data to compare the three "races" of Europe according to William Z. Ripley and Madison Grant's theory of Nordic supremacy. ${ }^{66}$ This involved a large degree of statistical manipulation and speculation since "race" in this sense was not recorded for the men taking the test, other than "black" or "white." 67 The data was available for country of origin, however, and by estimating the racial compositions of each country, Brigham went on to argue - by transferring the A, B, C, D, and E scores of the army tests into Binet's mental age format— that men of the Nordic race were on average 1.61 mental years ahead of the Alpines, and 1.85 years ahead of Mediterraneans. $^{68}$

Aside from confirming the belief among American men of Anglo-Saxon ancestry that they were mentally superior to recent waves of immigrants and black Americans, the data collected from the mental tests revealed that the average mental age for white American men was thirteen. This "fact" would be used in the early 1920s to argue for stricter immigration laws by alarmists who pointed to Southern and Eastern Europeans arriving with inherently weaker minds and their intermingling with the pure Nordic stock. ${ }^{69}$ The testing data as reported by Yerkes and his colleagues was much more nuanced than this, however, and it is worth going into more detail

\footnotetext{
${ }^{65}$ Gould, 249. Gould also points out that in 1945, Ashley Montagu re-examined the test results and discovered that northern black men in some states, on average, scored better than the average for white men in southern states.

${ }^{66}$ In Ripley and Grant's view, Europe was divided between the Nordic, Mediterranean, and Alpine races.

${ }^{67}$ Carl C. Brigham, A Study of American Intelligence (Princeton: Princeton University Press, 1923 ), 157.

${ }^{68}$ Ibid., 168

${ }^{69}$ Ordover, 25-26.
} 
to see exactly how "objective" scientific data can be reframed and reconceptualized for political purposes.

In his principle report on the mental tests, Psychological Examining in the United States Army, Yerkes pointed out that the "mental age" scale used the age of sixteen as a standard for adult men; but, in his words,

The figure is based, however, upon examination of only 62 persons; 32 of them highschool pupils from 16 to 20 years of age, and 30 of them "business men of moderate success and of very limited educational advantages." This group is too small to give very reliable results. ${ }^{70}$

In this respect, it is incredible that such a scale would be used to interpret the average intelligence of American men. How could a sample of 62 people provide a benchmark for measuring the mental capacities of 100,000 drafted men (the army sample used in this case), let alone the entire male American population? Logically, if the draft represented a cross-section of all American men, then they would provide a better basis for a benchmark of mental age. That is to say, the average American man had a mental age equivalent to that of the average American man.

In the words of Yerkes, the results of Army Alpha and Army Beta for the sample of 100,000 men in question were "transmuted" to the mental age scale. ${ }^{71}$ The term, borrowed from medieval alchemy, is ironically appropriate. As the army tests and the Binet scale were different measurements which were used to measure different mental aptitudes for different contexts (the former for "military intelligence" and the latter for progress in school), it is clear that Yerkes was willing to take some shortcuts in his work and manipulate his statistics. His colleagues did not question his interpretation of the results. In fact, they all largely shared the same point of view.

\footnotetext{
${ }^{70}$ Yerkes ed., Psychological Examining in the United States Army, 785.

71 Ibid.
} 
To them, the test results proved beyond a reasonable doubt that intelligence, determined by biological heredity, was "stronger" in American men of Nordic extract and tended to be more "feeble" in other racial groups. Yerkes gave little if any credence to the influence of one's environment on mental development in reporting the army data. ${ }^{72}$ This was a significant change in his understanding of heredity from the prewar era, as evidenced by his critical review of Davenport's Heredity in Relation to Eugenics in 1913:

Perhaps he underestimates their role; possibly he overestimates the applicability of the laws of heredity upon which he bases his eugenic recommendations. At any rate, it is inevitable that a reader who turns from such a book at Thomson's Heredity to Davenport's Heredity in Its Relation to Eugenics will deem the latter one-sided, possibly even unfair to the facts now well established. ${ }^{73}$

The transmutation of Dr. Robert M. Yerkes, and indeed the whole eugenic school of psychological thought, was complete. Hereditary determinism would become their answer to the social problems of the day, and it would give their army data (and discipline) a new cultural and political authority.

Davenport would come to praise the work being done in psychological testing during the war, calling it "excellent." " Although it is clear that his work at the ERO had influenced some of the army's efforts to collect and organize information about their men, he was relatively late to approach them in the same way that Yerkes did. Davenport first began his work in a civilian capacity for the army in April of 1918 — a whole year after American entry into the war-and was given a commission as a Major in July of the same year. ${ }^{75}$ Since he had begun collaborating with the army so late, his opportunity to conduct and organize original, ground-level

\footnotetext{
${ }^{72}$ Gould, 228.

${ }^{73}$ Yerkes, review of Heredity in Relation to Eugenics, 119.

${ }^{74}$ To quote him, "The modern psychological and psychiatric examinations of officers and recruits are excellent." Davenport and Scudder, Naval Officers, 1.

${ }^{75}$ Charles B. Davenport and Albert G. Love, Army Anthropology: Observations Made on Draft Recruits, 19171918, and on Veterans at Demobilization, 1919 (Washington: Government Printing Office, 1921), 50.
} 
examinations was limited. In a style that defined the majority of his research work at the ERO, however, he was happy enough to simply interpret data that was already collected (or slated to be collected by someone else).

Such a method allowed him to add his name to many eugenic studies and therefore amass, at least at face value, a vast list of eugenic publications. His duty with the army, as he reported in the massive, 635-page Army Anthropology, was to collect and analyze records from their Medical Department. ${ }^{76}$ While Yerkes and his committee of psychologists worked diligently to develop and implement a system of intelligence testing, Davenport simply pulled his data from the Army's draft boards. Along the way, however, the specific information that the board would record and store had changed. He therefore had at his disposal the measurements for height, weight, and chest circumference of the first 1,000,000 drafted men; for the next $2,000,000$ men, he also had the list of each man's "physical defects" as noted by the physicians on the draft boards. Finally, in the summer and fall of 1919, Davenport was able to convince army brass to let him conduct a special series of twenty bodily measurements for 100,000 soldiers at demobilization camps. ${ }^{77}$

Like Yerkes, Davenport was convinced that the research drawn from the vast number of drafted men in the U.S. Army was groundbreaking. "Any survey of the physical, mental and temperamental health of a large section of the population taken without selection had until recently not been made," he argued. Such a project, in his words,

would have a biological and eugenical significance in so far as it would reveal the inherent failures in man to make a complete adaptation to the rapidly advancing requirements of a highly artificial civilization, the constitutional limitations of the various

\footnotetext{
${ }^{76}$ Ibid.

${ }^{77}$ Ibid., 3, 34, 53.
} 
races to meet the conditions imposed by that civilization, and the influence of military selection on the breeding stock of the next generation. ${ }^{78}$

From the outset, then, the army research was explicitly tied to the question of races and their suitability for modern society. His choice of words implies that none was completely "adapted"-its place was not in "highly artificial civilization," but the natural world. The authenticity of nature and the artificiality of modern civilization, as evidenced by the literature of Edgar Rice Burroughs, Roosevelt, and Osborn, was a strong theme in evolutionary narratives, as was the animalistic unfitness — marked by physical and mental shortcomings — of certain races for the civilized world.

Davenport found that for every 1000 drafted men, slightly less than half (468) possessed at least one "physical defect." Some were noted as having more than one, and the total number of defects per 1000 men was 557. These defects ranged from specific limbs or body parts like flatfoot (the most common) to more general conditions like being under-height or underweight, as well as disease and some mental conditions such as epilepsy. Davenport's interpretation of the results with respect to race and nationality, however, reveal generalizations that can only be described as careless. He argued, for example, that "sections containing many French Canadians" tended to have a high frequency of certain physical defects. ${ }^{79} \mathrm{He}$ did not crossreference these assertions by directly linking French Canadians with those conditions - their large representation in a group (defined by Davenport only as "many") was enough to link that group's traits more generally with them.

French Canadians, according to his analysis, showed a high frequency for physical defects like "defective appendages," "defective physical development," "malnutrition," "cleft

\footnotetext{
${ }^{78}$ Charles B. Davenport and Albert G. Love, “Defects Found in Drafted Men," The Scientific Monthly 10, no. 1 (Jan. 1920): 5-6.

${ }^{79}$ Davenport and Love, Army Anthropology, 51.
} 
palate," and "nervous and mental defects." ${ }^{80}$ He therefore claimed that "they form the poorest of the groups from a military standpoint." ${ }^{, 81}$ Using similar methods, he attributed defects to other ethnic groups: Scandinavians and Germans were more prone to goiter but less so to some diseases like tuberculosis, Native Americans were disproportionately well-developed physically but suffered more frequently from cleft palate and harelip, and Finns were observed more often to have multiple sclerosis, heart disease, and "defective teeth.",

In a similar vein, he described the high level of specific defects according to state with vague, impressionistic language: "In New England again we have a center of high proportion of physical defects which may be at least in part explained by the presence of recent immigrants belonging to races of short stature." ${ }^{83}$ The question of height was one of the recurring arguments of Davenport and eugenicists in the postwar era, who favored immigration restrictions. According to him, the Nordics (again using the terminology of Ripley and Grant) were the tallest, at least in Europe. He noted that Polish Jews were, on average, 63 inches tall, a whole 7 below that of Scots. ${ }^{84}$

With these statistics in mind, he problematized the height of immigrants in a military context: "If there is any desire to keep down the proportion of our population who are below the stature requirement for military service, it can only be done by restricting immigration of people belonging to short races." 85 There was a certain irony in this pronouncement, given his assertion that "the Asiatic races are the shortest of all the main races." $" 86$ If his thesis regarding the height

\footnotetext{
${ }^{80}$ Ibid.

${ }^{81}$ Ibid.

${ }^{82}$ Ibid.

${ }^{83}$ Charles B. Davenport and Albert G. Love, Physical Examination of the First Million Draft Recruits: Methods and Results (Washington: Government Printing Office, 1919), 109.

${ }^{84}$ Charles B. Davenport, "The Mean Stature of American Males," Quarterly Publications of the American Statistical Association 17, no. 132 (Dec. 1920): 104.

${ }^{85}$ Davenport and Love, "Defects Found in Drafted Men," 19.

${ }^{86}$ Davenport, "The Mean Stature of American Males," 104.
} 
of the various "races" and their military fitness were true, it failed to explain the rapid growth of the Japanese Empire in the interwar period and its military strength during the Second World War.

All in all, Davenport reported that about 12 percent of men were refused for military service based on defects noted by draft boards, whether physical or mental. ${ }^{87}$ This was not necessarily seen as a cause for alarm by eugenicists, but it aligned rather neatly with their concept of the "submerged tenth" of the population whom they targeted, at least in abstract, as possessing defective genes that should be removed from the racial stock—-presumably by preventing them from breeding further. ${ }^{88}$ Interestingly, unlike Davenport, Yerkes had to be more careful in arguing that his data reflected the "average" American man. The draft boards had already identified a number of feeble-minded and otherwise mentally defective men before they arrived for intelligence testing in the army camps. ${ }^{89}$ On the other hand, Davenport's records drawn from the draft boards had — in theory — missed the mentally defective men who would later be identified by the mental tests.

Davenport's most creative application of biometrical methods to the problem of interpreting army data lay with his search for an "index of build." This was, in his words, the degree to which a man was "robust" and therefore able to withstand hardship. ${ }^{90}$ It had a definite military application, and also appealed to a male identity that was centered on the physical power of the body. Davenport's interest in the bodies of soldiers and their physique was such that he would develop a number of formulas over time, all based on the army records. In 1920, he stated this figure as $\frac{W t(100)}{H t^{2}}$ or weight (in pounds) multiplied by 100 and then divided by height (in

\footnotetext{
${ }^{87}$ Davenport and Love, "Defects Found in Drafted Men," 11.

${ }^{88}$ Black, 52.

${ }^{89}$ Yerkes ed., Psychological Examining in the United States Army, 785.

${ }^{90}$ Charles B. Davenport, "The Best Index of Build," Quarterly Publications of the American Statistical Association 17, no. 131 (Sept. 1920): 341, 344.
} 
inches) squared. ${ }^{91}$ A high number meant that a man had a more robust build, as compared to a lower one: in introducing the index, his chart of 18 examples (taken from military records) contained a lowest score of 2.3 and a highest score of $3.95 .^{92}$ This formula was readily criticized; in the words of one reviewer, "A man of any height with corresponding average weight may be said to have a good build, but it is yet to be proved that his constitution and power of resistance are necessarily good." 93

By the time he published Army Anthropology in 1921, it had been modified to $\frac{W t(1000)}{H t^{2}}$. This multiplied the weight by 1000 instead of 100, which, as a purely aesthetic change, seemed only to deliberately exaggerate the range of possible scores. His initial reluctance to use a more complex formula was due to the limitations of the army data. Some of his arguments relied on records that dated back to the Civil War, especially those concerning the change in average height from then to the First World War-which sought to "prove" the degeneracy of the race during that time due to a gradual shortening of American soldiers. The Civil War records had the height, weight, and chest circumference for every man drafted into the Union Army. Davenport's preference for a simple formula was in large part due to the fact that, using those records, he would be able to calculate the robustness of American soldiers from the 1860s and compare them with those of his day (he found that the soldiers of 1919 were more robust, at least in part because the Mediterranean race was shorter than Nordics). ${ }^{94}$

In his 1923 Body-Build and its Inheritance, he found a compromise. If weight was too arbitrary a factor to indicate a man's physical toughness then why not replace it with chest circumference? He therefore proposed that body build be represented as "the ratio of transverse

\footnotetext{
${ }^{91}$ Davenport, "The Best Index of Build," 342.

92 Ibid., 343.

${ }^{93}$ Margaret E. Gantt, review of Army Anthropology by Charles B. Davenport and Albert G. Love, Journal of the American Statistical Association 18, no. 138 (June 1922): 291.

94 Davenport, "The Mean Stature of American Males," 105-106.
} 
chest diameter to stature, or (since the chest diameter is rarely known) chest-girth to stature."${ }^{.95}$ While it certainly indicated a belief on his part that strong men had big chests, it is perhaps more interesting for our purposes to note Davenport's interest in representing male bodies using statistical data. In particular, he was concerned with questions of what average bodies were like and whether or not a specific man being measured was above or below that standard. If a man had an index of 2.52, or was 63 inches tall, those "facts" only had meaning when compared to other bodies or some statistical benchmark.

As much as Davenport began to appreciate biometrics and make it a central part of his research methods, he was not willing to abandon the Mendelian analysis that still formed the foundation of American eugenic thought. As evidenced in his Naval Officers: their Heredity and Development (1919), which presented pedigree charts for subjects like Admirals John Paul Jones and Horatio Nelson, his understanding of physical and mental traits and their heredity was thoroughly Mendelian. ${ }^{96}$ It is clear from his statistical work with the army data, however—and in spite of his prewar condemnation of biometrics, at least as conceived by Pearson and Galtonthat biometrical methods were useful to him in analyzing large collections of data. To an extent, they were effective in crunching numbers with which to articulate eugenic arguments about the need for population control and immigration restrictions in particular.

Davenport's final project with the army occurred after the end of the war in demobilization camps during the summer and fall of 1919. Unlike the earlier data he worked with, he was able to directly supervise and set the terms for what became known as the "anthropometric measurements" of 100,000 soldiers. Ostensibly, the measurements were taken

\footnotetext{
${ }^{95}$ Charles B. Davenport, Body-Build and its Inheritance (Washington: Carnegie Institution of Washington, 1923), 152.

${ }^{96}$ In this book, Davenport analyzed all of the mental traits that he believed made for a good naval officer and argued that they were consistently present in the family pedigrees of such men. Davenport and Scudder, Naval Officers, 2-9.
} 
as an experiment for making uniforms, but Davenport used the data as part of the 1921 International Exhibit of Eugenics at the American Museum of Natural History to argue for immigration restriction (Appendix F). Using tools such as a Scaver measuring rod, cloth tape, and paper metric scales, he and his team of anthropologists recorded twenty different measurements of each man's body. These included stature, the height of the knee, pubis, and sternal notch, and arm length, shoulder width, and transverse diameter of chest.

Jane Davenport, his daughter, sculpted a statuette entitled "The Average American Male" which was displayed at the 1921 exhibit, taking place alongside the International Congress of Eugenics. The statuette was intended to show that the white male body had become physically weakened due to miscegenation with the waves of immigrants from Eastern and Southern Europe since the Gilded Age, a message made clear by its partner exhibit, a more physically impressive model based on the measurements of Harvard's fifty strongest athletes. ${ }^{97}$ Ironically, the original intention of collecting the army measurements, at least on the part of the army brass, seems to have been to show the physical benefits of military service. ${ }^{98}$

If viewed on its own, "Average American Male" might have not have been as straightforward in its message. To viewers, he was seen, as Mary Coffey writes, to have "slight shoulders, [a] distended belly, and lack of firm musculature" when compared to the eugenic ideal. ${ }^{99}$ Yet, even if one takes for granted that the anthropometric measurements were recorded scientifically and objectively, the attempt to represent that data in the form of a statuette suffered from major conceptual flaws.

\footnotetext{
${ }^{97}$ Mary K. Coffey, “The American Adonis: A Natural History of the 'Average American' (Man), 1921-32,” in Susan Currell and Christina Cogdell eds., Popular Eugenics: National Efficiency and American Mass Culture in the 1930s (Athens, OH: Ohio University Press, 2006), 185.

${ }^{98}$ I would argue that this was the case given that the Adjutant General of the Army made it clear that only soldiers with at least four months of active service were to be examined. Davenport and Love, Army Anthropology, 60.

${ }^{99}$ Coffey, 198.
} 
Dr. Davenport's statistics consisted of mere numbers. In the case of the shoulders, his army anthropologists recorded solely the "transverse diameter of the shoulders at head of humeri." ${ }^{" 100}$ This meant that while the width of the body from one shoulder to the other was known, there was no indication whatsoever for the shape or musculature of the shoulders. The point might be made doubly so for the stomach or the arms. Charles and Jane Davenport, with measurements more appropriate (and intended) for the tailoring of a shirt or pair of pants, had recreated the body of the American man along with all of his dimensions. Their "scientific" construction literally embodied fears of biological degeneracy and the precarious position of the national male body, but also shared with the rest of the army eugenic projects a large degree of subjective interpretation.

After the war, Davenport, Yerkes, and the eugenics movement found a forum to voice these ideas as Congress considered legislation to end the longstanding open door immigration policy. The man chosen to present their arguments and data in favor of restrictionism was Harry H. Laughlin, protégé of Charles Davenport and the administrative head of the ERO. Since the office's founding, Laughlin had used his position to form personal and institutional networks with a number of eugenicists and eugenics groups across the country, as well as mental asylums and prisons. He also oversaw the writing and publication of eugenic literature. It was under Davenport's leadership, with the invaluable assistance of Laughlin, that the eugenics movement in the United States had risen to prominence.

Laughlin testified before the House Committee on Immigration in 1920, 1922, and 1924. Representative Albert Johnson (R-WA), the restrictionist chairman of the committee (and the namesake of the 1924 Johnson Act), had invited him to testify with the special distinction of

\footnotetext{
${ }^{100}$ Davenport and Love, Army Anthropology, 61.
} 
being labeled an "expert" on eugenics. ${ }^{101}$ His testimony to Congress focused on the data collected by Yerkes and his colleagues through the army mental tests. They were judged to be the most appropriate for the context: the tests were well-known to the American public, and had an almost mystical reputation as scientific and objective. Secondly, the fear of mental deficiency, the moron, and feeble-mindedness among Americans had reached a fever during the war and was still strong. Lastly, the focus on mental attributes was consistent with eugenic thought since the very beginning. The nervous system and intelligence of humans were, to them, the main attributes that separated them from lesser organisms and made them suitable for civilization, even if something could be said about physical defects as well. ${ }^{102}$

The arguments presented by Laughlin were a critical part of the successful effort to pass restrictionist Acts of Congress in 1921 and $1924 .{ }^{103}$ He referred to the scores from Army Alpha and Army Beta in arguing that people from non-Nordic countries had a strong tendency to be less intelligent than the "native" population in the United States and people who had originated from Nordic ones. These records, he argued, were irrefutable:

They are, by far, the most extensive and reliable data which have thus far been secured on this subject. Until better and more accurate records are secured these must be accepted as the most nearly approximating the truth, and infinitely superior to the unsupported opinion of the critic. ${ }^{104}$

The strength of the arguments lay precisely in their scientific façade. They were employed by other pro-restrictionist voices outside the inner circles of eugenics and psychology, including

\footnotetext{
${ }^{101}$ Dowbiggin, 226-227.

${ }^{102}$ O'Brien, 7, 66. The language used in press reports about the army mental tests suggests a fascination with the secret and scientific nature of the testing. See "All Soldiers Must Pass Mental Tests," New York Times, 21 January 1918, 11; W. V. Bingham, "Army Always on Lookout for Specialists,” The New York Times, 14 April 1918, SM3; "Secret Mind Tests of the Army," The New York Times, 16 February 1919, 69.

${ }^{103}$ Allen, "The Eugenics Record Office at Cold Spring Harbor,” 249; Ordover, 25-26; O’Brien, 9; Gerstle, $104-108$.

${ }^{104}$ U.S. House, Committee on Immigration and Naturalization, Europe as an Emigrant-Exporting Continent and the United States as an Immigrant-Receiving Nation Hearing, 8 March 1924 (Washington: Government Printing Office, 1924), 1278.
} 
professors of public economy. ${ }^{105}$ The eugenic consensus on placing heavy immigration quotas, as articulated by Laughlin, effectively gave a scientific mantle to the xenophobic sentiment in the country that had erupted after the war. This both reinforced and popularized it, without the need for people to read the long volumes of reports and statistics published on the army examinations. ${ }^{106}$

The specific data that Laughlin cited, which also included the records of state institutions, was not however unambiguously supportive of the legislation. Laughlin interpreted his statistics according to the biologically determinist view that had defined eugenics by the First World War, as well as a creative dose of Mendelian genetics. He calculated the expected "quota" for feeblemindedness that each national group entering the United States would be expected to have, based on an estimation that it occurred once per 200 people in the United States. Curiously, though, immigrants arriving at Ellis Island were much below their quotas - in other words, they were not as feeble-minded, on average, as Americans. People descended from immigrants that had come from Southern and Eastern Europe, however, had surpassed their expected quota as a group by figures of $160 \%$ to just under $200 \%$. His argument was not that environmental factors were to blame, but that feeble-mindedness, as a recessive trait, was simply hidden in the first generation only to appear in later ones, and its activation was exacerbated by miscegenation with the predominantly Nordic American race. ${ }^{107}$

Eugenic thought had always been fearful of interracial reproduction. A common analogy meant to illustrate its negative effects was borrowed from animal breeding: a thoroughbred

\footnotetext{
105 “Seek Higher Type Among Immigrants," The New York Times, 24 February 1923, 2.

106 Gould, 261.

${ }^{107}$ U.S. House, Committee on Immigration and Naturalization, Analysis of America's Modern Melting Pot Hearing, 21 November 1922 (Washington: Government Printing Office, 1923), 738.
} 
mixed with a common horse would produce offspring that were not as effective at racing. ${ }^{108}$ The use of a biological vocabulary to address and problematize racial mixture, however, worked to hide a fear of immigrant men's sexuality and their pursuit of American women, or vice versaand perhaps immigrant women and American men. Much like the army data from which the arguments were drawn, they served to make women's bodies invisible, despite their contribution of half the hereditary traits (via what would later be termed DNA) in the nation's population. The army data, by its nature, excluded women, who were not considered fit for the army and, according to conservative voices, true civic (i.e., political) membership in the republic anyway. It is in this light that we can see how the subtle gendering of the alien immigrant served to exclude them from American society.

Osborn stressed the need of the state to "safeguard the health and morals of its people," and that such a program of eugenic control was "patriotic." 109 His concerns with immigration restriction, as with the regenerative power of nature, were rooted in anxieties about race and gender. American men had to rediscover a powerful masculinity, and part of that project involved the regulation of the national male body: not just anyone was entitled to be American. Only those who were biologically "fit" should be granted such a privilege. This argument insinuated that, in an evolutionary sense, some people were not suited for the political institutions of a civilized community like that of the United States. In light of the arguments and "facts" put forward by eugenics experts, some warned of the decline of American democracy if the average man's mental age continued to fall past thirteen - a statistic that, as we have seen, was essentially meaningless and devoid of its original contexts. ${ }^{110}$

\footnotetext{
108 Allen, "The Misuse of Biological Hierarchies," 113-114.

${ }^{109}$ Osborn, "Lo, the poor Nordic!"” 18.

${ }^{110}$ Gould, 254.
} 
In arguing for immigration restriction, eugenicists portrayed Eastern and Southern Europeans as unfit to belong in industrial society due to their backwards state of evolution. Crime, prostitution, and political radicalism were simply the effects of being unable to properly abide by the rules of civilization. ${ }^{111}$ Their primitive minds were better suited to a state of nature, or perhaps the rural countryside, which was devoid of complex urban and industrial organization. Lothrop Goddard spoke for the eugenics movement as a whole when he argued that charity and state-run institutional care had allowed feeble-mindedness to prosper. It negated the law of natural selection under which the incapable would not survive. ${ }^{112}$

Even into the 1930s, debates about immigration portrayed "uncivilized" men as also being unmasculine. They did not possess the mental or moral, if not also physical, traits of masculinity to the same level of the "American race." ${ }^{113}$ It is interesting to note how the army data—which showed foreigners to have less "military" intelligence than the native populationcould be so seamlessly applied to a broad social and political context. Its use in the debates leading to the passage of the Johnson Act implied that these people, on account of this low intelligence, were not suitable for entry or citizenship in the United States. At some level, this may have played upon classical republican notions of the martial citizenry, whose civic duties included taking up arms in defense of the polity. ${ }^{114}$ If a man was too stupid to serve in the military, then he was not worthy of entering into that political compact—a statement that attacked his masculinity by denying him the power afforded to men in the male spheres of civics or military service.

\footnotetext{
${ }_{111}$ Allen, "The Eugenics Record Office at Cold Spring Harbor," 257-260.

112 Quoted in Kline, 15-16.

${ }_{113}$ Kimmel, 141-142.

${ }^{114}$ Pettegrew, 204.
} 
Laughlin, Davenport, Yerkes, and their eugenicist allies were not without their critics as they pushed a political agenda, however. Some, like Evelyn Garfield, pointed out that the army data did not have any reference to race per se but merely to country of origin. ${ }^{115}$ Race, even as Grant and the eugenicists understood it, transcended political boundaries, especially in Europe. Combined with the improper translation of scores from Alpha and Beta to the Binet scale, as well as the use of "military intelligence" scores posing as general intelligence, it is clear that the arguments of the eugenicists suffered from their own internal contradictions.

Indeed, it is difficult to reconcile the methods of the army tests with the conclusions that were drawn from them. It is certainly true that the xenophobic sentiment of the war years and early 1920s had played a role in their interpretations, but the phenomenon I wish to highlight is the professional and scientific credibility that men like Davenport and Yerkes had to articulate these views. Even if their methodology was flawed, their authority as experts was sufficient to convince Congress to pass these laws - even if they were simply giving a veneer of science to white supremacy. In exercising this power to pronounce the bodies of non-Nordic men as illegitimate, however, they would test the limits of that credibility, and it would be challenged by scientists working in other fields of human evolution.

Ironically, their insistence on objective, scientific investigation and evidence led eugenicists to retreat towards their own particular points of view—ostensibly backed by such scientific methodology — and ignore what other voices in the scientific community had to say about the question of evolution and the nature of the body. During and after the immigration debates of the early 1920s, geneticists became increasingly more vocal about the simplistic

\footnotetext{
${ }^{115}$ Evelyn Garfield, "Aliens in the Psychology Tests (To the Editor of the New York Times)," The New York Times, 4 March 1923, XX8.
} 
understanding of heredity that formed the basis of eugenic thought in the United States. ${ }^{116}$ And, while the criticism of eugenics for its tendency to rely on hereditarian (and not environmental) factors to explain physical and mental traits had been around since the very beginning, it became increasingly clear to many that the proliferation of such hard line ideas was dangerous. One such critic, L. L. Bernard, voiced the concerns of many sociologists and cultural anthropologists in his review of Davenport's Naval Officers:

That naval officers would tend to recur in families is probably more credible from the environmentalist's point of view than from that of the eugenist. Has the Carnegie Institution no funds for this more valuable type of investigation? ${ }^{117}$

The Carnegie Institution, the main source of funding for the ERO after the war, was aware of the mounting criticism. In the late 1930s, it formed a number of committees to review the institution as well as the scientific basis and usefulness of its work. Davenport left the ship while it was still sinking. Laughlin, his successor, oversaw the final years of the American eugenics movement, at least as it had existed as a self-conscious one. ${ }^{118}$ Its effective demise came with the closing of the ERO in 1939. Some eugenicists would subtly redefine themselves as part of the new "family planning" movement and carry on well into the post-Second World War period. ${ }^{119}$ In retrospect, as much as the Johnson Act had been one of the crowning achievements of American eugenics, it had also spelled the beginning of their slow downfall. Like Osborn's gendered and racialized natural history, eugenics increasingly came to be seen as outdated and out of touch with the mainstream scientific community.

The effort of eugenicists to lobby for the Johnson Act is a definitive tale of the Progressive Era. It was, at least to them, the successful application of scientific principles to a

\footnotetext{
${ }^{116}$ Allen, "The Eugenics Record Office at Cold Spring Harbor," 250.

${ }^{117}$ L. L. Bernard, review of Naval Officers: Their Heredity and Development by Charles B. Davenport and Mary Theresa Scudder, American Journal of Sociology 25, no. 2 (Sept. 1919): 241-242.

118 Allen, "The Eugenics Record Office at Cold Spring Harbor," 226.

${ }^{119}$ Kline, 4.
} 
social problem: order being imposed on a chaotic world. Indeed, in his testimony to Congress, Laughlin identified the economic nature of immigration, but stressed that it had a "biological" nature that demanded more attention. ${ }^{120}$ It was only through the lens of science that this biological secret could be known, understood, and mastered. In his words, By national eugenics we shall have to correct the errors of past national policies of immigration, but by new statutes which are sound biologically we can cause future immigration to improve our native family stocks. ${ }^{121}$

The degeneracy of white male bodies in the United States was a cultural idea that pervaded pop culture and academic literature alike. Everywhere, it was draped in the language of evolution and biology and, by the end of the First World War, eugenic experts had decided to press their claims to truth on the matter and extend their institutional power to federal legislation. There, they successfully pushed for laws that could regulate the nature of national bodies as envisioned by physical anthropology and psychology. Their laboratory may have been the U.S. Army, but their research promised solutions for the betterment of the white male body in the country as a whole. The restrictionist immigration act of 1924 was the consequence of decades of ideational development that was rooted in biologically determinist views of gender, race, and the precarious - yet powerful — place of the male body in civilization and the natural world.

Davenport and Yerkes saw an opportunity with the army draft to measure the minds and bodies of millions of American men and develop new methods for doing so. Their projects produced a wealth of data, collected through "objective" scientific methods. They and the rest of the eugenics establishment were not content merely with possessing such powerful knowledge, however. With the consolidation of their institutional power at the ERO, state institutions, and (briefly) in the U.S. Army came a new goal: using their scientific knowledge to regulate what

${ }^{120}$ Europe as an Emigrant-Exporting Continent, 1238.
${ }^{121}$ Ibid. 
kinds of bodies were to be included or excluded in the American republic. The Johnson Act was one such manifestation of that goal; the Supreme Court case Buck v. Bell (1927), which ruled that sterilization was constitutionally sound, was another. ${ }^{122}$

For their mental or physical shortcomings, some bodies and minds were pronounced to be "feeble," "defective," and "unfit," among other discursive terms. Civilization and democracy were social and political institutions to which a race (or individual) had to "evolve" to. The unfit could not survive in such an environment, leading to crime, chaos, and biological degeneracy in American society. Davenport and Yerkes had developed tools for constructing a new knowledge about a racialized male identity that stressed the essentialism of biology, evolution, and heredity, and the monopoly of psychology and eugenic experts to read the body as a text.

Their legacy, the Johnson Act, would remain in place until 1965. When President Coolidge signed the law, it was celebrated as a triumphant moment for biological determinism and the immutability of evolutionary laws, a realization that man's true self could be understood essentially through science despite all the promises of civilization and its doctrines-including longstanding traditions of personal liberty and free immigration. American legislators had voted overwhelmingly to restrict immigration and therefore close the doors not only to immigrants seeking a new life in the United States but also to the promises of the Enlightenment ideals upon which the country was conceived. As anatomist Harvey Ernest Jordan argued in a lecture on eugenics in 1914, "It is a popular fiction that 'men are born free and equal.' Nothing really is further from the truth." 123

\footnotetext{
${ }^{122}$ Carlson, 50.

${ }^{123}$ Harvey Ernest Jordan, "Eugenics: Its Data, Scope and Promise, as Seen by the Anatomist," in Aldrich et al., 116.
} 


\section{Chapter 5}

\section{Conclusion: Science at the Intersection of Gender, Race, and Nationalism}

Long before William James had begun to write about the "split personality" of man, the European intellectual and literary tradition celebrated a darker, bestial nature that lay beneath the civilized self. This theme was prevalent in the classical centaur myths, the political thought of Niccolò Machiavelli, and folk tales like Beauty and the Beast. By Darwin's time, therefore, the idea that men were like animals, or at least could behave like them, was nothing new. What was new was the way in which the new biology positioned civilized men and their bodies in a system of natural laws - the same evolutionary processes that affected all organisms. According to this grand narrative, men were animals.

As we have seen, these biological ideas had a profound impact on the way that some men began to define their identities as "Nordic," upper and middle class Americans. A critical part of these definitions relied on categories of race, gender, and class that were imposed on the bodies of others. Through scientific commentary, these bodies were constructed as being different, inferior, and less evolved. While all men could trace their origins and authentic selfhood to a mythologized natural world, these evolutionary narratives asserted a hierarchy where AngloSaxondom reigned supreme. The transcendental claims to power of this group of American men had therefore shifted from a civilized "soul" to an evolutionary history marked by violence, conquest, and struggle against natural environments.

Yet with such a powerful heritage came an inherent duty to preserve it. As a discourse of masculinity, evolutionary essentialism as articulated by Burroughs, Osborn, Andrews, Grant, Yerkes, and Davenport disciplined white male bodies even as it enabled their social authority. ${ }^{1}$

\footnotetext{
${ }^{1}$ Reeser uses the example of military masculinity to make the point that masculinity can discipline and empower people simultaneously by accepting and internalizing the rules of that discourse. Reeser, 96.
} 
Civilization was viewed as a degenerate influence on one's masculine power due to its lack of Spencerian stimulus and its feminizing tendencies, while the presence of non-Nordic men and women threatened to dilute the physical and mental strength of future generations of Americans through miscegenation. Just as these narratives identified problems in the modern metropolis, however, they also offered solutions. Individually, men needed to embrace physical strain and competition, if not outright violence, especially in natural spaces; and, as a national community, Americans needed to apply the lessons of evolution to the literal construction of male bodies through a program of eugenics.

As political scientist Rogers M. Smith has argued, debates about citizenship in the United States have not only been framed by Enlightenment political theory. Ideologies of race have also played a critical role in defining a white, Anglo-Saxon national identity for the country. ${ }^{2}$ Even if Laughlin had not testified before the U. S. House Committee on Immigration and presented a biologically determinist argument in favor of restrictionism, evolutionary narratives of white male identities and their bodies were firmly rooted in the American psyche. By insinuating that the bodies of these new immigrants from Eastern and Southern Europe were physically and mentally different—not to mention inferior — they cast these people as being outside of an idealized national community. The rising influence of this scientific discourse came at a time when Anglo-Saxon American men expressed anxiety over the growing power of women, immigrants, and organized labor in the urban city. Each of these was seen as threatening a traditional national identity and the cultural hegemony of the Victorian middle class. ${ }^{3}$

American literature in the early twentieth century was influenced by these evolutionary themes. Characters such as Lauth, Buck, or Tarzan promised that civilized bodies were still

\footnotetext{
${ }^{2}$ Rogers M. Smith, Civic Ideals: Conflicting Visions of Citizenship in U.S. History (New Haven: Yale University Press, 1997), 2-3.

${ }^{3}$ Bederman, 11-14.
} 
powerful, if only they could rediscover the primeval masculinity of their ancestors and thereby rekindle a Spencerian fighting strength. Who in all of nature could stand up to such might? As the king of the apes promises, "None in all the jungle may face Tarzan of the Apes in battle, and live." "4arzan's physical and mental greatness was available to all Anglo-Saxon men of good breeding, provided they were exposed to the right environmental stimulus. And, like Tarzan, those men could impose a natural order — a hierarchy of race, gender, and class — that had been disrupted by the chaotic world of the Gilded Age. At the same time, this literature also represented an escapist fantasy from civilization which had been compromised by these unnatural forces.

Likewise, a culture of antimodernism prompted this same group of American men to search for an authentic, timeless male identity in a mythologized prehistoric world of struggle. The natural history museums of the great American cities were temples to a new cosmic ordering of life that favored the strenuous and pugnacious and eschewed the comfortable life of the civilized middle class. The natural history of man, at least to Andrews and Osborn, was a story with moral lessons for modern American men. Paleontology, their scientific discipline, provided both a means to acquire knowledge about the natural world and opportunities for masculine empowerment. The story of man and his authentic nature lay not in the gilded research laboratories of civilization but "out there" in primitive spaces, with landscapes and beasts and people as primeval as the early days of Dawn Man himself. Osborn's theories did not go uncontested, however, and the energetic president of the AMNH butted heads with scientists, anthropologists, and Christian fundamentalists who challenged his views. Yet his success in constructing a masculine, racialized narrative of human evolution, even as it was challenged by

\footnotetext{
${ }^{4}$ Burroughs, Tarzan of the Apes, chapter XXIII.
} 
the scientific establishment and elsewhere, spoke to the power that could be wielded by men like him in that world of science and its institutions.

This same privileging of scientific knowledge was a critical part of the passage of the anti-immigrant Johnson Act in 1924. By the 1920s, eugenicists held the cultural authority to influence debates about the immigration question by placing the white male body at its center. When the United States entered the First World War and drafted millions of men, Davenport and Yerkes seized the opportunity to apply — and develop — their statistical methods of measuring bodies and minds to help sort out the "fit" from the "unfit." The standards for military service, with its preference for certain physical and mental traits, then became the basis to assess whether or not the bodies of non-Nordics should be entitled to become members of the American republic. The fears of miscegenation, of foreigners with awkward bodies and weak minds, and of the degeneracy of the old American racial stock, were all articulated in biological terms. The point here was not that eugenic science reinforced existing racial prejudices (racists would have probably accepted the arguments of Laughlin regardless) but that scientists had made racism respectable and morally justifiable. Osborn made this point clear in 1924:

I find no form of matter so stable in nature as that on which heredity depends, consequently the selection, preservation and multiplication of the best heredity is a patriotic duty of first importance. In the selection of the best we should know no prejudice. If we extenuate nothing, we write down nothing in malice. ${ }^{5}$

The synergy of science and postwar xenophobia proved to be a potent one, such that there was little opposition in Congress or the presidency to the passage of the Johnson Act.

In this thesis, I have attempted to demonstrate that some American men from a certain background (middle and upper class, Anglo-Saxon) used the scientific language of evolution to claim for themselves a transcendental identity rooted in natural history. This identity was located

\footnotetext{
${ }^{5}$ Osborn, "Lo, the Poor Nordic!" 18.
} 
at the intersection of gender, class, and race, meaning that it did not privilege all men, nor all whites (or "Nordics"). In this sense, it served to empower only a slim minority of Americans even as it held them to be the locus for a national identity. By closely examining the textual signs used in these evolutionary narratives, it is evident that both popular and expert science (itself an arbitrary separation) used a common vocabulary to express anxiety over a changing American nation.

These recurring themes included the privileging of nature as a masculine space of empowerment through violence (as opposed to a hollow and decadent civilization), evolutionary history as the basis for Nordic male supremacy, the threat of miscegenation to the white male body, and finally, the immutability of the laws of evolution and biology. If there is a historical lesson to be learned here, it is that scientific knowledge is framed by the cultural context of its time and place. This context frames the questions that science seeks to ask. For example, the immigrant studies in the early twentieth century posited that the bodies of these people were inferior to the old American stock. The research of Franz Boas argued otherwise. While there is room within the scientific worldview to challenge existing ideas, the fact that one of the questions of the day was "Are immigrants from Eastern and Southern Europe inferior to the Anglo-Saxon race?" clearly shows the power relations inherent in the gaze of science. Even people like Boas who fought against scientific racism could only respond by saying "no"- the question itself was inescapable.

The history of science and its complicity with the discourses of gender, race, and class has yet to be fully written, and the opportunities for further research in this area are unlikely to go away anytime soon. And these histories are still relevant: it can tell us volumes about scientific attitudes towards queer sexuality and disability in the present, for example. In her 
sociological book on evolutionary narratives of masculinity, Martha McCaughey points out that there has been almost no literature written about "men's narratives of their bodies in perpetuating violence against women." ${ }^{, 6}$ This knowledge, reinforced with a scientific stamp of approval—and as we know, scientists hardly have a monopoly on science-is a blueprint for shaping power, identities, and experiences in our society.

This was certainly true for the early twentieth century in the United States. Evolutionary narratives, drawing from the textual signs of nature, violence, and racial biology, classified some bodies as legitimate and others as illegitimate through a variety of cultural forms. Literature, museum education, scientific publications, and eugenics-inspired legislation framed these bodies according to a grand narrative of natural history, inscribing them with a series of timeless truths about those people and their identities. Men might have found themselves in civilization for the moment, but beneath that thin veneer laid a natural "self" that was inescapably bound to the laws of nature.

To conclude, I will defer to a passage in the final chapter of Tarzan of the Apes where Tarzan proposes to Jane. Eric Cheyfitz has interpreted this passage as a representation of U.S. foreign policy, specifically, the imperial desire for the racialized other to submit to, and embrace, American civilization on the terms of the colonizing power. ${ }^{7}$ I disagree with this interpretation, however. As I have argued, the character of Tarzan is the literary embodiment of Anglo-Saxon virility, empowered by the same Spencerian upbringing that drove the evolution of his primeval ancestors. This is the key to his meaning as a character, and it is on these terms that we can begin to understand him as a textual sign. Rather, Tarzan's heartfelt speech to Jane describes his own

\footnotetext{
${ }^{6}$ McCaughey, 9.

${ }^{7}$ Eric Cheyfitz, "Tarzan of the Apes: US Foreign Policy in the Twentieth Century," American Literary History 1, no. 2 (Summer 1989): 339.
} 
racialized and gendered identity, of which a prehistoric past of natural struggle is the principle component. His story embodies the natural history of the American man:

"You are free now, Jane," he said, "and I have come across the ages out of the dim and distant past from the lair of the primeval man to claim you - for your sake I have become a civilized man - for your sake I have crossed oceans and continents - for your sake I will be whatever you will me to be. I can make you happy, Jane, in the life you know and love best."

${ }^{8}$ Burroughs, Tarzan of the Apes, chapter XXVIII. 


\section{Bibliography}

\section{Primary Sources}

Aldrich, Morton A. et al. Eugenics: Twelve University Lectures. New York: Dodd, Mead and Company, 1914.

Andrews, Roy Chapman. "Explorations in Mongolia: A Review of the Central Asiatic Expeditions of the American Museum of Natural History." The Geographical Journal 69, no. 1 (Jan. 1927): 1-19.

Andrews, Roy Chapman. The New Conquest of Central Asia. New York: The American Museum of Natural History, 1932.

Andrews, Roy Chapman. Whale Hunting with Gun and Camera: A Naturalist's Account of the Modern Shore-Whaling Industry, of Whales and their Habits, and of Hunting Experiences in Various Parts of the World. New York: D. Appleton and Company, 1916.

Andrews, Roy Chapman and Henry Fairfield Osborn. On the Trail of Ancient Man. New York: G. P. Putnam's Sons, 1926.

Berkey, Charles P. and Frederick K. Morris. Geology of Mongolia: A Reconnaissance Report Based on the Investigations of the Years 1922-1923. New York: The American Museum of Natural History, 1927.

Bernard, L. L. Review of Naval Officers: Their Heredity and Development by Charles B. Davenport and Mary Theresa Scudder. American Journal of Sociology 25, no. 2 (Sept. 1919): 241-242.

Brigham, Carl C. A Study of American Intelligence. Princeton: Princeton University Press, 1923.

Bryan, William Jennings. Seven Questions in Dispute. New York: Fleming H. Revell Company, 1924.

Burroughs, Edgar Rice. Tarzan and the Ant Men. 1924. Available online at http://gutenberg.net.au/ebooks06/0600651h.html (last accessed 4 February 2014).

Burroughs, Edgar Rice. Tarzan and the Lost Empire. 1929. Available online at http://gutenberg.net.au/ebooks06/0600911h.html (last accessed 4 February 2014).

Burroughs, Edgar Rice. Tarzan of the Apes. 1914. Available online at http://www.gutenberg.org/files/78/78-h/78-h.htm (last accessed 4 February 2014).

Burroughs, Edgar Rice. The Return of Tarzan. 1915. Available online at http://www.gutenberg.org/files/81/81-h/81-h.htm (last accessed 4 February 2014). 
Burroughs, Edgar Rice. “The Tarzan Theme.” Reader's Digest (June 1932). Available online at http://www.erbzine.com/mag0/0058.html (last accessed 4 February 2014).

Cheyfitz, Eric. "Tarzan of the Apes: US Foreign Policy in the Twentieth Century." American Literary History 1, no. 2 (Summer 1989): 339-360.

Conrad, Joseph. Heart of Darkness. Garden City, New York: Doubleday, Page \& Company, 1916.

Davenport, Charles B. Body-Build and its Inheritance. Washington: Carnegie Institution of Washington, 1923.

Davenport, Charles B. Heredity in Relation to Eugenics. New York: Henry Holt and Company, 1911.

Davenport, Charles B. Review of Social Problems: Their Treatment, Past, Present and Future. Questions of the Day and of the Fray by Karl Pearson. American Journal of Sociology 18, no.6 (May 1913): 833-835.

Davenport, Charles B. "The Best Index of Build." Quarterly Publications of the American Statistical Association 17, no. 131 (Sept. 1920): 341-344.

Davenport, Charles B. "The Mean Stature of American Males." Quarterly Publications of the American Statistical Association 17, no. 132 (Dec. 1920): 484-487.

Davenport, Charles B. The Trait Book. Cold Spring Harbor, NY: Eugenics Record Office, 1912.

Davenport, Charles B. and Albert G. Love. Army Anthropology: Observations Made on Draft Recruits, 1917-1918, and on Veterans at Demobilization, 1919. Washington: Government Printing Office, 1921.

Davenport, Charles B. and Albert G. Love. "Defects Found in Drafted Men." The Scientific Monthly 10, no. 1 (Jan. 1920): 5-25.

Davenport, Charles B. and Albert G. Love. Physical Examination of the First Million Draft Recruits: Methods and Results. Washington: Government Printing Office, 1919.

Davenport, Charles B. and Mary Theresa Scudder. Naval Officers: Their Heredity and Development. Washington: Carnegie Institution of Washington, 1919.

Gantt, Margaret E. Review of Army Anthropology by Charles B. Davenport and Albert G. Love. Journal of the American Statistical Association 18, no. 138 (June 1922): 290-292.

Grant, Madison. The Passing of the Great Race, Fourth Edition. New York: Charles Scribner's Sons, 1922. 
Gregory, William King. "Henry Fairfield Osborn." Proceedings of the American Philosophical Society 7, no. 3 (1936): 395-409.

Gregory, William King. "The Origin, Rise and Decline of Homo Sapiens." The Scientific Monthly 39, no. 6 (Dec. 1934): 481-496.

Kellogg, Vernon. "War and Human Evolution: Germanized." The North American Review 207, no. 748 (March 1918): 364-369.

Laughlin, Harry H. The Second International Exhibition of Eugenics. Baltimore: Williams \& Wilkins, 1923.

London, Jack. The Call of the Wild. New York: The MacMillan Company, 1903.

Norris, Frank. "Lauth." Overland Monthly 21, no. 129 (September 1893): 241-260.

Norris, Frank. McTeague: A Story of San Francisco. New York: Doubleday and McClure, 1899.

The New York Times (New York, NY).

Osborn, Henry Fairfield. "Application of the Laws of Action, Reaction, and Interaction in Life Evolution." Proceedings of the National Academy of Sciences of the United States of America 3, no. 1 (Jan. 15, 1917): 7-9.

Osborn, Henry Fairfield. "Aristogenesis, the Observed Order of Biomechanical Evolution." Proceedings of the National Academy of Sciences of the United States of America 19, no. 7 (July 15, 1933): 699-703.

Osborn, Henry Fairfield. "Evolution and Education at the Tennessee Trial." Science, New Series, vol. 62, no. 1594 (July 17, 1925): 43-45.

Osborn, Henry Fairfield. Men of the Old Stone Age: Their Environment, Life, and Art. New York: Charles Scribner's Sons, 1916.

Osborn, Henry Fairfield. "Paleontology versus Devriesianism and Genetics in the Factors of the Evolution Problem." Science, New Series, Vol. 73, no. 1899 (May 22, 1931): 547-549.

Osborn, Henry Fairfield. "Present Status of the Problem of Human Ancestry." Proceedings of the American Philosophical Society 67, no. 2 (1928): 151-155.

Osborn, Henry Fairfield. "Recent Discoveries Relating to the Origin and Antiquity of Man." Proceedings of the American Philosophical Society 66, "The Record of the Celebration of the Two Hundredth Anniversary of the Founding of the American Philosophical Society (1927): 373-389. 
Osborn, Henry Fairfield. "SAMUEL WENDELL WILLISTON: The Man and the Paleontologist." Sigma Xi Quarterly 7, no. 1, In Memoriam: Samuel Wendell Williston (March 1919): 2-8.

Osborn, Henry Fairfield. “The Earth Speaks to Bryan.” The Forum (June 1925): 796-803.

Roosevelt, Theodore. African Game Trails: An Account of the African Wanderings of an American Hunter-Naturalist. New York: Charles Scribner's Sons, 1910.

"The Roy Chapman Andrews Lectures: unearthing Asia's secrets in quest of 'the missing link." Streator, IL: A.H. Anderson Printing Co., 1926. Available online at http://sdrcdata.lib.uiowa.edu/libsdrc/details.jsp?id=/andrews/1 (last accessed 5 February 2014).

Trabue, M. R. Review of A Point Scale for Measuring Mental Ability by Robert M. Yerkes, James W. Bridges, and Rose S. Hardwick. The Journal of Philosophy, Psychology and Scientific Methods 14, no. 12 (June 7, 1917): 330-333.

U.S. House. Committee on Immigration and Naturalization. Analysis of America's Modern Melting Pot Hearing. 21 November 1922. Washington: Government Printing Office, 1923.

U.S. House. Committee on Immigration and Naturalization. Europe as an Emigrant-Exporting Continent and the United States as an Immigrant-Receiving Nation Hearing. 8 March 1924. Washington: Government Printing Office, 1924.

Yerkes, Robert M. "A Point Scale for Measuring Mental Ability." Proceedings of the National Academy of Sciences of the United States of America 1, no. 2 (Feb. 15, 1915): 114-117.

Yerkes, Robert M. "Measuring the Mental Strength of an Army." Proceedings of the National Academy of the Sciences of the United States of America 4, no. 10 (Oct. 15, 1918): 295-297.

Yerkes, Robert M. "Mental Examination of Police and Court Cases." Journal of the American Institute of Criminal Law and Criminology 7, no. 3 (Sept. 1916): 366-372.

Yerkes, Robert M. ed. Psychological Examining in the United States Army. Washington: Government Printing Office, 1921.

Yerkes, Robert M. Review of Heredity in Relation to Eugenics by Charles B. Davenport. American Journal of Sociology 18, no. 1 (Jul 1912): 115-120.

Yerkes, Robert M. Review of The Hill Folk by Florence H. Danielson and Charles B. Davenport. American Journal of Sociology 19, no. 2 (Sept. 1913): 260-264.

Yerkes, Robert M., James W. Bridges, and Rose S. Hardwick. A Point Scale for Measuring Mental Ability. Baltimore: Warwick \& York, 1915. 
Yoakum, Clarence S. and Robert M. Yerkes eds. Army Mental Tests. New York: Henry Holt and Company, 1920.

\section{Secondary Sources}

Allen, Garland E. “The Eugenics Record Office at Cold Spring Harbor, 1910-1940.” Osiris 2, vol. 2 (1986): 225-64.

Allen, Garland E. "The Misuse of Biological Hierarchies: The American Eugenics Movement, 1900-1940." History and Philosophy of the Life Sciences 5, no. 2 (1983): 105-128.

Baatz, Simon. Knowledge, Culture, and Science in the Metropolis: The New York Academy of Sciences, 1817-1970. New York: The New York Academy of Sciences, 1990.

Beck, Naomi. "Social Darwinism.” In The Cambridge Encyclopedia of Darwin and Evolutionary Thought.

Bederman, Gail. Manliness and Civilization: A Cultural History of Gender and Race in the United States, 1880-1917. Chicago: University of Chicago Press, 1995.

Bender, Bert. "Frank Norris on the Evolution and Repression of the Sexual Instinct." NineteenthCentury Literature 54, no. 1 (June 1999): 73-103.

Bender, Daniel E. American Abyss: Savagery and Civilization in the Age of Industry. Ithaca: Cornell University Press, 2009.

Bennett, Tony. Pasts Beyond Memory: Evolution, Museums, Colonialism. London: Routledge, 2004.

Black, Edwin. War against the Weak: Eugenics and America's Campaign to Create a Master Race. New York: Four Walls Eight Windows, 2003.

Bloom, Lisa. Gender on Ice: American Ideologies of Polar Expeditions. Minneapolis: University of Minnesota Press, 1993.

Brinkman, Paul D. The Second Jurassic Dinosaur Rush: Museums and Paleontology in America at the Turn of the Twentieth Century. Chicago: The University of Chicago Press, 2010.

Cain, Victoria E. M. “'The Direct Medium of the Vision': Visual Education, Virtual Witnessing and the Prehistoric Past at the American Museum of Natural History, 1890-1923." Journal of Visual Culture 9, no. 3 (2010): 284-303.

Carey-Webb, Allen. "Heart of Darkness, Tarzan, and the 'Third World': Canons and Encounters in World Literature, English 109." College Literature 19/20, no. 3/1, Teaching Postcolonial and Commonwealth Literatures (Oct. 1992 - Feb. 1993): 121-141. 
Carlson, Elof Axel. Times of Triumph, Times of Doubt: Science and the Battle for Public Trust. Cold Spring Harbor, New York: Cold Spring Harbor Laboratory Press, 2006.

Carson, John. “Army Alpha, Army Brass, and the Search for Army Intelligence." Isis 84, no. 2 (June 1993): 278-309.

Childs, Donald J. Modernism and Eugenics: Woolf, Eliot, Yeats, and the Culture of Degeneration. Cambridge: Cambridge University Press, 2001.

Clark, Constance Areson. God_or Gorilla: Images of Evolution in the Jazz Age. Baltimore: The Johns Hopkins University Press, 2008.

Coffey, Mary K. "The American Adonis: A Natural History of the 'Average American' (Man), 1921-32." In Susan Currell and Christina Cogdell eds. Popular Eugenics: National Efficiency and American Mass Culture in the 1930s, 185-216. Athens, OH: Ohio University Press, 2006.

Connell, R. W. Masculinities, Second Edition. Berkeley: University of California Press, 2005.

Cuddy, Lois A. and Claire M. Roche eds. Evolution and Eugenics in American Literature and Culture, 1880-1940. Lewisburg: Bucknell University Press, 2003.

Discovery Communications. "Searching for Lost Worlds: Dragon Hunters." 1999. Available online at http://gutenberg.net.au/ebooks06/0600911h.html (last accessed 20 February 2014).

Dowbiggin, Ian Robert. Keeping America Sane: Psychiatry and Eugenics in the United States and Canada, 1880-1940. Ithaca and London: Cornell University Press, 1997.

Dryden, Linda. Joseph Conrad and the Imperial Romance. New York: St. Martin's Press, 2000.

Dudley, John. "Inside and Outside the Ring: Manhood, Race, and Art in American Literary Naturalism." College Literature 29, no. 1 (Winter 2002): 53-82.

Filene, Peter. Him/Her/Self: Gender Identities in Modern America, Third Edition. Baltimore: The Johns Hopkins University Press, 1998.

Gallenkamp, Charles. Dragon Hunter: Roy Chapman Andrews and the Central Asiatic Expeditions. New York: Penguin, 2001.

Gerstle, Gary. American Crucible: Race and Nation in the Twentieth Century. Princeton: Princeton University Press, 2001.

Gould, Stephen Jay. The Mismeasure of Man. New York: W. W. Norton \& Company, 1996.

Haraway, Donna. Primate Visions: Gender, Race, and Nature in the World of Modern Science. New York: Routledge, 1989. 
Hyatt, Marshall. Franz Boas, Social Activist: The Dynamics of Ethnicity. New York: Greenwood Press, 1990.

Jacobson, Matthew Frye. Barbarian Virtues: The United States Encounters Foreign Peoples at Home and Abroad, 1876-1917. New York: Hill and Wang, 2000.

Johnston, Andrew M. "Sex and Gender in Roosevelt's America." In Serge Ricard ed., A Companion to Theodore Roosevelt, First Edition. Hoboken, NJ: Blackwell Publishing, 2011.

Jones, Jeannette Eileen. In Search of Brightest Africa: Reimagining the Dark Continent in American Culture, 1884-1936. Athens, GA: University of Georgia Press, 2010.

Jurca, Catherine. "Tarzan, Lord of the Suburbs.” Modern Language Quarterly 57, no. 3 (1996): 479-504.

Kasson, John F. Houdini, Tarzan, and the Perfect Man: The White Male Body and the Challenge of Modernity in America. New York: Hill and Wang, 2001.

Kimmel, Michael. Manhood in America: A Cultural History, Third Edition. Oxford: Oxford University Press, 2012.

Kline, Wendy. Building a Better Race: Gender, Sexuality, and Eugenics from the Turn of the Century to the Baby Boom. Berkeley: University of California Press, 2001.

Kjærgaard, Peter C. "The Missing Links Expeditions-or how the Peking Man was not found." Endeavour 36, no. 3 (September 2012): 97-105.

Largent, Mark A. "Darwinism in the United States, 1859-1930." In The Cambridge

Encyclopedia of Darwin and Evolutionary Thought.

Lears, T. J. Jackson. No Place of Grace: Antimodernism and the Transformation of American Culture, 1880-1920. New York: Pantheon Books, 1981.

Leverenz, David. "The Last Real Man in America: From Natty Bumppo to Batman.” American Literary History 3, no. 4 (Winter 1991): 753-781.

Lewin, Roger. Bones of Contention: Controversies in the Search for Human Origins. Chicago: The University of Chicago Press, 1997.

McCaughey, Martha. The Caveman Mystique: Pop-Darwinism and the Debates over Sex, Violence, and Science. New York: Routledge, 2008.

Milner, Richard. The Encyclopedia of Evolution. New York: Facts on File, 1990.

Nesteby, James R. "The Tenuous Vine of Tarzan of the Apes." Journal of Popular Culture 13, no. 3 (1980): 483-487. 
Novacek, Michael. Time Traveler: In Search of Dinosaurs and Ancient Mammals from Montana to Mongolia. New York: Farrar, Straus and Giroux, 2002.

O'Brien, Gerald V. Framing the Moron: The Social Construction of Feeble-Mindedness in the American Eugenic Era. Manchester: Manchester University Press, 2013.

Ordover, Nancy. American Eugenics: Race, Queer Anatomy, and the Science of Nationalism. Minneapolis: University of Minnesota Press, 2003.

Pettegrew, John. Brutes in Suits: Male Sensibility in America, 1890-1920. Baltimore: The Johns Hopkins University Press, 2007.

Putney, Clifford. Muscular Christianity: Manhood and Sports in Protestant America, 1880-1920. Cambridge, MA: Harvard University Press, 2001.

Rafter, Nicole Hahn ed. White Trash: The Eugenic Family Studies, 1877-1919. Boston: Northeastern University Press, 1988.

Rainger, Ronald. An Agenda for Antiquity: Henry Fairfield Osborn \& Vertebrate Paleontology at the American Museum of Natural History, 1890-1935. Tuscaloosa: University of Alabama Press, 1991.

Rea, Tom. Bone Wars: The Excavation and Celebrity of Andrew Carnegie's Dinosaur. Pittsburgh, University of Pittsburgh Press: 2001.

Reeser, Todd. Masculinities in Theory. Chichester, UK: Wiley-Blackwell, 2010.

Ross, Dorothy. The Origins of American Social Science. Cambridge: Cambridge University Press, 1991.

Sklansky, Jeffrey. The Soul's Economy: Market Society and Selfhood in American Thought, 1820-1920. Chapel Hill: University of North Carolina Press, 2002.

Smith, Rogers M. Civic Ideals: Conflicting Visions of Citizenship in U.S. History. New Haven: Yale University Press, 1997.

Sommer, Marianne. "Seriality in the Making: The Osborn-Knight Restorations of Evolutionary History.” History of Science (September/December 2012), Vol. 48: 461-482.

Sommer, Marianne. "The Lost World as Laboratory: The Politics of Evolution between Science and Fiction in the Early Decades of Twentieth-Century America." Configurations 15, no. 3 (Fall 2007): 299-329.

Taliaferro, John. Tarzan Forever: The Life of Edgar Rice Burroughs, Creator of Tarzan. New York: Scribner, 1999. 
Thomson, Keith. The Legacy of the Mastodon: The Golden Age of Fossils in America. New Haven: Yale University Press, 2008.

Vernon, Alex. On Tarzan. Athens, GA: University of Georgia Press, 2008.

Wrobel, David M. The End of American Exceptionalism: Frontier Anxiety from the Old West to the New Deal. Lawrence, KA: University Press of Kansas, 1993. 


\section{Appendices}

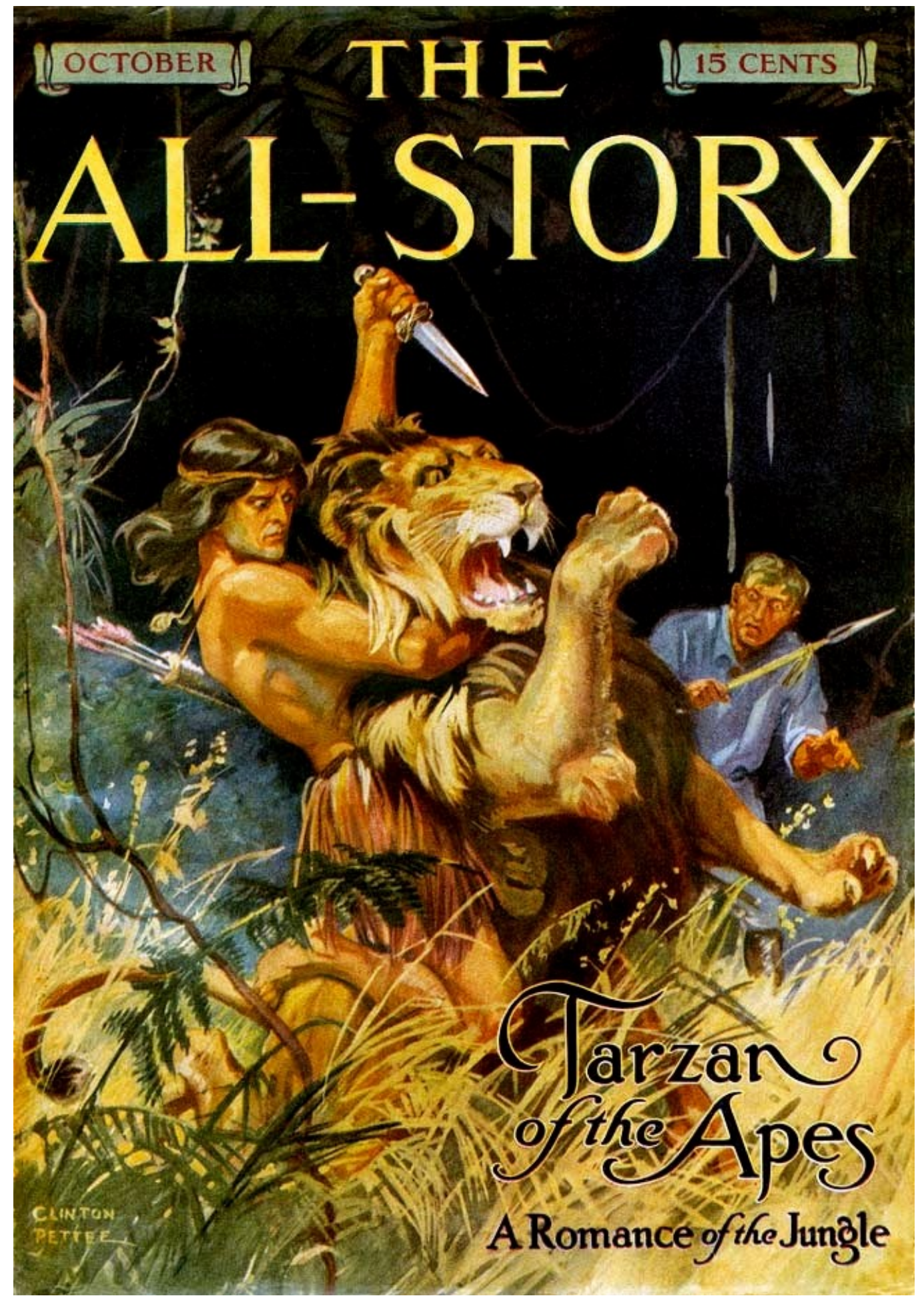

Appendix A. The cover of the October 1912 All-Story serial, featuring Tarzan of the Apes, illustrated by Clinton Pettee. From Wikipedia Commons

(http://commons.wikimedia.org/wiki/File:Tarzan_All_Story.jpg), last accessed 6 May 2014. 


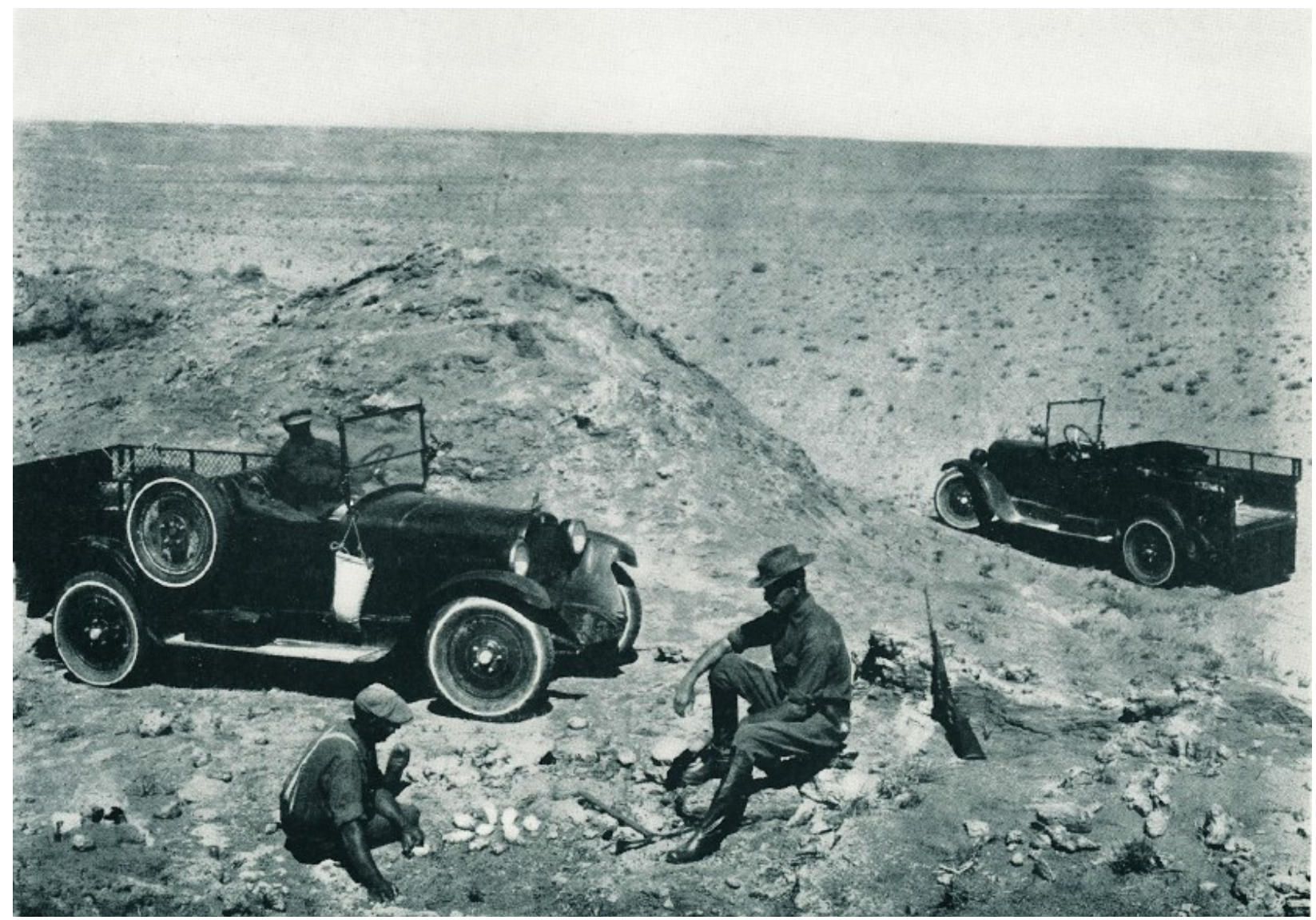

Appendix B. A photograph from the 1923 season of the Central Asiatic Expeditions. This carefully posed shot shows Andrews (right) and paleontologist Georg Olsen (below left) examining a nest of fossilized dinosaur eggs while the signs of American technological progress surround them. The Gobi desert, re-imagined as a new frontier, stretches as far as the eye can see. From Roy Chapman Andrews and Henry Fairfield Osborn, On the Trail of Ancient Man (1926). 


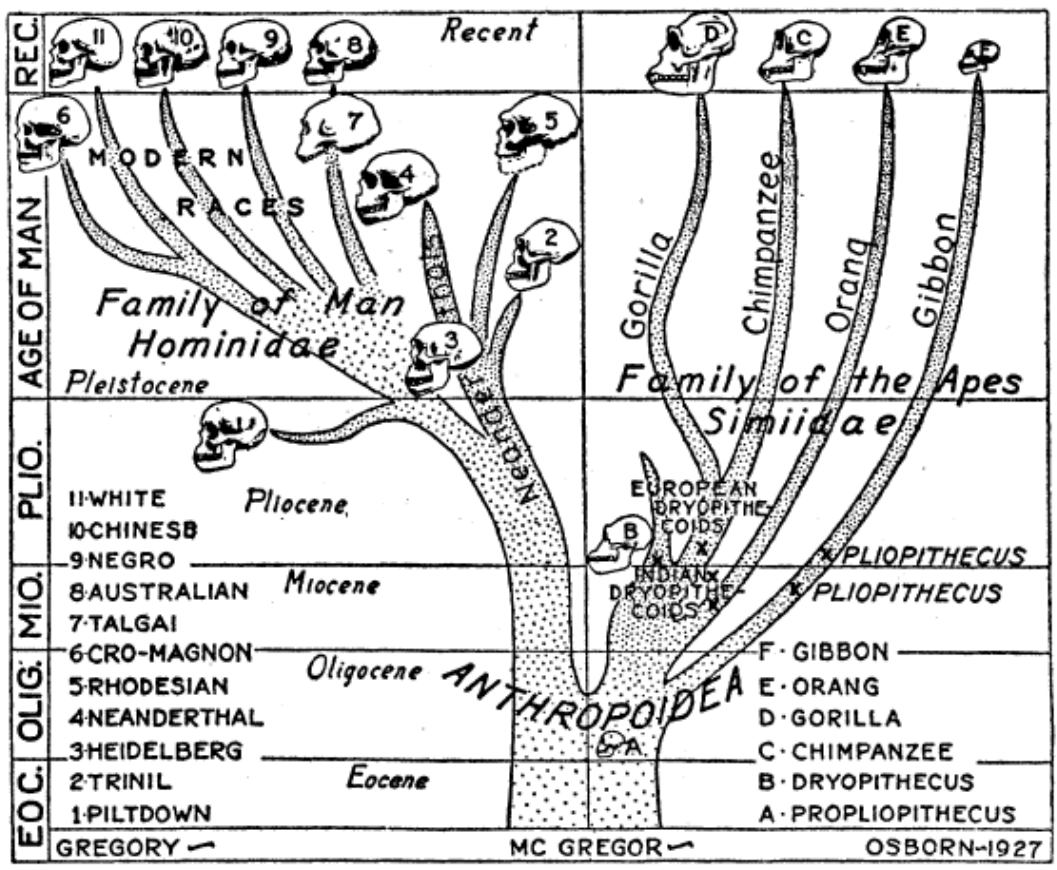

Appendix C. This chart from Osborn's 1927 publication, "Recent Discoveries Relating to the Origin and Antiquity of Man," portrays the hominid line of evolution as being separate from the simians, or apes, as early as the Oligocene - much earlier than any of his colleagues were willing to accept. His conceptualization of the human "races" as different species (or subspecies) is also evident here.

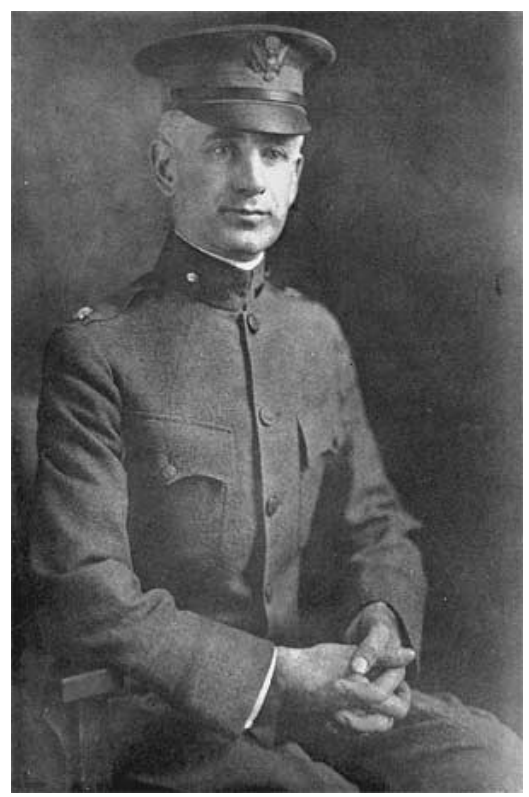

Appendix D. Robert M. Yerkes, Harvard Professor of Psychology, in uniform as a U.S. Army

Major in 1919. From the Primate Freedom Project website (http://www.primatefreedom.com/centeryerkes/robertyerkes.shtml), last accessed 3 January 2014). 


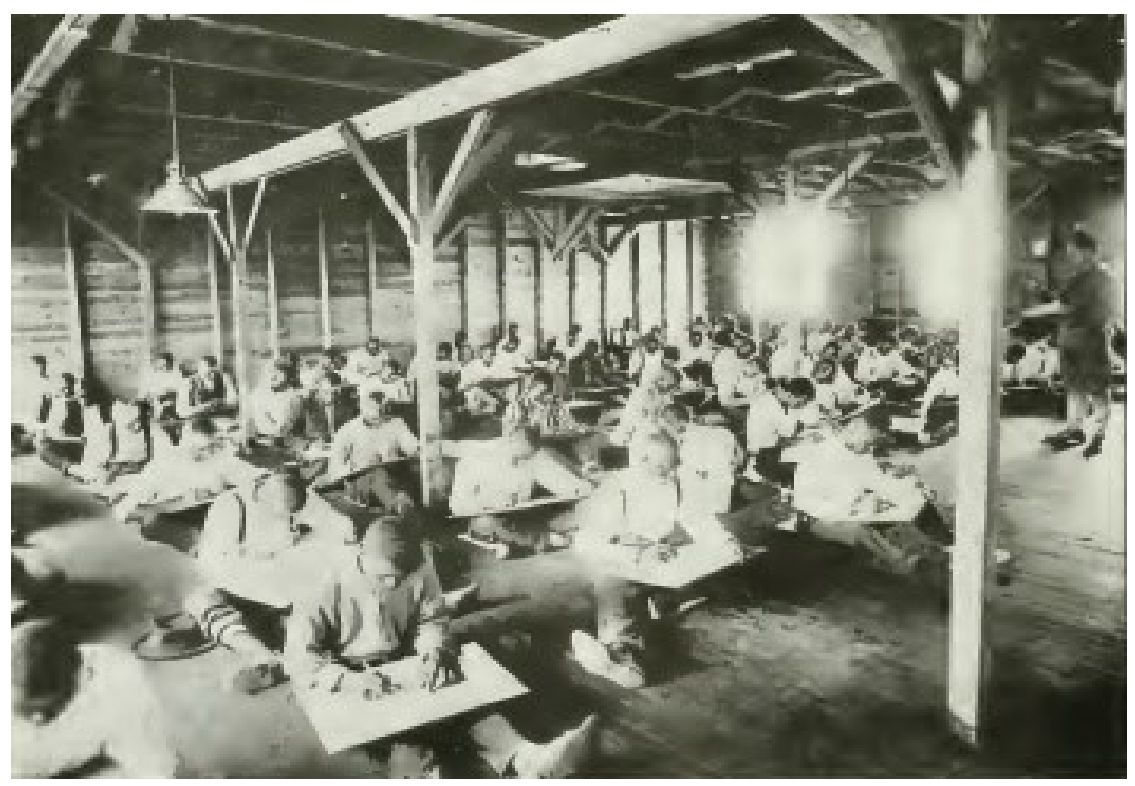

Appendix E. A group of U. S. Army soldiers taking the Army Alpha test. From Robert M. Yerkes ed., Psychological Examining in the United States Army (1921).
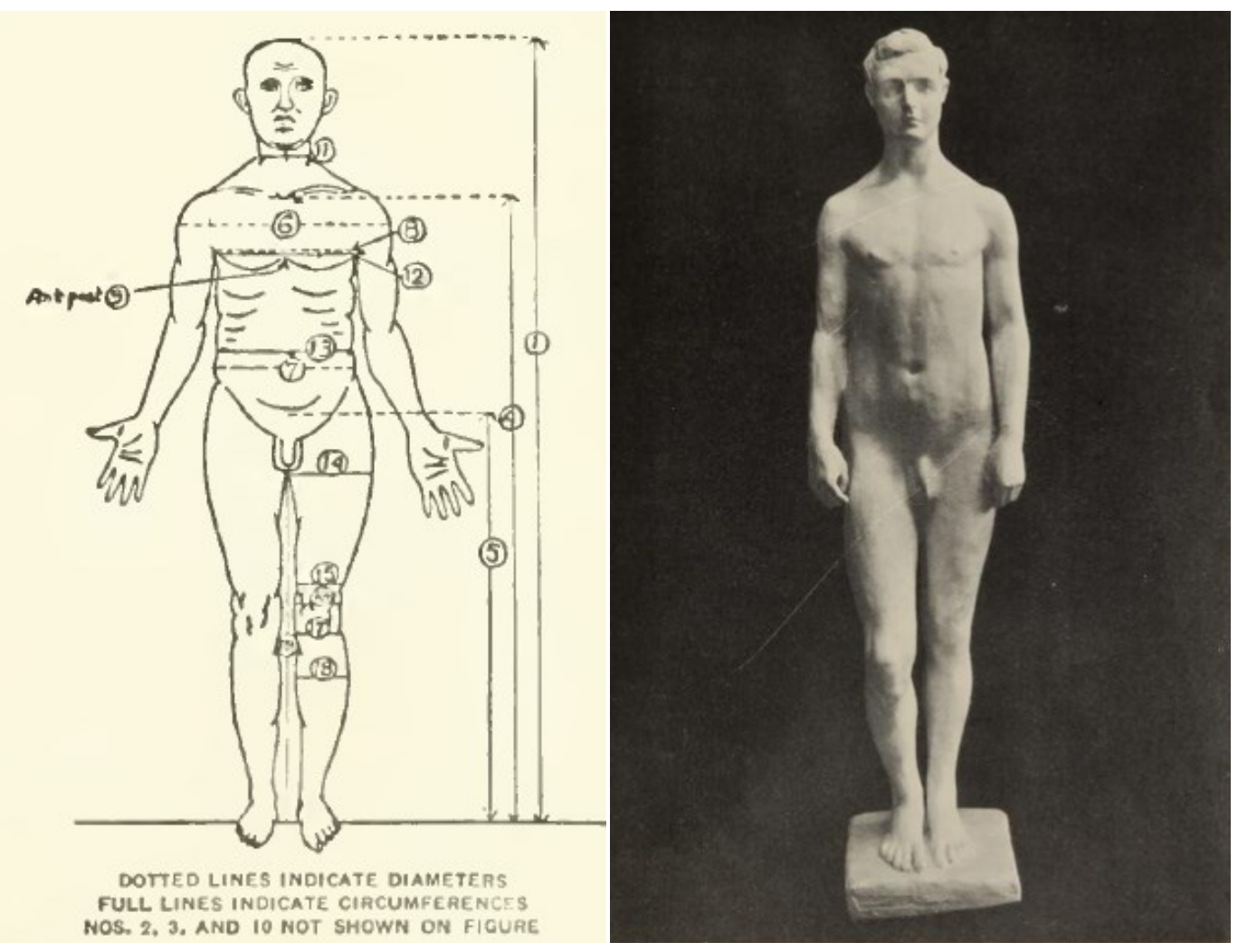

Appendix F. Left: Body measurements taken by Charles Davenport for 100,000 U. S. Army troops at demobilization camps in 1919. From Charles B. Davenport and Albert G. Love, Army Anthropology (1921). Right: "The Average American Male" by Jane Davenport, first displayed in 1921. From Harry H. Laughlin, The Second International Exhibition of Eugenics (1923). 